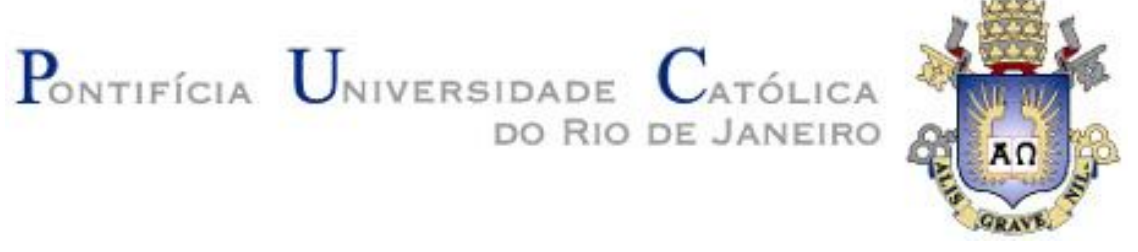

Marcelo Zeuli

\title{
Basel III: Towards a Safer Financial System? Evaluating the Recommendations of the Bank of International Settlements for Market and Liquidity Risks in Brazil
}

TESE DE DOUTORADO

Thesis presented to the Programa de PósGraduação em Administração de Empresas of the Departamento de Administração, PUC-Rio as partial fullfilment of the requirements for the degree of Doutor em Administração de Empresas.

Advisor: Prof. André Luiz Carvalhal da Silva

Rio de Janeiro

December 2015 


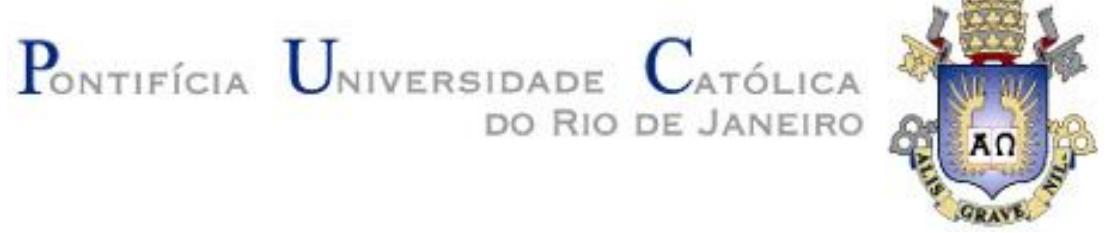

Marcelo Zeuli

\section{Basel III: Towards a Safer Financial System? \\ Evaluating the Recommendations of the Bank of International Settlements for Market and Liquidity Risks in Brazil}

Thesis presented to the Programa de Pós-Graduação em Administração de Empresas da PUC-Rio, as partial fulfilment of the requirements for the degree of Doutor.

Prof. Andre Luiz Carvalhal da Silva Advisor Departamento de Administração - PUC-Rio

Prof. Luiz Eduardo Teixeira Brandão Departamento de Administração - PUC-Rio

Prof. Gustavo Silva Araujo Banco Central

Prof. Marcio Magalhães Janot Banco Central do Brasil

Prof. Paulo Roberto da Costa Vieira UNESA

Profa. Mônica Herz Vice-Decana de Pós-Graduação do CCS

Rio de Janeiro, December $14^{\mathrm{TH}}, 2015$ 
All rights reserved.

Marcelo Zeuli

The author graduated in Electrical Engineering (Pontifical Catholic University of Rio de Janeiro, 1984), has a Master degree in economics (Economics Institute, UFRJ, 2005) and a Master degree in Administration (COPPEAD / UFRJ, 2000). He has professional experience in Finance and Macroeconomics (Brazilian Central Bank), as well as Marketing and Information Technology (IBM Brasil).

Bibliographic data

Zeuli, Marcelo

Basel III: towards a safer financial system? evaluating the recommendations of the bank of international settlements for market and liquidity risks in Brazil / Marcelo Zeuli; orientador: André Luiz Carvalhal da Silva. - 2015.

93 f. : il. (color.) ; $30 \mathrm{~cm}$

Tese (doutorado)-Pontifícia Universidade Católica do Rio de Janeiro, Departamento de Administração, 2015.

Inclui bibliografia.

1. Administração - Teses. 2. Acordo de Basiléia III. 3. Risco de mercado e liquidez. 4. Mercado imobiliário. I. Silva, André Luiz Carvalhal da. II. Pontifícia Universidade Católica do Rio de Janeiro. Departamento de Administração. III. Título.

CDD: 658 


\section{Acknowledgments}

To all my relatives who encouraged me on this journey.

I thank my advisor, Professor Andre Carvalhal, for the encouragement and guidance necessary in this long journey to Doctorate, as well as my technical advisor, Márcio Silva de Araujo (Brazilian Central Bank), with his unfailing help in all phases of this project.

I thank the Brazilian Central Bank, its Post-Graduate Program (PPG), the staff of the UNIBACEN / DIOPE / CPROG sector (highlighting Claudinei Santos) and the friends from the COPES / PASBC sector (Suzete Salgueiro Leite, Cláudio Manoel Moraes, Dr. Júlio Cesar Caldas, Rogério Lima, Jose Colaço, Francisco Batista, Antonio da Costa Alves and Pierre Ferraz). Without them this work would not have been realized.

I am grateful to the teachers who participated in the Examining Committee: Luiz Eduardo Brandão, Gustavo Silva Araújo, Márcio Janot and Paulo Roberto da Costa Vieira, as well as the invited teachers: Claudio Barbedo, Leonardo Lima Gomes, Liana Ribeiro, Marcelo Maia Verdini, Myrian Beatriz Neves, Osmani Guillen and Rubens Teixeira da Silva.

I thank the Professors Guilherme Arcoverde, John P. Nolan, Juan Carlos Zambrano Arismendi, Markus Haas, Osmani Guillen and Ricardo Leal, for the suggestions and for providing econometric softwares which were fundamental for this thesis.

I thank the teachers and staff of IAG / PUC / RJ (highlighting Fabio Etienne and Teresa Campos), for the excellent courses and invaluable support.

I am very grateful to my colleagues at PUC / RJ, especially Alex Sandro Moraes, Ana Carla Bon, André Luis Leite, Camila Epprecht, Carlos Fontoura, Cristina Luz, Flávio Val, Macelly Morais, Renata Kurtz, Sergio Pereira, Sylvia Moraes and Sandro Sartório (in memoriam).

To all my friends who encouraged me on this journey 


\section{Abstract}

Zeuli, Marcelo; Silva, André Luiz Carvalhal da (Advisor). Basel III: Towards a Safer Financial System? Evaluating the Recommendations of the Bank of International Settlements for Market and Liquidity Risks in Brazil. Rio de Janeiro, 2015. 93p. Doctoral Thesis - Departamento de Administração, Pontifícia Universidade Católica do Rio de Janeiro.

This thesis analyzes some aspects of the Basel III Accord, from the Bank for International Settlements (BIS) and their applications on three different situations in the Brazilian market. First, we analyze whether two main recommendations, minimum capital requirements and the use of Stressed VaR, would mitigate the effects of the Brazilian pre-election crisis in 2002 if they were already implemented. We innovate in three situations: using the VIX as a volatility alternative (proxy) for stress scenarios when no historical data is available; modeling financial time series with SWGARCH and alpha-stable innovations (according to BRODA et al., 2013) and analyzing Market Risk with two approaches simultaneously: the Early Warning, from the International Monetary Fund (IMF) and the Capital Requirements (BIS). Second, we discuss a supposed dichotomy in banking regulation: the simultaneity of liquidity risk regulation versus the lender of last resort institute. We rebate this dichotomy and innovate both by demonstrating that perpetual call options may offer a theoretically feasible alternative or complement to capital requirements; and by identifying that the Brazilian liquidity index is a random walk process, meaning a constant effort to keep this index at a safer level. Third, focusing a well known kind of crisis, we innovate by evaluating if the real estate market risk could be mitigated with the development of abandon real options with volatility regime-switching risk, simulated from the monthly returns of the real estate selling prices listed in the FIPE-ZAP index.

\section{Keywords}

Basel III agreement; market and liquidity risk; real estate market; options. 


\section{Resumo}

Zeuli, Marcelo; Carvalhal, André Luiz da Silva. Basiléia III: Rumo a um Sistema Financeiro mais Seguro? Avaliando as Recomendações do Bank for International Settlements sobre Riscos de Mercado e Liquidez no Brasil. Rio de Janeiro, 2015. 93p. Tese de Doutorado - Departamento de Administração, Pontifícia Universidade Católica do Rio de Janeiro.

Esta tese analisa alguns aspectos do acordo de Basiléia III, proposto pelo Bank for International Settlements (BIS) e suas aplicações em três situações diferentes no mercado brasileiro. Em primeiro lugar, analisamos se duas das principais recomendações, requerimentos de capital e Stressed VaR, atenuariam os efeitos da crise pré-eleitoral brasileira em 2002, caso já estivessem vigentes neste passado recente. Inovamos ao propor o VIX como alternativa (Proxy) de volatilidade em situações de stress quando não há histórico disponível; ao modelar séries financeiras com SWGARCH e inovações alpha-estáveis (BRODA et al., 2013) e ao abordarmos o risco de mercado, simultaneamente, tanto via Indicadores Antecedentes - Early Warning, do Fundo Monetário Internacional (FMI) - como via Requerimentos de Capital (BIS). Segundo, questionamos uma possível dicotomia no campo da regulação bancária, quando a regulação de risco de liquidez coexiste com o instituto do emprestador de última instância. Rebatemos esta suposta dicotomia e inovamos, tanto ao verificar que opções de compra sem vencimento podem proporcionar um complemento ou alternativa, teoricamente viável para os requisitos de capital; como ao evidenciar que o índice de liquidez agregada dos bancos brasileiros segue um passeio aleatório, o que implica um constante esforço em manter este índice em um nível seguro. Terceiro, ao avaliar um tipo de crise bem conhecida, inovamos ao propor que o risco de mercado imobiliário pode ser mitigado com opções reais, modeladas com mudança de regime de volatilidade dos preços imobiliários, simuladas a partir dos retornos mensais dos preços de venda constantes no índice FIPE-ZAP.

\section{Palavras-chave}

Basiléia III; riscos de mercado e de liquidez; mercado imobiliário; opções. 


\section{Summary}

1 Introduction 10

2 Backtesting Basel III: Evaluating The Market Risk Of Past Crises In Brazil Through The Current Regulation 14

$\begin{array}{ll}2.1 \text { Introduction } & 14\end{array}$

2.2 Theoretical Review 18

2.3 Data And Methodology 24

2.4 Results 28

2.5 Discussion 36

3 The Liquidity Regulation Versus The Lender Of Last Resort: A Dichotomy? (Pricing Options For Capital Adequacy) 38

$\begin{array}{lll}3.1 & \text { Introduction } & 38\end{array}$

3.2 Review On Banking Regulation And Financial Time Series 41

3.3 Data And Methodology 46

$\begin{array}{lll}3.4 \text { Results } & 50\end{array}$

3.5 Discussion 61

$4 \quad$ Hedging Against Price Bubbles Through Options With Volatility Regime-Switching Risk In The Brazilian Real Estate Market (2008-2015) 63

4.1 Introduction 63

4.2 Review On Bubbles, Financial Crises And Financial Time Series 65

4.3 Data And Methodology 69

$\begin{array}{lll}4.4 & \text { Results } & 73\end{array}$

4.5 Discussion 82

5 Conclusions $\quad 85$

$\begin{array}{llr}6 & \text { References } & 87\end{array}$ 


\section{List of figures}

Figure 2.1: Agregated Brazilian Basel Index (all Brazilian Banks) .............................. 16

Figure 2.2: Currency Swaps Prices - Daily Volatility (DTM= Days to Maturity) .................31

Figure 3.1: Fed Funds Daily Data: Rates, Variation and Volatility..............................50

Figure 3.2: Brazilian Daily Rediscount - Financial Volume …..................................52

Figure 3.3: LI - Curve Fit, Monthly Returns and Unconditional Volatility.........................54

Figure 3.4: Daily Returns of Exchange Rate (U.S. Dollars/ Brazilian Reais) ...................56

Figure 3.5: Daily Conditional and Unconditional PTAX Volatility..................................56

Figure 4.1: Stress Test for Real Estate Portfolios of Banks in Brazil.............................66

Figure 4.2: Net Present Value of FIPE-ZAP Real Estate in Sao Paulo .........................67

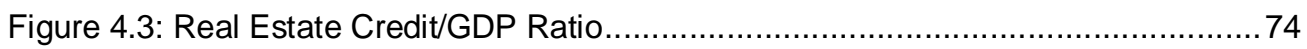

Figure 4.4: Real Estate Loans x GDP Compared to Household Expenditures ............... 74

Figure 4.5: Firm's Market Value (BMF\&BOVESPA) Deflated by Inflation / GDP............. 75

Figure 4.6: Unconditional Volatility Levels of Real Estate Selling Prices........................79

Figure 4.7: Option Value/Real Estate Price for São Paulo and Rio de Janeiro ...............81

Figure 4.8: Predicting Strike Prices from Monthly GDP (São Paulo and Rio) .................. 82 


\section{List of tables}

Table 2.1: Brazilian's BASEL III Chronogram (Minimum Capital Requirements) .............. 16

Table 2.2: Daily Loss Limits based on the monthly Regulatory Capital Limits.................17

Table 2.3: Expected Short Fall related to VaR under RiskMetrics ${ }^{\mathrm{TM}}$..............................24

Table 2.4: Sudden Changes, Unconditional Volatility of Currency Swap Prices............... 30

Table 2.5: Daily losses for PTAX and Currency Exchange Swaps ............................... 32

Table 2.6: Stable Distributions- VIX, Currency Exchange Swaps and S\&P 500 ..............32

Table 2.7: Only two Violations referring to the Overall Maximum VIX volatility .................33

Table 2.8: Only Nine Violations referring to Maximum Historical VIX until Date .............. 33

Table 2.9: S\&P 500 Daily Return's GARCH Fit (January, 1950 to August, 2015) ............34

Table 2.10: S\&P 500 return's MLE Fitting (Stable and Normal Innovations .................... 35

Table 2.11: MLE returns fitting (S\&P 500 and Currency Swaps). ................................ 35

Table 3.1: Brazilian's Basel III Chronogram (Minimum Capital Requirements ................ 39

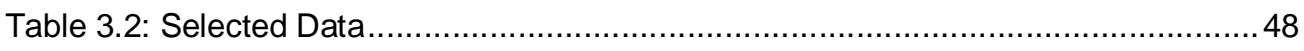

Table 3.3: GARCH Fitting for Fed Funds from September 2008 to June $2015 . \ldots \ldots \ldots \ldots . . . . .51$

Table 3.4: Poisson pdf , Multiples of Average Rediscount (Lambda $=0.1062)$..............52

Table 3.5: Variance Ratio Test and Mean Reverting Model Fitting (LI) ..........................53

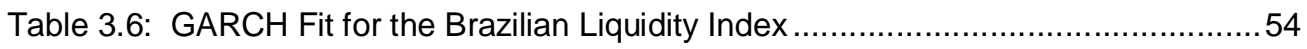

Table 3.7: Linear Regressions, Liquidity Index and Financial Variables.........................55

Table 3.8: AR (1)-GARCH $(1,1)$ Modeling for PTAX daily returns (1994 to 2015) ..........57

Table 3.9: Alpha Stable Distribution for the Currency Exchange Rates (PTAX) ..............5 57

Table 3.10: Average Time to Reach Capital Level Departing from 5\% ...........................58

Table 3.11: Reaching a Specific Capital Level Departing from 11\% ............................58

Table 3.12: Call Prices/Asset Value Ratios, Strike Prices Varying from $5 \%$ to $17 \% \ldots . . . .59$

Table 3.13: Cost of Rediscount Financing versus Regular Options .............................59

Table 3.14: Perpetual Options Simulation Example …….............................................6 60

Table 4.1: Examples of FIPE-ZAP Real Estate Index............................................. 70

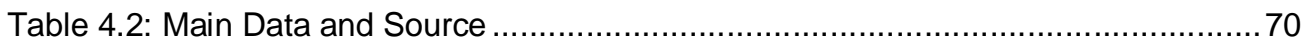

Table 4.3: Real Estate Companies, BMF\&BOVESPA's Governance Index ....................71

Table 4.4: Main Algorithms used in this chapter.................................................... 71

Table 4.5: FIPE-ZAP Fit Regression with Lagged Monthly Inflation and GDP ................ 76

Table 4.6: Regressions with Lagged Employment Rate, Rio and Brazil.........................76

Table 4.7: Correlations of Selling and Rental Real Estate Prices in Sao Paulo................77

Table 4.8: GARCH Fitting for FIPE-ZAP Index in Rio de Janeiro and São Paulo.............78

Table 4.9: Unconditional Volatility Levels of FIPE-ZAP Index.....................................78

Table 4.10: SWGARCH for Sao Paulo Single Room Monthly Index (SPD1) ....................79

Table 4.11: Average Option Value/Real Estate Price for 1-Room Flat (SP) ....................80 


\section{1. Introduction}

This thesis analyzes some Basel III recommendations of the Bank for International Settlements and their applications on three different situations in the Brazilian financial market.

Since 2007 the world economy has been going through troubled times, unchained by the international financial crisis that motivated the development of the so called new Basel Agreement, Basel III, a set of recommendations directed to all banks, with the purpose of mitigating financial risks, proposed by the Bank for International Settlements (BIS).

Caruana (2010) stated that Basel III added significant progress to the prudential financial regulation since the beginning of the global financial crisis, which was the landmark of a new global economic context that imposed major challenges. The Basel III agreement has some items considered to be a radical revision of the previous agreement (Basel II).

Nevertheless, another point of view state that Basel III is in fact a set of amendments to Basel II, changing measures that were deemed insufficient, either in conception or in metric. It either increases the requirements already existent in Basel II or creates new demands, where the crisis has highlighted the procedures that are insufficient either to mitigate the instability of the financial markets or to avoid the occurrence of more serious crises. The BIS acknowledges the transient characteristic of the current Basel III recommendations, as seen in BIS (2011).

The minimum capital requirements (with its main item, the regulatory capital) are the main concern since Basel I. It provides, in rough terms, a cushion for crisis times. It can be seen as an alternative to the early warning approach (i.e., antecedent indicators) from the International Monetary Fund (IMF). Concerning to this approach, to a recent past and to the financial vulnerability concept, according to Blejer and Schumacher (1998), the 1990's currency crises revitalized the search for antecedent indicators (early warning, in IMF's jargon) of financial vulnerability. The evaluation of the solvency and vulnerability of the financial 
sector (financial institutions and Central Banks) implies to evaluate the vulnerability and credibility of a country.

As pointed by Dornbusch (1998), understanding the recent crises requires a change of analytical approach, exchanging sustainability for vulnerability:

"The moment the focus shifts from sustainability to vulnerability the whole discussion changes. Then the focus is on the bad scenario and just how bad it might be".

In this approach it is important to identify possible regulation failures and provide a set of alternatives, taking into account that daily failures - not captured by a monthly time frame - can spread an initially local problem.

With respect to regulatory failures, there is a long history since Basel I, which exhibited one fundamental weakness: it relied on a model of the banking firm that was becoming quickly obsolete. The bank envisaged in Basel I was the Glass/Steagal type of commercial bank that populated the banking sector in the U.S. during the 20th century. Its balance sheet had demand deposits as its main liability and commercial loans as its essential asset. The most relevant risks such a bank was subject to were liquidity risk and credit risk. This approach not only ignored the universal bank model (dominant in Western Europe): it also ignored that in the U.S. itself banks had been gradually abandoning the specialized model, moving towards the universal bank for years. The changing process accelerated in the 1990s, until the final demise of the segmented bank, when the Glass/Steagal Act (created in 1933) was replaced by a new legislation by December, 1999.

Moreover, clear leading indicators of financial crises were not accordingly considered. Cynamon and Fazzari (2008) showed that the consumer side of the U.S. economy was troublesome for a considerable amount of time. The household consumption stayed over the 94\% income level since 1992 and over the $96 \%$ income level since 1999, with a sharp fall from 2007, precisely the beginning of the global financial crisis.

Our analysis of the three different situations in the Brazilian market is presented in the next three chapters. First, are the Basel III recommendations, from the Bank for International Settlement's (BIS) Basel agreement, effective to a broad set of financial crises? Would the effects of past crises be mitigated if those recommendations were already implemented in the past? Two of the main Basel III agreement's recommendations are selected to a back test: the minimum capital 
requirements and the Stressed Value at Risk (SVaR) methodology, introduced in BIS (2009), that incorporates a tail risk measure to the usually adopted Value at Risk (Var) methodology. We analyzed a country specific crisis, which occurred in Brazil in the pre-election period of 2002. The currency exchange rate and the currency exchange swaps contracts are examined in the empirical tests of a volatility-based VaR methodology.

Neither the early warning approach (IMF) nor the capital requirements (BIS) are fit to deal with the surge of quite high volatility levels that demand quite high capital requirements. The main conclusions are: (a) We confirm the general consensus among economists that there is no methodology capable to forecast crises with a high degree of accuracy; (b) to circumvent either the lack of historical information or the lack of optimal window for stress patterns, we innovate by calibrating the Stressed VaR with a historical volatility index (the VIX), working as a volatility scale; (c) other densities, apart from the standard normal curve adopted by the BIS, shall be considered when calibrating financial series, consequently we innovated by modeling SWGARCH with alpha stable densities (based on Broda et al., 2013); and (d) daily oscillation limits (stop-loss) may have a significant role on crisis mitigation.

Second, we discuss a supposed dichotomy in banking regulation: the liquidity risk regulation versus the lender of last resort (LOLR) institute. Does the financial system needs both alternatives simultaneously? This simultaneity is justifiable for a number of reasons, starting with investments diversification prescribed by the portfolio selection approach (MARKOWITZ, 1952). We rebate this dichotomy and innovate both showing that third alternatives are theoretically feasible; and by identifying that the Brazilian liquidity index is a random walk process, meaning a constant effort to keep this index at a safer level. In a necessary search for an effective contextualization with the international financial crisis and the recommendations from the Basel III agreement, we proceed with four different analyses concerning to the liquidity shortage risk. We evaluate the U.S. low risk/high liquid assets and the Brazilian rediscount in light of the quantitative easing approach and the low interest rates of U.S. risk free assets. We analyze the Brazilian liquidity index and verify its relation with other financial and economic variables. We also examine the daily returns of assets such as exchange rates, assets that exhibit a high daily volatile pattern that is not captured 
by lower frequency (monthly) databases. Then, aiming at complementary loans for cash/high liquid assets in bank's net worth, we simulate call options, according to the risk weighted assets (RWA) methodology (Basel II and III) for credit, market and operational risks. Perpetual call options, as in Alvarez and Dixit (2014), originated from any kind of lender (not necessarily a LOLR) may offer a theoretically feasible alternative/complement to capital requirements, with underlying assets modeled with Geometric Brownian motion.

Third, do the high price levels in the Brazilian real estate market unfold a real estate Bubble? Whatever the case, the real estate market risk could be mitigated with the development of abandon options, hedging against brisk prices and wages falls. Real options with volatility regime-switching risk - an innovative approach based on the price regime-switching risk model from Driffill et al. (2013) - were simulated from the monthly returns of real estate selling prices for the cities of São Paulo and Rio de Janeiro, available from the FIPE-ZAP index. The results indicate that there is no significant premium variation within the range of the existing volatility levels of the monthly returns. Moreover, until mid-2014, the bullish market frequently would dismiss the exercise of the abandon options. For market monitoring purposes, the methodology can be used more effectively when either evaluating neighborhood price information (currently existing in the FIPE-ZAP database but not disclosed) or taking into account that prices are collected on a daily basis.

This thesis is organized as follows. The next chapter performs a back testing of Basel III by evaluating the market risk of a recent past crisis in Brazil through the current recommendations. Chapter 3 deals with a supposed dichotomy: the simultaneity between the liquidity regulation versus and the lender of last resort institute as well as evaluates pricing options for capital requirements. In Chapter 4, we evaluate real options with volatility regime-switching risk in the Brazilian real estate market. Chapter 5 concludes the research. 


\section{2 \\ Backtesting Basel III: Evaluating the Market Risk of Past Crises in Brazil through the Current Regulation}

\section{1 Introduction}

Would the Basel III agreement, proposed by the Bank for International Settlements (BIS), be effective, if applied to past financial crises? Could those crises be better mitigated if the Basel III recommendations were already implemented? Caruana (2010) stated that Basel III generated significant progress in prudential financial regulation since the beginning of the global financial crisis that is the landmark of a new global economic context which imposes major challenges. This chapter turns the statement "Basel III: Towards a Safer Financial System" - title of the technical document from Caruana (ibid.) - to a question and submits two key Basel III agreement's recommendations, minimum Capital Requirements and Stressed VaR to a back test, by emulating their existence at the time of a selected past crisis.

The Basel III agreement has some items considered a radical revision of Basel II, such as new parcels of capital requirements, like the counter-cyclical capital, that takes into account macroeconomic risks. Nevertheless, in another perspective, Basel III is not a new agreement, but rather a set of proposed amendments to the previous agreement, changing the latter measures that were deemed insufficient, either in conception, or in the used metric. Basel III either increases the requirements of Basel II or creates new demands, where the crisis has highlighted the procedures to be either insufficient to control the instability of the financial markets or to avoid the occurrence of more serious crises.

In order to establish a link between Basel III recommendations and the early warning approach (IMF), which was developed to face a recent past of crises, we refer to the vulnerability concept: according to Blejer and Schumacher (1998), the 1990 's currency crises revitalized the search for antecedent indicators of financial vulnerability. The evaluation of the solvency and vulnerability of the financial 
sector (banks and Central Banks) implies to evaluate the vulnerability and credibility of a country. Their proposed VaR implementation intended to be a general-purpose market risk analysis tool.

There are other five initial guidelines. First, Abiad (2003) stated that there is a general consensus among economist that there is no methodology able to forecast crises with a high degree of accuracy. Second, many authors enunciate but not empirically broadly test their proposed methodology. Third, as Blejer and Schumacher (ibid.) stated, a vulnerability analysis should not only deal with traditional operations, but with all assets that compose its portfolio, including the derivatives. Fourth, to validate the capital requirements recommendations it is necessary to verify their effectiveness when applied to currency based assets (highly volatile) from bank's portfolios. Fifth, there is a timeline guideline which is the transient characteristic of nowadays Basel III recommendations. From BIS (2011), two excerpts:

(a) "The Committee is introducing these changes in a manner that minimizes the disruption to capital instruments that are currently outstanding. It also continues to review the role that contingent capital should play in the regulatory capital framework."

(b) "The Committee will put in place rigorous reporting processes to monitor the ratios during the transition period and will continue to review the implications of these standards for financial markets, credit extension and economic growth, addressing unintended consequences as necessary."

Consequently, it is crucial to observe the chronogram of Basel III implementation and its emphasis on the risk weighted assets (RWAs). Table 2.1 shows the Brazilian road map: the implementation chronogram of the Basel III recommendations for minimum capital requirements, where a key term is the regulatory capital $(\mathrm{RC})$. 
Table 2. 1: Brazilian's BASEL III Chronogram (Minimum Capital Requirements)

\begin{tabular}{|c|c|c|c|c|c|c|c|}
\hline Implementation & Jan, $1^{\text {st }}$ & Jan, $\mathbf{1}^{\text {st }}$ & Jan, $1^{\text {st }}$ & Jan, $1^{\text {st }}$ & Jan, $1^{\text {st }}$ & Jan, $1^{\text {st }}$ & Jan, $1^{\text {st }}$ \\
\hline Date: & $/ 13$ & $/ 14$ & $/ 15$ & $/ 16$ & $/ 17$ & $/ 18$ & $/ 19$ \\
\hline Core Capital & $4.5 \%$ & $4.5 \%$ & $4.5 \%$ & $4.5 \%$ & $4.5 \%$ & $4.5 \%$ & $4.5 \%$ \\
\hline Level I & $5.5 \%$ & $5.5 \%$ & $6.0 \%$ & $6.0 \%$ & $6.0 \%$ & $6.0 \%$ & $6.0 \%$ \\
\hline Regulatory Capital & $11.0 \%$ & $11.0 \%$ & $11.0 \%$ & $9.875 \%$ & $9.875 \%$ & $8.625 \%$ & $8.0 \%$ \\
\hline Capital Conservation & - & - & - & $0,625 \%$ & $1.250 \%$ & $1.875 \%$ & $2.5 \%$ \\
\hline $\begin{array}{l}\mathrm{RC}+\text { Capital } \\
\text { Conservation }\end{array}$ & $11.0 \%$ & $11.0 \%$ & $11.0 \%$ & $10.5 \%$ & $10.5 \%$ & $10.5 \%$ & $10.5 \%$ \\
\hline $\begin{array}{l}\text { Counter-Cyclical } \\
\text { Capital }\end{array}$ & - & To $0.625 \%$ & To $1.25 \%$ & To $1.875 \%$ & To $2.5 \%$ & To $2.5 \%$ & To $2.5 \%$ \\
\hline
\end{tabular}

Source: Brazilian Central Bank (2011).

Three observations outstand: (a) since 2005, the aggregated and individual Basel index of Brazilian banks stayed above 15\%, as seen in Figure 2.1; (b) no systemic bank crisis occurred in Brazil at least in the last 60 years (Laeven and Valencia, 2008); and (c) the Regulatory Capital percentage of $11 \%$ (monthly), is equivalent to 20 days of $0.52 \%$ daily variation (see Table 2.2), a rather small variation compared to the daily volatility of quite a lot finance time series, specially those found in emerging market economies (Bekaert and Harvey, 1997). As an example, for the 30-day term currency swaps (U.S. Dollars/Brazilian Reais), the average standard deviations ranged from $1.55 \%$ (from 1999 to 2003) to $1.40 \%$ (from 2004 to 2014 ). Only $29.40 \%$ of the daily variations were lower than $.52 \%$, from 1999 to 2003 , while only $28.48 \%$ of the daily variations were lower than $.52 \%$, from 2004 to 2014 .

Figure 2.1: Agregated Brazilian Basel Index (all Brazilian Banks)

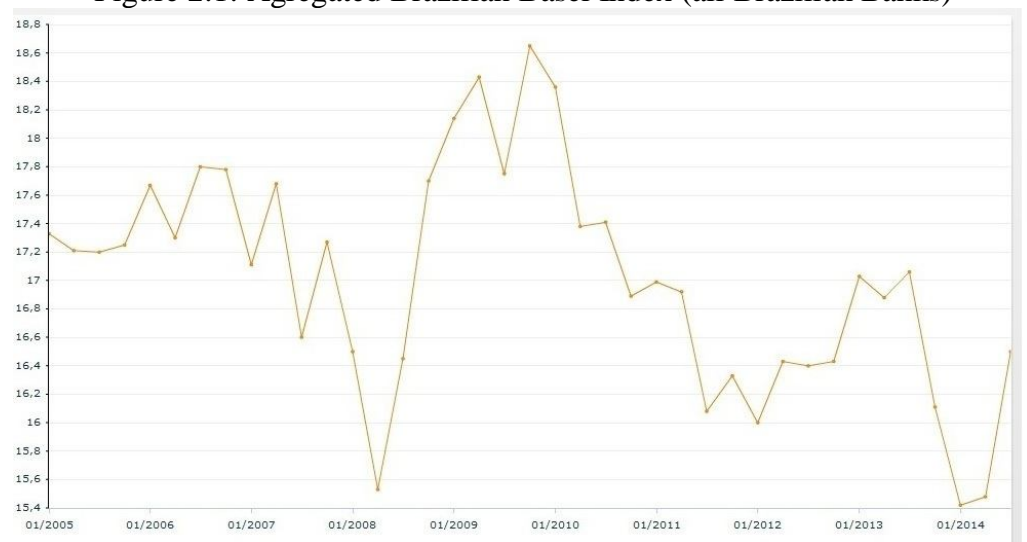

Source: Brazilian Central Bank (2015). 
Table 2.2: Daily Loss Limits based on the monthly Regulatory Capital Limits

\begin{tabular}{llll}
\hline Monthly $\leftrightarrow$ Daily level & Monthly $\leftrightarrow$ Daily level & Monthly $\leftrightarrow$ Daily level & Monthly $\leftrightarrow$ Daily level \\
\hline $8.00 \% \leftrightarrow 0.39 \%$ & $11.00 \% \leftrightarrow 0.52 \%$ & $15.00 \% \leftrightarrow 0.70 \%$ & $17.00 \% \leftrightarrow 0.79 \%$ \\
\hline
\end{tabular}

The volatility-based risk methods, such as the Value at Risk (VaR), became very popular in the 1990's, departing from the Riskmetrics ${ }^{\mathrm{TM}}$ document (JP MORGAN, 1996). The financial time series variance is usually modeled with GARCH (Generalized Autoregressive Conditional Heteroscedasticity) in order to capture the heteroscedasticity of the conditional variance of financial series, a stylized fact known since Engle (1982) and Bollerslev (1986).

Additionally, financial time series can be also subject to sudden or structural breaks. Consequently, a two-step protocol for volatility modeling is used in this chapter:

(a) The unconditional variance levels can be previously determined, for instance, with the ICSS (Iterative Cumulative Sum of Squares) algorithm from Inclán and Tiao (1994).

(b) The regime-switching feature, either a switching-regime GARCH model (SWGARCH) or a Levy process (with jumps) is incorporated into the volatilitybased risk methods.

We developed a retrospective view of some Basel III recommendations as if they were already effective in the recent past. We choose a VaR methodology to evaluate the Brazilian pre-election period of 2002, known as a "confidence crisis". The high volatiles currency exchange rate and mark-to-market currency exchange swaps are examined through empirical tests of a volatility-based methodology. The events of the second semester of 2002 were especially important, as the currency exchange swaps contracts debts exceeded $40 \%$ of the Brazilian internal debt in the end of this year. We evaluate the effect of two of the main BIS Basel III recommendations, minimum capital requirements and Stressed $\mathrm{VaR}$, over currency exchange based assets.

A main concern is the absence of relevant historical data before June, 2002 for currency exchange based assets, since the Brazilian currency floating regime started in 1999.02 and currency swaps contracts grew relevance only from June, 2002. We choose a key counterexample in which the insights can be extrapolated for other possible crisis that may happen in the very beginning either of a new currency (example: the Euro in January, 2002) or a new financial factor (our own 
example: the U.S. Dollars/Brazilian Reais currency exchange coupon, created in August, 1999) or even a new financial asset. Consequently, this chapter intends to contribute to improve the evaluation of the global regulatory recommendations that are part of the Basel III agreement.

The next section is a review of the Basel regulation and financial time series econometrics. The third section comprises the methodology and a brief description of both Brazilian currency exchange based financial series and of the VIX, a candidate for Global Volatility available since January, 1990. The results section comprises the validation of stressed $\mathrm{VaR}$ approaches for the chosen scenario, the evaluation of the VIX and the S\&P 500 volatility as volatility alternatives (proxies) for the stressed volatility when lacking historical data. The fifth section discusses the results.

\section{2 \\ Theoretical Review}

This section presents a brief review of the BIS regulation and financial time series econometrics.

\section{Basel Regulation}

The Basel Committee on Banking Supervision was established in 1974 to advise national financial regulators on common capital requirements for internationally active banks, whose membership included representatives from the central banks and prudential regulators of more than 25 nations.

In 1988, the Basel Committee devised the initial Basel Capital Accord, which was a coordinated response to some of the perceived failings of deregulation as banks, in the rush to compete for larger market shares and had rapidly increased their domestic and foreign exposures. At some institutions these exposures were not matched by increases in the institutions' capital bases, leading the minimum capital levels within the global financial system to erode.

Deregulation also allowed internationally active banks to take advantage of differences in national treatment of similar assets for capital purposes. These inconsistencies were exploited across jurisdictions in a manner that was producing unhealthy competition and regulatory arbitrage. In short, national standards did not always link capital requirements to actual risk levels and did not always account for exposures beyond those reflected within the balance sheet. 
Consequently, a regulatory consensus started to build around a set of global standards that would provide guidance on the proper capital levels for internationally active banks, known as Basel II. In 2004, the Basel Committee offered a more comprehensive and risk-sensitive approach to capital regulation adopting the new framework Basel II, which developed a three "pillars" approach: (1) minimum capital requirements, (2) supervisory review process, and (3) market discipline.

The first pillar, already existent since Basel I, is reported to be the most important - and the most controversial - part of Basel II. Operational risk was added as a third factor for RWAs calculus, followed by a whole revision of Basel I recommendations concerning to RWAs. For accuracy reasons, targeting to match bank's capital requirements with its risky assets, Basel II provided three methods of assessing credit risk: a basic "standardized" approach and two variants of an "internal ratings-based" approach — foundational and advanced. Under the standardized approach, banks calculate RWAs not only by reference to Basel's elementary buckets, but also by the external credit ratings from firms like Standard \& Poor's, Moody's Investor Service, and Fitch Ratings. The two internal ratings-based approaches permit banks to be more sophisticated and rely in varying degrees on their own risk.

The Basel III agreement is often considered an amendment of Basel II. Concerning RWAs, the new agreement recommends a temporary increase for its main item, the regulatory capital; meaning a raise from 8 to 11 percent relative to risky assets from bank's asset books and defining a permanent increase of capital requirements in charge of two new items: Capital Conservation and CounterCyclical Capital, this last concerning to macroeconomic risks.

Williamson (2000) shows that there is a time frame for contracts and a time frame for day-to-day negotiation. This explains why agreements such as Basel I, II and III can be time frame inconsistent with daily economic agents' activities. This could be a strong and clear reason why the BIS will constantly review its agreements, as explicitly declared in the BIS (2011) document - see the two excerpts exhibited in the introduction section of this chapter. 
Minsky's (2008) theories are invoked every time a new financial crisis occurs. His approach relates economic theory to political, economic, cultural and institutional environments and the need for financial regulations is a way to mitigate the financial instability of a capitalist economy. The main propositions of the financial instability hypothesis create a financial cycle.

While Caruana (2010) stated that Basel III would bring a safer financial system; BIS (2011) indicated the unpredictable nature of future crises. The unpredictable nature (and timing) of crisis can be seen as a plausible link to Minsky's thought. On the other hand, authors like Cynamon and Fazarri (2008) alleged that the American credit crisis was predictable, as well as Abiad (2003) and Morales and Schumacher (2003) focused on early warning crisis detection.

\section{Financial Time Series Econometrics Review}

There are two recurrent stylized facts for financial time series found in the academic literature: volatility clustering and autoregressive conditional heteroskedasticity (ARCH) effects. The theory and modeling with $\mathrm{ARCH}$ and Generalized Autoregressive Conditional Heteroskedasticity (GARCH) started with Engle (1982) and Bollerslev (1986). The existence of volatility clusters suggests either an approach under the viewpoint of changes in volatility regimes or an approach under the standpoint of volatility leaps.

For a long time it was thought that the stochastic processes associated with the financial series could be modeled through linear processes, almost always by random walk models. According to Brock et al. (1992), the most common reasons for deviations from the random walk model, as far as it affects the return of shares, are the volatility clustering and the calendar anomalies (for example, the weekend effect). The volatility clustering has been known for a long time, at least since Mandelbrot (1963).

The ARCH model, developed by Engle (1982), has an autoregressive structure in the conditional variances of the returns. This allows shocks of volatility to continue in time. The conditional variance is a linear function of the square of past innovations. Bollerslev (1986) proposed the GARCH models, in which the volatility of returns depends on the squares of precedent errors and precedent variances. The inclusion of information regarding past variances allows sensibility to the volatility clusters and allows that shocks in returns extend 
indefinitely in the future. The ARCH and GARCH models were conceived to deal with a single variance regime. By regime is understood that a constant or unconditional level of measure - e.g., average or variance- remains unchanged, so that a change in regime implies a change in level.

However, these models only reflect one series of coefficients for one equation of returns and one equation of volatility. For Diebold (1986 and 1996), and Lamoureux and Lastrapes (1990), the use of GARCH models is subject to error when sudden changes in variance occur, suggesting the introduction either of dummy variables for each change of variance identified ex-post, or procedures to visualize the detection of outliers or levels of unconditional variance, as in Tiao and Inclán(1994).

The introduction of time series subject to changes in regime departs from Hamilton (1990), who applied the EM (Estimation Maximation) algorithm for parameter estimation through maximum likelihood estimation (MLE). Hamilton and Susmel (1994), as well as Cai (1994), introduced the SWARCH (Switching $\mathrm{ARCH}$ ) models, a generalization of the ARCH model of Engle (1982), which allows discrete changes in its level parameters through a Markov process.

In the first specifications found in the literature, the ARCH or GARCH variance was dependent to the entire history of regimes, as seen in Gray (1996). The SWGARCH models combine GARCH with regime switching. Bauwens et al (2010) still pointed the dependence on the entire history of regimes. Nevertheless, Haas et al. (2004, p. 497) developed a model were variances only depend on past shocks and their own lagged values: the path-dependency restriction was removed. This specification is analytically treatable, allows a separation of the process of conditional variance and offers direct parameter estimation through maximum likelihood. Next, we describe the conditional variance equation for the SWGARCH models in equation 2.1:

\section{Equation 2.1: Conditional Variance in the SWGARCH Model}

The conditional variance equation for the SWGARCH models $(\mathrm{k}, \mathrm{p}, \mathrm{q})$ is:

$v_{t, k}=\alpha_{0}+\sum_{i=1}^{q} \alpha_{i} u_{t-i}^{2}+\sum_{j=1}^{p} \beta_{j} v_{t-j, k}$

Residuals: $u_{t}=\sqrt{v_{t}} \varepsilon_{t}$; Either $\varepsilon_{t} \sim N\left(0, \sigma_{s t}\right)$ or $\varepsilon_{t} \sim t-$ student . 
Where $v_{t, k}$ stands for the k-regime variance at period $\mathrm{t}, \alpha_{0}, \alpha_{i}, \beta_{j}$ are constants.

A way to deal with diffusion problems is the use of semi martingales, but the procedural structure is very complex. The alternative is the use of Lévy process, additive processes (non homogeneous processes) or the use of models of stochastic volatility with leaps (ORNSTEIN-UHLENBECK). Kim et al (2011) tested a distribution based on Lévy's processes, which allows the modeling without resorting to much abstraction.

Mandelbrot (1963) was pioneer on the use of stable (or alpha-stable) distributions to model skewness distributions and fat tails. The alpha-stable family is a class that includes several distributions subclasses such as the following: the Gaussian, Cauchy's and Lévy's distribution (also known as inverse Gaussian or Pearson V). The Lévy's continuous stochastic procedure has stationary and independent increments. The Alpha-stable distributions can model the negative skewness and the excess of kurtosis that characterize financial returns. They earned some popularity in the 1960's; nevertheless the interest has decreased, due both to mathematical complexity and huge computing power necessary to implement practical models.

Broda et al., (2013) proposed the Stable mixture GARCH models, incorporating GARCH modeling with stable densities, with a possible incorporation of a Markov switching structure, as done in Haas et al. (2004) and prescribed in Bauwens et al (2010).

Different specifications for market risk models can be found in the literature, yet the well known Value at Risk ( VaR) approach prevails. The VaR can be defined as the possible loss that could occur on a horizon of $n$ days with a small probability. For parametric distributions, according to Jorion (1998, p. 87), "VaR is simply a multiple of standard-deviation of a distribution, multiplied by a factor of adjustment that is directly related to the level of confidence". The simplest and most used procedure to calculate the VaR of a portfolio is the deltanormal method or standard variance-covariance model. The asset price changes are conditionally normally distributed, and the VaR of a portfolio is a linear combination of normal variables and is also normally distributed. Dornbusch (1998) and Blejer and Schumacher (1998) suggested the applicability of VaR to 
macroeconomic questions. Zangari (1997) stated that VaR applies only to stable environments.

Blejer and Schumacher (ibid.) suggested, in complement to VaR, the use of stress tests based on the extreme value theory (EVT). However, the use of stresstesting as a capital adequacy rule has two related shortcomings: (1) only a finite number of scenarios can be examined, yet there are an infinite number of possibilities; and (2) the stress-testing approach usually does not explicitly use the likelihood of the scenarios. Analogous to VaR, these two shortcomings generate the incentive for a firm to increase its catastrophic failure risk without changing its maximum loss.

The Stressed VaR approach was proposed by Kupiec (1998), incorporating stressed scenarios into the VaR methodology, in order to measure the tail risk. The author shows how assuming multivariate normal distributions for all risk factors leads to automatic consideration of value changes due to the non-stressed factors which are commonly ignored in stress testing or, in other words, using data from the 1997 Asian crisis, his conditional Gaussian Stress VaR (95\%) approach to stress testing leads to historically accurate estimated value changes for a global portfolio with instruments in the U.S., European and Asian time zones.

BIS (2009) introduced its version of Stressed Value-at-Risk (SVaR): capital requirements based on a continuous 12-month period of significant financial stress, but keep working with the standard 99\% confidence interval (one-tailed), 10-day holding period and the normal density. There is little academic literature on Kupiek's (1998) Stressed VaR, like Colletaz et al. (2013) and even less on the BIS's SVaR version, as pointed in BIS (2012). Instead, Kim et al. (2011) recommend the Average Value at Risk (AVaR) with stable innovations. On the other hand, as an operational example, the Brazilian Central Bank (2014 and 2015) utilizes, in Financial Stability Reports the traditional stress testing.

A candidate to substitute VaR and Stressed VaR is the Expected Shortfall (ES), as proposed in BIS (2012) and reiterated in BIS (2014). Unlike VaR, ES is a coherent risk measure, prescribed in Artzner et al (1999). 
When utilizing the RiskMetrics ${ }^{\mathrm{TM}}$ VaR (TSAY, 2010), there is a simple conversion from $\mathrm{VaR}$ to $\mathrm{ES}$. For a given upper tail probability $\mathrm{p}$, the expected shortfall, with log returns, normal conditional distribution with mean zero and variance $\sigma_{\mathrm{t}}^{2}$ is described as a VaR function, as seen in table 2.3, approximately a $19 \%$ increase for $\mathrm{p}=2.5 \%$ and $14 \%$ for $\mathrm{p}=1 \%$.

Table 2.3: Expected Short Fall related to VaR under RiskMetrics ${ }^{\mathrm{TM}}$

$$
E S_{q}=\frac{f\left(V_{q}\right)}{p} \sigma_{t} ; \text { or }: E S_{(1-p)}=\frac{f\left(V_{1-p}\right)}{p} \sigma_{t}
$$

Nevertheless, the time frame for institutional changes is bigger than a few years (as seen in Williamson, 2010) so that, until 2015, the VaR prevailed as the risk methodology in almost all documents and recommendations from BIS.

Many stock and futures exchanges, including BM\&FBOVESPA, require that all operations must be registered and establish some daily limits of oscillation for financial assets. In this case, stressed values can be directly deduced from the daily limits of oscillation, dispensing the search for historical stressed values inputs for stressed VaR. Moreover, when an asset has pre-established oscillation limits, it is possible to use a probability distribution with barrier formula, from Dixit and Pindyck (1994), nevertheless this was not the case for the currency based assets of our sample.

\section{3}

\section{Data and Methodology}

Our sample comprises daily data on currency exchange rate (PTAX), Brazilian currency swaps (U.S. Dollars/Brazilian Reais), the S\&P500 stock exchange index and the VIX index. The PTAX represents the currency exchange rate between U.S. dollars and Brazilian Reais. The VIX is a volatility index, calculated by the Chicago Board Options Exchange as a weighted blend of prices for a range of options on the S\&P 500. The VIX is quoted in percentage points and translates, roughly, to the expected movement (with the assumption of one standard deviation) in the S\&P 500 over the next 30-day period, which is then annualized. 
In 2002, the internal Brazilian debt comprehended two types of currencyindexed contracts: the currency exchange swaps, negotiated in the BM\&FBOVESPA, and the NTN-D (National Treasury Notes, D series). The mark-to-market currency exchange swaps series began in August 1999. The Central Bank currency exchange swaps contracts began to be negotiated in April 2002 with a monthly adjustment of positions. In July 2002, three types of swap contracts were established - SCC, SC2, and SC3 - and two of them (SCC and SC3) were daily adjusted. The number of contracts exceeded 200 on July, 2002 and the total financial volume surpassed US\$ 30 billions. The underlying asset is the spread between the interest rate and the currency exchange rate variation, defined as follows:

a) The interest rate of interbank deposits (DI), defined as the capitalized daily average of one-day DI rates, calculated by the Central of Custody and Financial Settlement of Securities (CETIP) and verified in the period between the trading day and the day preceding the expiration date;

b) The exchange rate variation, measured by the offered exchange rate of Brazilian reais per U.S. dollar for cash delivery traded in the foreign exchange market.

The daily adjustment of a contract is the difference between the position "carried over" from the previous day and the market quotation. It is credited to the holder of a long position (buyer), and debited to the holder of a short position (seller).

After collecting the data, our first step was to use the Iterative Cumulative Sum of Squares (ICCS) algorithm to identify the changes in the unconditional variances of the daily returns of the series of PTAX and currency swaps. Then, the daily returns were modeled with regime switching and heteroscedasticity, with the use of the SWGARCH code from Haas et al. (2004). Finally, the series were simulated with alpha-stable densities.

The sudden changes in the unconditional variance were evaluated with the ICCS algorithm developed by Inclán and Tiao (1994). Once estimated the change points, the next step was to identify political and/or economical events that could be responsible for changes in the level of unconditional volatility. The temporal series presents a stationary variance over the initial period. A sudden change in variance occurs some time later, possibly caused by some political and/or 
economic shock. The variance becomes stationary again, at another level, until another sudden change occurs. This process is repeated creating a temporal series of observations with an unknown number of sudden changes in variance.

\section{Equation 2.2: Equation of Returns}

Daily return $=R d=\operatorname{Ln}\left(\frac{\text { Index }_{t}}{\text { Index }_{t-1}}\right)$;

\section{Equation 2.3: Sudden Changes, Unconditional Volatility (AR/GARCH)}

$A R(1): R d_{t}=A_{0}+A_{1} R d_{t-1}+u_{t} ; v_{t}=C+p v_{t-1}+q u_{t-1}^{2}+L e v I_{t-1} u_{t-1}^{2}$

Conditions. $\mu_{t}=\sqrt{v_{t}} \varepsilon_{t} ; \varepsilon_{t}=t ; \mu=0 ; \sigma^{2}=1 ; d f=D(t-$ studen $t) ; I_{t}=1\left(u_{t}<0\right) ; I_{t}=0\left(u_{t} \geq 0\right)$ Where $\mathrm{A}_{0}$ is constant in the average equation; $\mathrm{C}$ is constant in the conditional variance equation; $\mathrm{Q}$ is the residuals coefficient; $\mathrm{P}$ is the conditional variance coefficient; Lev is the leverage coefficient, and D is the degree of freedom of the t-student distribution that models the return series. After running the GARCH model, the program runs the ICSS algorithm.

With regard to regime switching, the Hamilton's (1990) model was adapted to estimate a 2-state Markov model, with average and variance being variables of a 1-dimension vector. Each series was tested individually. The duration of each regime can be easily derived from the Markov chain properties. Defining $D$ as the duration of a specific regime, $S_{t}$ the state variable at time $t, j$ a index that stands for the regime $j, p_{j j}$ the probability of staying in the same regime $j$ from time $t$ to $t$ +1 .

Equation 2.4: Expected Regime Duration (calculated by induction)

$$
E(D)=\sum_{j=1}^{\infty} j P[D]=\left(1-p_{j j}\right)+2 \cdot p_{j j} \cdot\left(1-p_{j j}\right)+3 \cdot p_{j j}^{2} \cdot\left(1-p_{j j}\right)+\ldots=\frac{1}{1-p_{j j}}
$$

The probability $\mathrm{p}_{\mathrm{jj}}$ is the permanence in same regime $\mathrm{j}$ in consecutive time.

The SWARCH (switching ARCH) models from Hamilton and Susmel (1994) were utilized in preliminary tests, yet discarded on behalf of the parsimony of the SWGARCH models, which were based on Haas et al. (2004). Each series was modeled with SWGARCH, nesting a $\operatorname{GARCH}(1,1)$, as seen in equation 2.5:

Equation 2.5: Variance Equation for SWGARCH (HAAS et al., 2004)

$$
v_{t, k}=\alpha_{0}+\sum_{i=1}^{q} \alpha_{i} u_{t-q}^{2}+\sum_{j=1}^{p} \beta_{j} v_{t-p, k}
$$


Where $v_{t, k}$ stands for the $k$-regime variance at period $t, \alpha_{0}, \alpha_{i}, \beta_{j}$ are constants.

BIS (2009) recommends a stressed value-at-risk (SVaR), a methodology initially proposed by Kupiec (1998), exhibited in equation 2.6.

Equation 2.6: Required Capital calculated through Stressed VaR (BIS)

$$
\left.\left.R C_{t}=\operatorname{Max}_{\operatorname{VaR}} \operatorname{Vit}_{t},\left(3+k_{t}\right) \frac{1}{60} \sum_{i=1}^{60} \operatorname{VaR}_{t-i}\right]+\operatorname{Max}_{[} \operatorname{sVaR}_{t-1},\left(3+k_{t}\right) \frac{1}{60} \sum_{i=1}^{60} s \operatorname{VaR}_{t-i}\right]
$$

Where: Max, RC, VaR, SVar and k stand for Maximum, Required Capital, Value at Risk, Stressed Value at Risk and a constant defined by the country financial regulator (usually a Central Bank). The original formula from Kupiec (1998) specifies only the last term, without the multiplier (3+k) and an arbitrary number $\mathrm{N}$ in place of the fixed 60 .

The normal innovations densities are almost always prescribed in the BISs's recommendations. While there is a risk of double counting the VaR, for instance, when the present scenario is a stressed scenario (BIS, 2014), during non-turbulent periods, the first term (the volatility parcel already present in the VaR methodology) contributes marginally to the SVaR term, meaning a clear separation between volatility risk and tail risk.

The chosen method to optimize modeling is the MLE (Maximum Likelihood Estimation) with normal and alpha-stable innovations, based on Haas et al. (2004) and Broda et al. (2013), shown in equation 2.7 as the negative of the sum of innovations $X_{t}$. Alternatively, from Hall and Yao (2003), it is possible to apply a MLE generalization with a GARCH-like approach.

\section{Equation 2.7: The Normal Log Likelihood and the Stable Log Likelihood}

$\log \operatorname{lik}(X)=-\sum_{t=v}^{T}\left[\operatorname{LL}\left(X_{t}\right)\right]+\frac{T}{2 * \log (2 * \pi)} ;$ simplifies to $\log \operatorname{lik}(X)=-\sum_{t=v}^{T}\left[\operatorname{LL}\left(X_{t}\right)\right]$

The stable densities are defined according to Nolan (1997 and 2015). A random variable $X$ is stable $(\alpha, \beta, \gamma, \delta)$ if it has the following characteristic function (than can generate the second moment through a Fourier transform), described in equation 2.8: 
Equation 2.8: Stable ( $\alpha, \beta, y, \delta)$ Characteristic Function (to Fourier Transform)

$E[\exp (i u X)]=\left\{\frac{\exp \left(-\gamma^{\alpha}|u|^{\alpha}\left[1-i \beta\left(\tan \frac{\pi \alpha}{2}\right)(\operatorname{sign}(u)]+i \delta u\right) ; \alpha \neq 1\right.}{\exp \left(-\gamma|u|\left[1+i \beta \frac{2}{\pi}(\operatorname{sign}(u)) \ln |u|\right]+i \delta u\right) ; \alpha=1}\right\}$

Where $\alpha, \beta, \delta$ and $\gamma$ stand for the characteristic parameter (tail), skewness, scale (equivalent to variance) and location (equivalent to mean). For a normal distribution, the tail value is 2 , the skewness is zero, the scale is 1 and the mean is zero.

\section{4 \\ Results}

Currency exchange rate and currency swaps contracts: daily volatility.

In the first step of our test protocol, various changes in the unconditional volatility were detected in all daily returns series. When modeling the volatility with heteroskedasticity and regime switching - either with SWARCH or SWGARCH models - the number of levels implied a non-parsimonious number of parameters. The existence of various regimes of variance, with non-zero transition probabilities between these regimes, is not rejected. However, it is also appropriate to consider the hypothesis of the occurrence of various structural breaks, especially for the case of the huge jumps in the unconditional volatility of the daily returns series in the second semester of 2002, when the so-called confidence crisis occurred.

The high volatility levels of the Brazilian financial series in the second semester of 2002 were mainly determined by the uncertainty related to the Presidential election campaign. Razin \& Sadka (2004) identified the presidential elections and the expected change of political and economical regime as being the two triggers of the Brazilian confidence crisis, known as such in spite of the economic fundamentals of the Brazilian were solid. Those triggers are a clear example of the unpredictable nature of future crises, as proclaimed in BIS (2011). According to Meirelles (2004), the Brazilian Central Bank offered currency exchange swaps contracts at the height of the confidence crisis through which the country suffered in the second semester of 2002. 
The risk models based on either normal or t-student innovations, using data collected from 1999 to the first semester of 2002, were not able to forecast the jump of the volatility levels since June 2002, when the leftist candidate Lula, willing to calm down the market, launched the manifesto Letter to the Brazilians. The mark-to-market currency exchange swaps prices exhibited high unconditional volatility levels from July $26^{\text {th }}, 2002$. However, those high levels are possibly related not only due to the confidence crisis, but also to the increase in the number of currency swap contracts and to the large volume of conversions from contracts without daily adjustment (SC2) to contracts with daily adjustment (SC3) - an operational issue, rather linked to the operational risk of new terms of contracts than to market risk. The volatility decreased by August $13^{\text {th }}, 2002$, possibly as a result of the stand-by loan's announcement from the IMF (International Monetary Fund), nevertheless higher than the former levels before June 2002.

While the exchange rate (U.S. Dollars/ Brazilian Reais) rose to almost 4 by October $22^{\text {nd }}, 2002$, the eve of the second round of the presidential elections; its unconditional volatility levels were the greatest since the beginning of the currency floating regime, started by 1999.2.

Table 2.4 shows the sudden changes in the unconditional volatility of the daily returns of both currency exchange and currency swaps price units (PU, the unit of negotiation of currency swaps contracts) in the BM\&FBOVESPA stock exchange. The daily returns of swap prices presented 11 change points in the unconditional volatility. The table shows some political and/or economical events that could be responsible for the changes in the unconditional volatility of the daily series. 
Table 2.4: Sudden Changes, Unconditional Volatility of Currency Swap Prices

\begin{tabular}{|c|c|c|c|c|}
\hline Period & From & To & $\begin{array}{l}\text { Standard } \\
\text { deviation }\end{array}$ & Possibilities \\
\hline 1 & August, $25^{\text {th }}, 1999$ & October $7^{\text {th }}, 1999$ & $1.20 \%$ & $\begin{array}{l}\text { Initial phase of currency } \\
\text { floating regime in Brazil }\end{array}$ \\
\hline 2 & October $8^{\text {th }}, 1999$ & May $12^{\text {th }}, 2000$ & $0.73 \%$ & $\begin{array}{l}\text { COPOM's meeting kept } \\
\text { basic interest rate at } 19 \% \\
\text { per year }\end{array}$ \\
\hline 3 & May $15^{\text {th }}, 2000$ & October $20^{\text {th }}, 2000$ & $0.47 \%$ & "Quiet" period \\
\hline 4 & October $23^{\text {rd }}, 2000$ & December $1^{\text {st }}, 2000$ & $1.22 \%$ & "Quiet" period \\
\hline 5 & December $4^{\text {th }}, 2000$ & March $13^{\text {th }}, 2001$ & $0.53 \%$ & "Quiet" period \\
\hline 6 & March $14^{\text {th }}, 2001$ & December $17^{\text {th }}, 2001$ & $1.59 \%$ & $\begin{array}{l}\text { Argentine's default, } \\
\text { energy crisis, Sep } 11\end{array}$ \\
\hline 7 & December $18^{\text {th }}, 2001$ & June $3^{\text {rd }}, 2002$ & $0.88 \%$ & "Quiet" period \\
\hline 8 & June $4^{\text {th }}, 2002$ & July $25^{\text {th }}, 2002$ & $2.06 \%$ & $\begin{array}{l}\text { Beginning of Presidential } \\
\text { campaign in Brazil }\end{array}$ \\
\hline 9 & July $26^{\text {th }}, 2002$ & August $6^{\text {th }}, 2002$ & $8.49 \%$ & $\begin{array}{l}\text { Confidence crisis, swap } \\
\text { auctions and conversions } \\
\text { (SC2 for } \mathrm{SC} 3 \text { ) }\end{array}$ \\
\hline 10 & August $7^{\text {th }}, 2002$ & November $13^{\text {th }}, 2002$ & $2.54 \%$ & $\begin{array}{l}\text { Election's eve and IMF } \\
\text { stand-by Loan }\end{array}$ \\
\hline 11 & November $14^{\text {th }}, 2002$ & February $4^{\text {th }}, 2003$ & $1.50 \%$ & $\begin{array}{l}\text { Political transition; } \\
\text { beginning of Lula's } \\
\text { government }\end{array}$ \\
\hline
\end{tabular}

Figure 2.2 shows that the peak unconditional volatility of the currency swaps prices was almost the same (near $8 \%$ on August $8^{\text {th }}, 2002$ ) to all currency swaps series. At that time, some currency based assets were set to a maximum daily fluctuation of $7.5 \%$, meaning that the peak volatilities were coherent with some pre-established daily oscillation limits. The currency exchange rate (PTAX) exhibited unconditional volatility levels lower than those of the currency swaps contracts, which are subject to, at least, other two risk factors: interest rates and currency exchange coupon. 
Figure 2.2: Currency Swaps Prices - Daily Volatility (DTM= Days to Maturity)
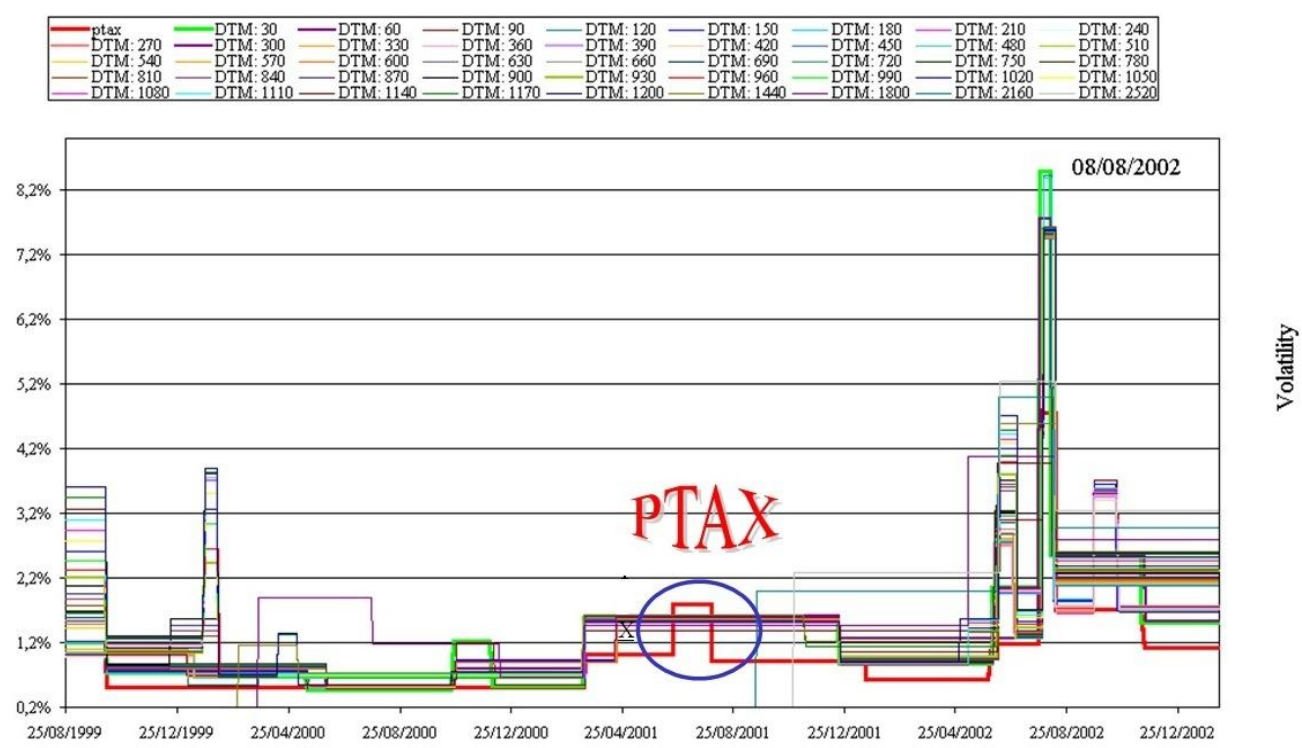

Table 2.5 exhibits the transition probabilities (P1 and P2), unconditional volatilities, regime durations (in days), and expected losses of the daily returns of currency swap prices and currency with two-regime volatility. The daily loss possibilities follow equation 2.9 which describes a $\mathrm{VaR}$ with one-day holding period divided by the mark-to-market asset value:

Equation 2.9: Expected Daily Loss, from Currency Exchange Swaps Prices

$$
\frac{\text { VaR }}{\text { Value }}=\left(S F \times M_{T} \times \sigma_{s, t}\right) / M T M_{t}=S F \times \sigma_{s, t}
$$

where $\sigma_{s, t}$ is the volatility of regime s at day $\mathrm{t}$; $\mathrm{SF}$ is the sensibility factor (2.33 for a $1 \%$ significance level); $M T M_{t}$ is the mark-to-market value of the contracted currency exchange swaps at day t. The main component of a Principal Component Analysis (PCA, based on Litterman and Scheinkman, 1991) is possibly a currency exchange factor, responsible for $96.05 \%$ of the variance over other factors that influence the currency swaps contracts.

The results confirm the effectiveness of the Stressed VaR approach from Kupiec (1998) adapted for a two-volatility regime switching model, however they do not shed a light for the BIS stressed VaR, in which the simultaneous use of high and (not very) low volatility parcels can be faced as an over specification. 
Table 2.5: Daily losses for PTAX and Currency Exchange Swaps

Note: Transition probabilities (P1 and P2), volatility, duration (days), and expected losses (VaR/portfolio ratio).

\begin{tabular}{ccccccccc}
\hline $\begin{array}{c}\text { Expiring } \\
\text { Days/asset }\end{array}$ & P1 & P2 & $\begin{array}{c}\text { Low } \\
\text { volatility }\end{array}$ & $\begin{array}{c}\text { High } \\
\text { volatility }\end{array}$ & $\begin{array}{c}\text { Low } \\
\text { volatility } \\
\text { duration }\end{array}$ & $\begin{array}{c}\text { High } \\
\text { volatility } \\
\text { duration }\end{array}$ & $\begin{array}{c}\text { Low } \\
\text { volatility } \\
\text { daily loss }\end{array}$ & $\begin{array}{c}\text { High } \\
\text { volatility } \\
\text { daily loss }\end{array}$ \\
\hline 270 & 0.9725 & 0.9644 & $0.91 \%$ & $2.83 \%$ & 36.37 & 28.10 & $2.12 \%$ & $6.59 \%$ \\
\hline 300 & 0.9734 & 0.9661 & $0.82 \%$ & $2.57 \%$ & 37.54 & 29.51 & $1.92 \%$ & $5.99 \%$ \\
\hline 330 & 0.9734 & 0.9661 & $0.75 \%$ & $2.37 \%$ & 37.60 & 29.50 & $1.76 \%$ & $5.51 \%$ \\
\hline 360 & 0.9735 & 0.9661 & $0.69 \%$ & $2.19 \%$ & 37.71 & 29.52 & $1.61 \%$ & $5.11 \%$ \\
\hline 390 & 0.9744 & 0.9678 & $0.65 \%$ & $2.04 \%$ & 38.99 & 31.04 & $1.51 \%$ & $4.76 \%$ \\
\hline 420 & 0.9758 & 0.9700 & $0.61 \%$ & $1.92 \%$ & 41.32 & 33.31 & $1.41 \%$ & $4.47 \%$ \\
\hline 450 & 0.9762 & 0.9707 & $0.57 \%$ & $1.81 \%$ & 42.00 & 34.16 & $1.32 \%$ & $4.21 \%$ \\
\hline 480 & 0.9772 & 0.9714 & $0.54 \%$ & $1.74 \%$ & 43.84 & 34.91 & $1.27 \%$ & $4.06 \%$ \\
\hline 510 & 0.9785 & 0.9728 & $0.52 \%$ & $1.67 \%$ & 46.60 & 36.76 & $1.22 \%$ & $3.89 \%$ \\
\hline PCA & 0.12 & 0.04 & $0.030 \%$ & $3.163 \%$ & 1.14 & 1.05 & $0.070 \%$ & $7.369 \%$ \\
\hline PTAX & 0.80 & 0.46 & $0.007 \%$ & $3.162 \%$ & 4.90 & 1.86 & $0.017 \%$ & $7.368 \%$ \\
\hline
\end{tabular}

\section{Evaluating the VIX index as a volatility Proxy}

Table 2.6 shows the alpha-stable distributions for currency swaps, VIX, and S\&P 500 series. The daily returns series were submitted to the STBLFIT and STBLPDF functions from Veillete (2010) and to the STABLEFIT function from Nolan (2015), with similar results which exhibit the non negligible probability of occurring the Black Monday volatility (October $\left.19^{\text {th }}, 1987\right)$, even in the S\&P 500 series that ends in September $18^{\text {th }}, 1987$. The Kolmogorov-Smirnov test rejected the null hypothesis of normality at the $1 \%$ significance level for all series.

Table 2.6: Stable Distributions- VIX, Currency Exchange Swaps and S\&P 500

Note: $\alpha, \beta, \delta$ and $\gamma$ stand for the characteristic parameter (tail), skewness, scale (equivalent to variance) and location (equivalent to mean), respectively.

\begin{tabular}{|c|c|c|c|c|c|}
\hline Series & $\alpha$ & $\beta$ & $\delta$ & $\Gamma$ & $\begin{array}{c}\text { Black Monday } \\
\text { Probability (-23\%) }\end{array}$ \\
\hline VIX (Since January $2^{\text {nd }}, 1990$ ) & 1.609991 & 1.00 & 0.002524 & 0.013149 & $0.187 \%$ \\
\hline Currency Swaps 1999-2003 & 1.393691 & 0.2464 & 0.006498 & 0.001661 & $0.733 \%$ \\
\hline Currency Swaps 2004-2014 & 1.612221 & -0.0708 & 0.006871 & $9.39 \mathrm{E}-05$ & $0.432 \%$ \\
\hline S\&P (Jan, $4^{\text {th }}, 1950-$ Aug. $\left.8^{\text {th }}, 2015\right)$ & 1.617643 & -0.1213 & 0.004959 & 0.000183 & $0.258 \%$ \\
\hline S\&P (Jan, $4^{\text {th }}, 1950-$ Sep. $\left.18^{\text {th }}, 1987\right)$ & 1.716187 & -0.0949 & 0.004569 & 0.000238 & $0.123 \%$ \\
\hline
\end{tabular}

Next, we calculate the VaR and Expected Shortfall for currency swaps positions based on the VIX index, according to equation 2.10. 


\section{Equation 2.10: VaR / ES for Currency Swaps, Based on Overall maximum VIX}

$$
\operatorname{VaR}_{p=1 \%}=S F \times \sigma_{t}=2.33 * 5.09 \%=11.868 \% \Rightarrow \text { EShortfall }=13.60 \%
$$

Where: $\mathrm{SF}$ is the sensibility factor $\left(\mathrm{SF}=2.33\right.$ for a $1 \%$ significance level), $\sigma_{t}$ is the volatility at day $\mathrm{t}$, and the overall maximum historical daily VIX volatility (until August, 2015) is 5.09\%.

The next tables $(2.7 ; 2.8)$ show that few violations occurred when using a maximum historical daily volatility VIX in the VaR for currency swaps: either only two days, when referring to overall maximum VIX, or only 9 days, when referring to maximum VIX until the analyzed period. Moreover, there is no violation when referring to the maximum Expected Shortfall of $13.60 \%$ (equation 2.13 ) at a $1 \%$ significance level.

Table 2.7: Only two Violations referring to the Overall Maximum VIX volatility

\begin{tabular}{cc}
\hline Day & Loss \\
\hline October 9th, 2008 & $-12.881 \%$ \\
\hline October 23rd, 2008 & $-12.648 \%$ \\
\hline
\end{tabular}

Table 2.8: Only Nine Violations referring to Maximum Historical VIX until Date

\begin{tabular}{ccll}
\hline Day & Loss & Day & Loss \\
\hline July $30^{\text {th }}, 2002$ & $-9.59 \%$ & September $30^{\text {th }} 2008$ & $-8.54 \%$ \\
\hline October $9^{\text {th }}, 2002$ & $-6.74 \%$ & October $9^{\text {th }}, 2008$ & $-12.88 \%$ \\
\hline May $25^{\text {th }}, 2006$ & $-9.47 \%$ & October $13^{\text {th }} 2008$ & $-10.91 \%$ \\
\hline August $17^{\text {th }} 2007$ & $-8.72 \%$ & October $23^{\text {rd }}, 2008$ & $-12.65 \%$ \\
\hline September $19^{\text {th }} 2008$ & $-8.48 \%$ & &
\end{tabular}

The VIX is calculated from S\&P500's derivatives. We generated an alternate volatility index based on S\&P500 volatility parameterizations. First, we fit the daily returns of the S\&P500 index to an ARMA $(1,1)-\operatorname{GARCH}(1,1)$ model. The results are shown in Table 2.9. The log likelihood value for normal innovations is $+56,296.80$. The variance level, 8.0625E-07, compared to the GARCH coefficient (0.91), indicate a dependence on historical values. Nevertheless, the persistence - sum of GARCH + ARCH coefficients - is high 
(99.37\%), suggesting changes in the unconditional variance that can be modeled with regime switch models (see DIEBOLD, 1986 and 1996). The log likelihood value for stable innovations is slightly superior to the result for the normal innovations $(+55,071.00)$, while the log likelihood value for GARCH with stable innovations is negative: $-16,507.60$.

Table 2.9: S\&P 500 Daily Return's GARCH Fit (January, 1950 to August, 2015)

\begin{tabular}{lcccccc}
\hline Parameter & C & AR (1) & MA (1) & K & GARCH (1) & ARCH (1) \\
\hline Value & 0.00054663 & -0.15823 & 0.25515 & $8.0625 \mathrm{E}-07$ & 0.91022 & 0.083508 \\
\hline Std Error & $7.30 \mathrm{E}-01$ & 0.080562 & 0.07882 & $6.61 \mathrm{E}-05$ & 0.0022535 & 0.0017177 \\
\hline T Statistic & 74.879 & -19.641 & 32.371 & 122.030 & 4.039 .206 & 486.150 \\
\hline Value (Stable) & 0.000291 & & & $9.42 \mathrm{E}-06$ & 0.85 & 0.05 \\
\hline SE (Stable) & 0 & & 0 & 0 & 0 \\
\hline T (Stable) & Inf & & & Inf & Inf & Inf \\
\hline
\end{tabular}

Next, we model the S\&P500 index with SWGARCH. The results from tables 2.10 and 2.11 show that MLE fitting for alpha-stable densities is very sensible to the volatility levels and, at first, they do not favor regime switching, as some of the single volatility regime $\operatorname{GARCH}(1,1)$ models, with stable innovations, exhibited better results than the switching regime models. Table 2.10 shows the results for the maximum likelihood estimation for the S\&P 500 index from January $4^{\text {th }}, 1950$ to August $20^{\text {th }}, 2015$ - with alpha-stable and normal innovations. The columns L1 and L2 are the unconditional volatility levels, ARCH and GARCH stand for the ARCH/GARCH coefficients, MLE_STBL, MLE_NORM and MLE_GARCH mean, respectively, ARMA $(1,1)-S W G A R C H$ $(1,1)$ with stable innovations/two volatility levels, ARMA $(1,1)-\operatorname{SWGARCH}(1,1)$ with normal innovations/two volatility levels and ARMA $(1,1)-\mathrm{GARCH}(1,1)$ with stable innovations/one high volatility level. All transition probabilities are equal to $50 \%$. 
Table 2.10: S\&P 500 return's MLE Fitting (Stable and Normal Innovations

\begin{tabular}{ccccccccc}
\hline L1 (\%) & L2 (\%) & ARCH1 & ARCH2 & GARCH1 & GARCH2 & MLE_STBL & MLE_NORM & MLE_GARCH \\
\hline 0.83 & 2.07 & 0.10 & 0.28 & 0.55 & 0.96 & 63,791 & 29,340 & 58.812 \\
\hline 0.83 & 1.87 & 0.10 & 0.28 & 0.55 & 0.96 & 63,660 & 29,292 & 58.619 \\
\hline 0.83 & 1.67 & 0.10 & 0.28 & 0.55 & 0.96 & 63,527 & 29,243 & 58.424 \\
\hline 0.50 & 1.00 & 0.28 & 0.05 & 0.10 & 0.82 & 54,053 & 8,510 & 45.700 \\
\hline 0.50 & 1.10 & 0.28 & 0.05 & 0.10 & 0.82 & 52,088 & 8,425 & 43.358 \\
\hline 0.50 & 1.20 & 0.28 & 0.05 & 0.10 & 0.82 & 50,234 & 8,367 & 41.193 \\
\hline 0.50 & 1.30 & 0.28 & 0.05 & 0.10 & 0.82 & 48,499 & 8,331 & 39.203 \\
\hline 0.50 & 1.40 & 0.28 & 0.05 & 0.10 & 0.82 & 46,892 & 8,314 & 37.384 \\
\hline 0.757 & 1.298 & 0.77 & 0.57 & 0.99 & 0.99 & 42,433 & 18,417 & 42.682 \\
\hline 0.806 & 2.393 & 0.76 & 0.94 & 0.65 & 1.00 & 21,541 & 25,082 & $\mathbf{6 5 , 2 5 8}$ \\
\hline E-7 & 0.81 & 0.99997 & 0.80268 & 0.99997 & 0.99997 & 176,700 & 93,256 & $\mathbf{1 5 9 , 0 6 0}$ \\
\hline
\end{tabular}

Table 2.11 shows comparative results for the maximum likelihood estimation for the S\&P 500 index, daily returns of Brazilian currency swaps (CS, with 30 days to maturity), and the main factor from currency swaps daily return's Principal Component Analysis (PCA, possibly the daily exchange rate between U.S. Dollars and Brazilian Reais); with alpha-stable and normal innovations allowing different transition probabilities. L1 and L2 are the unconditional volatility levels; G1 and G2 stand for the GARCH coefficients of IGARCH modeling; P11 and P22 are probabilities to stay in the same regime in consecutive times; STBL, NRM and GARCH mean, respectively, ARMA $(1,1)-S W G A R C H$ $(1,1)$ with stable innovations/two volatility levels, ARMA $(1,1)-\operatorname{SWGARCH}(1,1)$ with normal innovations/two volatility levels, and ARMA $(1,1)-\operatorname{GARCH}(1,1)$ with stable innovations/one high volatility level.

Table 2.11: MLE returns fitting (S\&P 500 and Currency Swaps).

\begin{tabular}{lccccccccc}
\hline Series & $\begin{array}{c}\text { L1 } \\
(\boldsymbol{\%})\end{array}$ & $\begin{array}{c}\text { L2 } \\
(\boldsymbol{\%})\end{array}$ & $\mathbf{G 1}$ & $\mathbf{G 2}$ & $\mathbf{P 1 1}$ & $\mathbf{P 2 2}$ & STBL & NRM & GARCH \\
\hline S\&P500 & E-06 & 2 & 99.86 & 99.136 & 0.26 & 0.29 & 102,286 & 70,321 & 169,723 \\
\hline S\&P500 & E-06 & 2 & 83.08 & 99.90 & 0.02 & 0.88 & 468,027 & 12,600 & 512,243 \\
\hline CS (1999-2003) & E-07 & 0.1 & 98.80 & 99.51 & 0.81 & 0.75 & 25,377 & 13,008 & NaN \\
\hline CS (2004-2014) & $8 \mathrm{E}-07$ & 1 & 96.59 & 98.15 & 0.20 & 0.14 & 22,213 & 9,175 & NaN \\
\hline PCA & E-3 & 3.523 & $99.105 \%$ & $99.396 \%$ & 0,20 & 0,11 & 26,388 & -685 & NaN \\
\hline
\end{tabular}




\section{5 \\ Discussion}

This chapter evaluated the adequacy of two main Basel's recommendations for market risk - minimum capital requirements and Stressed VaR - analysing a past financial vulnerability through the market risk exposure originated from currency exchange based assets. Would the effects of past crises be mitigated if those Basel III recommendations were already implemented? The chosen country and time were Brazil in the eve of the 2002's presidential election. After applying the standard delta normal VaR methodology to the quite high daily return's volatilities; both of the exchange rate (U.S. Dollars/Brazilian Reais) and of the currency swaps prices (from August, 1999 to February, 2003); it is possible to answer upon the effects of the two chosen recommendations.

First, is Stressed VaR effective for crisis periods? The answer is no when there is no recent turbulence to be referenced. In the specific case of the 2002's Brazilian scenario, the number and volume of currency swaps only grew a couple of months before the crisis peak, so that the past does not work as a stress reference. Moreover, the high volatility levels did not sustain for a long period (from the end of July, 2002 to early August, 2012), and might not be eligible for future references. Also, the currency exchange volatility did not follow the currency swaps volatility, since they depend on different factors. Consequently, currency based assets cannot proxy the new asset (currency swaps), which is a strong reason to avoid much exposure from new financial instruments.

The BIS SVaR works like a sum of historical VaR and historical tail risk, therefore it is feasible with a necessarily pre-existent historical background, meanwhile capital requirements is a general approach. The stress reference usually works in a window approach, with the moving averages replaced by the window of stress. In the absence of historical data, we suggest that VIX volatilities can be used as an alternative volatility for the Stressed VaR. Besides that, while we follow BIS (2012) and BIS (2014) which recommend the substitution of VaR and Stressed VaR by the Expected Shortfall methodology, we also suggest that SWGARCH models can be a good alternative to describe the volatility of the financial series, competing with alpha-stable innovations models. In future tests, the transition probabilities between states may vary with time. 
On the other hand, there is a key advantage for stable-based models, since they do not separate volatility from tail risk, what forcibly occurs when using models based on the standard normal distributions, as usually prescribed in BIS's documents.

Second, concerning Basel III capital requirements: would have been effective in past crises? The answer is a conditional yes, once there is a previous point not much discussed in literature: the daily oscillation limits that, in the Brazilian case, exceeded $8.5 \%$ a day in the year 2002 - not to mention the key role of margins calls. Our simulations showed that assets with long term maturity exhibited a $6.59 \%$ daily loss (with a duration of 28.10 days), meaning a $13.18 \%$ loss in two days. The oscillation limits can play a stop loss role, mitigating crisis effects. In other words, a control over price oscillations should be more effective compared to a macro control over minimum capital requirements.

In this view, while the global Basel index rose from $8 \%$ to $11 \%$ due to the emergent need to quick respond to the financial crisis, the Brazilian banks have operated with a Capital Requirements index above 11\% since 1998. Until now, the increase of the Regulatory Capital requirements will be transferred to new Requirements items, such as the counter cyclical capital buffer. However, readers shall take into account the risk of disclosing information in crisis times, when transparency becomes a very sensitive issue, as observed in Eichengreen (2003).

Last but not least, three considerations: (a) market risk apparently is the most observable of the financial risks; (b) other risk experiences are scarce in the recent Brazilian history, as no systemic bank crisis occurred in the recent past (50 years, according to Laeven and Valencia, 2008) and (c) the use of past crises deals with just one similarity: high volatility, from different sources. 


\section{3 \\ The Liquidity Regulation versus the Lender of Last Resort: a Dichotomy? (Pricing Options for Capital Adequacy)}

\section{1.}

Introduction

This chapter deals with a supposed dichotomy in the field of banking regulation: the liquidity risk regulation versus the lender of last resort (LOLR). Why does the financial system need both alternatives simultaneously? As a matter of fact, this simultaneity is justifiable by a number of reasons already discussed in Carlson et al. (2015). Moreover, we can rebate this dichotomy by following the portfolio selection approach (MARKOWITZ, 1952) that prescribes diversification for any kind of financial investments. We innovate showing that third alternatives to capital requirements are theoretically feasible as well as identifying that the Brazilian Liquidity Index is a random walk process, meaning both a constant effort to keep this index at a safer level and a constant search for liquidity alternatives.

In a necessary search for an effective contextualization with the international financial crisis and the recommendations from the Bank for International Settlements (BIS) that constitute the Basel III agreement, four groups of analyses were made concerning the liquidity shortage risk. First, we evaluate the U.S. low risk/high liquid assets and the Brazilian rediscount (which is a kind of perpetual option without legal tender) in light of the quantitative easing approach, the quite low interest rates of U.S. risk free assets (with a quite low yield since 2009) and the absence of systemic crises in Brazil in the recent past. Second, we test the Brazilian liquidity index and verify its behavior and relation with other financial and economic variables. Third, we examine the daily returns of currency based assets that are highly volatile, which means a high probability of market value losses, a pattern that is not captured by lower frequency (monthly) databases. Fourth, we simulate call options, according to the risk weighted assets (RWA) approach of the Basel II and Basel III agreements, for credit, market and 
operational risks. Call options without maturity, as in Alvarez and Dixit (2014), originated from any kind of lender (not necessarily a LOLR) offer a theoretically feasible alternative/complement to capital requirements, with underlying assets modeled with Geometric Brownian motion, although more costly than the usual rediscount offered by Central Banks, and not always warranted.

Caruana (2010) stated that the Basel III agreement generated significant progress in prudential financial regulation since the beginning of the global financial crisis, a landmark of a new global economic context that imposes major challenges. The main recommendation for capital requirements is the increase from 8 to 11 percent of the "cushion" required to cover losses from risky assets, allocated in the net worth of the banks and calculated following the risk weighted assets (RWA) methodology - a methodology established since the Basel II agreement. Table 3.1 shows the Brazilian road map for Basel III implementation, where a key term is the regulatory capital (RC).

Table 3.1: Brazilian's Basel III Chronogram (Minimum Capital Requirements

\begin{tabular}{|c|c|c|c|c|c|c|c|}
\hline Implementation Date: & $\begin{array}{l}\text { Jan, } 1^{\text {st }} \\
/ 13\end{array}$ & $\begin{array}{l}\text { Jan, } 1^{\text {st } /} \\
14\end{array}$ & $\begin{array}{l}\text { Jan, } 1^{\text {st }} \\
/ 15\end{array}$ & $\begin{array}{l}\text { Jan, } 1^{\text {st }} \\
/ 16\end{array}$ & $\begin{array}{l}\text { Jan, } 1^{\text {st }} \\
/ 17\end{array}$ & $\begin{array}{l}\text { Jan, } 1^{\text {st }} \\
/ 18\end{array}$ & $\begin{array}{l}\text { Jan, } 1^{\text {st }} \\
/ 19\end{array}$ \\
\hline Core Capital & $4.5 \%$ & $4.5 \%$ & $4.5 \%$ & $4.5 \%$ & $4.5 \%$ & $4.5 \%$ & $4.5 \%$ \\
\hline Level I & $5.5 \%$ & $5.5 \%$ & $6.0 \%$ & $6.0 \%$ & $6.0 \%$ & $6.0 \%$ & $6.0 \%$ \\
\hline Regulatory Capital & $11.0 \%$ & $11.0 \%$ & $11.0 \%$ & $9.875 \%$ & $9.875 \%$ & $8.625 \%$ & $8.0 \%$ \\
\hline Capital Conservation & - & - & - & $0,625 \%$ & $1.250 \%$ & $1.875 \%$ & $2.5 \%$ \\
\hline $\begin{array}{l}\mathrm{RC}+\text { Capital } \\
\text { Conservation }\end{array}$ & $11.0 \%$ & $11.0 \%$ & $11.0 \%$ & $10.5 \%$ & $10.5 \%$ & $10.5 \%$ & $10.5 \%$ \\
\hline $\begin{array}{l}\text { Counter-Cyclical } \\
\text { Capital }\end{array}$ & - & To $0.625 \%$ & To $1.25 \%$ & To $1.875 \%$ & To $2.5 \%$ & To $2.5 \%$ & To $2.5 \%$ \\
\hline
\end{tabular}

Source: Brazilian Central Bank (2011).

The liquidity concept was historically developed before the credit, market and operational risk concepts, nevertheless strongly tied to credit and market risk fluctuations that influences bank's ability to pay its debts.

Concerning to Brazil, the Central Bank Resolution 4090/2012 provides for the management structure of liquidity risk, defined as: (a) the possibility of the bank becoming unable to efficiently meet its expected and unexpected current and future obligations, including those arising from binding guarantees, without affecting their daily operations and incurring significant losses; and (b) the 
possibility of the institution becoming unable to negotiate a position at market price, because of its size related to the volume usually transacted or due to any market discontinuity. The financial institutions should consider the liquidity risk in individual countries where they operate and in the currencies to which they are exposed, observing any restrictions on the transfer of liquidity and convertibility of currencies, such as those caused by operational problems or impositions made by a country.

Concerning risky assets, Hagendorff and Vallascas (2013) report a global decrease of the RWA related to total assets. Nevertheless, in spite of the possible global decrease of risky assets, even high liquid/low risk assets do not cease to exhibit a likelihood of high volatilities, keeping the need to risk mitigation and liquidity regulation strongly linked and being permanent concerns, giving space for macroeconomic alternatives. An outstanding example is the quantitative easing policy from the Federal Reserve. In this approach, a Central Bank quantitatively buys financial assets from banks, causing a price increase of financial assets and a simultaneous increase of both broad money and monetary base.

The next section is a quick review on Banking Regulation and Financial Time Series. The third section comprises the data and methodology. The results section is divided into six parts. First, we analyze the volatility and yield of American low risk and high liquid assets, second we test the Brazilian rediscount and third we test the aggregated liquidity index reported by the Brazilian Central Bank. Then, we model the volatility of the daily returns of the exchange rates (U.S. Dollars/ Brazilian Reais and Euro/Brazilian Reais) since they exhibit high daily volatilities (meaning high loss probabilities) not captured by monthly data. Finally, we evaluate a complementary/alternative lending to the capital requirements recommendations from the Basel agreement, in line with the RWA approach: the financial options model, which is evaluated in two steps: (a) European calls implemented with geometrical Brownian innovations; and (b) a perpetual option model, according to Alvarez and Dixit (2014). The chapter ends with a discussion section. 


\section{2. Review on Banking Regulation and Financial Time Series}

\section{Banking Regulation}

The Basel Committee on Banking Supervision was established in 1974 to advise national financial regulators on capital requirements for internationally active banks. The first agreement, Basel I, focused exclusively on the credit risk of bank's assets when calculating risk weighted assets. Believing that the original focus was too narrow, the Basel Committee revised Basel I by adding a market risk element to the Risk Weighted Assets (RWA) calculation.

In 2004, the Basel Committee offered a more comprehensive and risksensitive approach to capital regulation adopting a new framework. Basel II developed a three-pillar approach: (1) minimum capital requirements, (2) supervisory review process, and (3) market discipline. The first pillar is reported to be the most important - and controversial — part of Basel II. The Operational risk was added as a third factor for RWAs calculation, yet the major contribution was the whole revision of Basel I approach to RWAs.

For accuracy reasons, targeting to match the bank's capital requirements with its risky assets, Basel II provided three methods of assessing credit risk: a basic "standardized" approach and two variants of an "internal ratings-based" approach - foundational and advanced. Under the standardized approach, banks calculate RWAs not only by reference to Basel's elementary buckets, but also by the external credit ratings from firms like Standard \& Poor's, Moody's Investor Service, and Fitch Ratings. The two internal ratings-based approaches permit banks to be more sophisticated and rely in varying degrees on their own risk.

The Basel III agreement is frequently considered an amendment of Basel II and is summarized in BIS (2011). It recommends a temporary increase in the regulatory capital following the RWA approach: a raise from 8 to 11 percent relative to bank's risky assets that will be progressively allocated to new RWA items such as the counter cyclical capital buffer. 
The concepts of liquidity risk and the lender of last resort (LOLR), as seen in Bordo (1990) are older than the fundamentals of modern finance (Markowitz, 1952). They start with Thornton (1802) and Bagehot (1873), who developed the key elements of the classical doctrine of the LOLR in England, which holds that monetary authorities in the face of panic should lend unsparingly but at a penalty rate to illiquid but solvent banks. More recently, authors like Goodhart (1985 and 1987), broadened the power of LOLR to include aid to insolvent financial institutions.

Brunnermeier and Pedersen (2009) presented some take away lessons: (i) the liquidity suddenly dries up; fragility in liquidity is in part due to destabilizing margins, which arise when financiers are imperfectly informed and the fundamental volatility varies; (ii) the market liquidity and fragility co-move across assets since changes in funding conditions affect speculators' market liquidity provision of all assets; (iii) the market liquidity is correlated with volatility, since trading more volatile assets requires higher margin payments and speculators provide market liquidity across assets such that illiquidity per capital use, i.e., illiquidity per dollar margin, is constant; (iv) the flight to quality phenomena arise in this framework since when funding becomes scarce speculators cut back on the market liquidity provision; (v) the market liquidity moves with the market since funding conditions also do.

According to Carlson et al. (2015), the liquidity shortfalls can arise for two very different reasons: "First, sound institutions can face either runs or deterioration in the liquidity of markets they depend on for funding. Second, solvency concerns can cause creditors to pull away from troubled institutions." In other words, using examples from the recent crises:

(1) Central Bank lending may be the best response in the former situation, while orderly resolution (by the institution as it gets through the problem on its own or via a controlled failure) may be the best response in the second situation;

(2) Liquidity regulations are a necessary tool in both situations, because they help ensure that the authorities will have time to assess the nature of the shortfall and arrange the appropriate response, and because they provide an incentive for banks to internalize the externalities associated with any liquidity risks. 
According to Tabak et al. (2012), despite the importance of stress testing the liquidity risk, most Central Banks do not publish the results of such tests, perhaps a reflection of the complexity of liquidity modeling and the need for more detailed data (at a higher frequency). While many banks have been conducting liquidity stress tests after the recent global financial crisis, yet not disclosing the results, the Brazilian Central Bank has been disclosing liquidity stress test results since 2009.

In a quantitative easing operation, a Central Bank buys specified amounts of assets from financial institutions, which raise the prices of those assets and lower their yield, while simultaneously increase both broad money as well as the monetary base. The standard monetary policy is to buy or sell short-term government bonds in order to keep interbank interest rates at a specified target value, nevertheless turned to be ineffective with the sub-prime crisis. Beyond that, as seen in Araújo et al. (2015), some Central Banks nowadays execute unconventional monetary policy by purchasing risky assets financed by issuing riskless nominal liabilities (reserves), as an additional dimension of policy alongside conventional monetary policy.

A possible conflict with inflation targeting is reported in Agénor and Pereira (2011, p. 36), who state that a minimum liquidity coverage ratio, following the Basel III recommendations, requires an increase of the bank reserves. This increase in the reserve requirement rate lowers the deposit rate and induces households to shift consumption towards the present, thereby increasing aggregate demand and inflationary pressures.

The rediscount is a usual tool for restoring liquidity and is composed of two types in Brazil. The first is a refinancing operation and is called "selective rediscount", which is made by the discounting of securities by financial institutions with the Brazilian Central Bank. The second type, called "liquidity rediscount" or emergency financial assistance, is a line of credit made available to banks. Although they are different modalities, the terms "selective discount" and "liquidity rediscount" have been used interchangeably in the financial market, resulting in a single daily rediscount time series. 
In 2002, under the Brazilian Payment System (SPB) reform, new instruments were developed such as: (a) intraday rediscount at zero cost, a mechanism that enabled the necessary real time liquidity to transactions; (b) intraday repo to ensure financial institutions the real time necessary liquidity, although the institution does not have reserve bank account and thus cannot have recourse to intraday rediscount.

The deadlines for the rediscount operations were extended and the Brazilian Central Bank was authorized to impose stringent prudential measures to manage financial institutions. The Brazilian Central Bank usually has measures to face the liquidity constraints in domestic and foreign currencies, such as changes on reserve requirements, credit lines in domestic and foreign currency, auctions of foreign currency on the spot market and foreign exchange swap contracts.

The liquidity index (LI) relates the volume of liquid assets available to the financial institution with stressed cash flows. The stressed cash flow disbursements simulate the expected standards, having as parameter the history of past crises. Institutions with LI above $100 \%$ have sufficient liquid assets to withstand the stress scenario. Since the methodology simulates a 30-day scenario, where the net assets would have to be converted into cash, they are marked-tomarket and/or suffer weighting that simulates price reduction in the case of forced sale. This liquidity metric is based on the same concepts underlying the liquidity coverage ratio (LCR) index introduced by Basel III. The LCR is the ratio of high liquid assets (such as government bonds) and total net cash outflows in a 30-day stress scenario period.

\section{Financial Time Series Econometrics Review}

This part of the section is a quick review on financial time series that deals with heteroskedastic effects; time series subject to changes in regime; diffusion problems and leaps; options modelling and geometric Brownian motion (GBM).

The most common stylized facts for financial time series are volatility clustering and autoregressive conditional heteroskedastic (ARCH) effects which literature starts with Engle (1982) and Bollerslev (1986). The existence of volatility clusters suggests approaches either under the viewpoint of changes in volatility regimes or under the standpoint of volatility leaps. Concerning to time series with leaps, Kim et al (2011) provided a quick overview of Lévy processes. 
A previous identification of possible unconditional volatility levels is possible through the determination of the discrete changes in the unconditional variance, which can be investigated with the ICSS (Iterative Cumulative Sum of Squares) algorithm from Inclán and Tiao (1994).

The time series subject to changes in regime grew in relevance with Hamilton's (1989 and 1990) studies on switching regimes models. The EM (Estimation Maximation) algorithm estimates parameters through maximum likelihood estimation (MLE), and the EM-algorithm can be adapted to non-normal distributions and yields maximum likelihood estimates of the model parameters. In order to model the daily returns of the currency exchange rate, we chose the switching generalized autoregressive conditional heteroskedasticity (SWGARCH) model. According to Haas et al. (2004), SWGARCH models combine GARCH with regime switching, so that the regime variances only depend on past shocks and their own lagged values. However, due to the considerable number of unconditional volatility levels, the SWGARCH modeling can lead to non parsimonious models.

Another way to deal with diffusion problems and leaps is the use of semi martingales, but the procedural structure is very complex. The alternative is the use of Lévy additive (non homogeneous) processes or the use of models of stochastic volatility with leaps (Ornstein-Uhlenbeck).

Mandelbrot (1963) was pioneer on the use of stable distributions (or alphastable) to model skewed distributions and fat tails. The alpha-stable distributions can model the negative skewness and the excess of kurtosis that characterize financial asset's returns. They earned some popularity in the 1960's, yet the interest has decreased since then, due to either mathematical complexity or huge computing power necessary to implement models, or to the success of the Gaussian approach.

The option-modelling alternative for capital requirements consists of insurance-like options to exercise in case of turmoil. Perpetual options may be suitable for unknown crisis timing (see Alvarez and Dixit, 2014). However, Christensen (2014) states that perpetual options are only used as a bound: "For practical questions in financial markets this case is not so important; perpetual options are only used as a bound for finite time problems". The underlying assets are modelled with the geometric Brownian motion. According to Hull (2012), the 
main advantages of GBM modelling are: the expected returns independent from the value of the process; the process only assumes positive values; the paths show the same kind of pattern as in real prices and the calculations are relatively easy.

\section{3.}

\section{Data and Methodology}

We collected the following data for this study: the Brazilian liquidity index (LI), Brazilian rediscount, low risk/high liquid U.S. assets (federal funds and Treasury Bills rates), a global volatility index (VIX), a global housing index (GHPI), a Brazilian real estate index (FIPE-ZAP price index), U.S. Dollars/Brazilian Reais and Euro/Brazilian Reais exchange rates (PTAX), and Brazilian macroeconomic variables such as GDP, inflation, international reserves, employment rate, and the Brazilian short term (SELIC) interest rate.

The liquidity index for financial institutions, calculated by the Brazilian Central Bank, is the ratio between the total net assets that banks have to honor their obligations and the possible loss of liquidity that banks would be subject under stress scenario. Stressful situations provide unexpected deposit withdrawals and sudden changes in the market scenario. The Brazilian Central Bank publishes the aggregate LI for the whole bank sector in the Financial Stability Report (REF), along with a detailed analysis of the liquidity of the financial system.

Concerning to individual bank specifications, the LI is the ratio of total liquidity (TL) and the estimated liquidity need for stress situations (NEL). The TL is the amount of liquid assets that each institution can afford to pay its obligations. It is calculated as the sum of asset that can be transformed into cash the next day, such as government bonds, interbank deposits (DIs), DI-linked certificates of deposit (CDs), with maturity over one day, weighted by coefficients associated with a possible early redemption of these instruments. The LT calculation also considers the balance of other financial assets such as cash, stocks, foreign currencies and investments in gold, funds and foreign bonds.

The Brazilian rediscount was retrieved from the Brazilian Central Bank website. The positive values mean monetary base expansion (releasing loans to financial institutions) and the negative values represent monetary base contraction (returns or loans payments). 
Concerning low risk/high liquid U.S. assets, the federal funds rate is the interest rate at which depository institutions actively trade balances, held at the Federal Reserve, with each other, usually overnight, on an uncollateralized basis. The Brazilian equivalent is the SELIC short-term interest rate. The Treasury bills (T-bills) are short-term debt obligation backed by the U.S. government with a maturity of less than one year. T-bills are issued through a competitive bidding process at a discount from par, which means that rather than paying fixed interest payments like conventional bonds, the appreciation of the bond provides the return to the holder. The source data is the Federal Reserve's website.

The VIX is a volatility index, calculated by the Chicago Board Options Exchange as a weighted blend of prices for a range of options on the S\&P 500 index. It works as a referential volatility index in many publications, such as the Brazilian Financial Stability Reports (Brazilian Central Bank, 2015).

The Global House Price Index, from The Global Housing Watch (IMF) tracks the developments in the housing markets across the world on a quarterly basis. It provides current data on house prices as well as metrics used to assess valuation in housing markets, such as house price-to-rent and houseprice-to-income ratios.

The FIPE-ZAP price index database consists of Brazilian real estate rental and sales prices in selected cities. The FIPE compound index covers a weighted index of the 7 greatest cities while the FIPE broad index is a compound index of all cities covered. The FIPE-ZAP index considers apartments announcements and takes into account the location, the number of bedrooms and area.

The Brazilian macroeconomics variables used in this study were collected from the Brazilian Central Bank database, and consist of GDP, international reserves, employment rate, and SELIC interest rate. The U.S. Dollars/Brazilian Reais and the EURO/Brazilian Reais rates are named PTAX. The chosen inflation rate is the FIPE consumer price index (IPC). Table 3.2 shows the selected time series and their sources. 
Table 3.2: Selected Data

\begin{tabular}{cccc}
\hline & Series & Acronym & Source \\
\hline 1 & Basel Index & BI & Brazilian Central Bank \\
\hline 2 & Liquidity Index & LI & Brazilian Central Bank \\
\hline 3 & Rediscount & RD & Brazilian Central Bank \\
\hline 4 & Federal Funds Rate & FF & Federal Reserve \\
\hline 5 & VIX & VIX & Chicago Board Options Exchange \\
\hline 6 & Global House Price Index & GHPI_M & International Monetary Fund \\
\hline 7 & PTAX (currency exchange) & PTAX & Brazilian Central Bank \\
\hline 9 & Monthly Inflation & IPC & Brazilian Central Bank \\
\hline
\end{tabular}

The determination of the discrete changes in the unconditional variance of the data can be evaluated with the ICSS (Iterative Cumulative Sum of Squares) algorithm, from Inclán and Tiao (1994). The time-series presents a stationary variance over the initial period. A sudden change in the variance occurs some time later, possibly caused by some political and/or economic shock. The variance becomes stationary again, at another level, until another sudden change occurs. This process is repeated creating a temporal series of observations with an unknown number of sudden changes in variance (see equations 3.1 and 3.2).

\section{Equation 3.1: Equation of Returns}

Daily return $=R d=\operatorname{Ln}\left(\frac{\text { Index }_{t}}{\text { Index }_{t-1}}\right)$;

\section{Equation 3.2: AR/GARCH to Sudden Changes in the Unconditional Volatility}

$A R(1): R d_{t}=A_{0}+A_{1} R d_{t-1}+u_{t} ; v_{t}=C+p v_{t-1}+q u_{t-1}^{2}+L e v I_{t-1} u_{t-1}^{2}$

Conditions. $\mu_{t}=\sqrt{v_{t}} \varepsilon_{t} ; \varepsilon_{t}=t ; \mu=0 ; \sigma^{2}=1 ; d f=D(t-$ student $) ; I_{t}=1\left(u_{t}<0\right) ; I_{t}=0\left(u_{t} \geq 0\right)$ Where $\mathrm{A}_{0}$ is constant in the average equation; $\mathrm{C}$ is constant in the conditional variance equation; $\mathrm{Q}$ is the residuals coefficient; $\mathrm{P}$ is the conditional variance coefficient; Lev is the leverage coefficient, and D is the degree of freedom of the t-student distribution that models the return series. After running the GARCH model, the program runs the ICSS algorithm. 
The daily returns of currency exchange rates, both U.S. Dollars/Brazilian Reais and Euro/Brazilian Reais (PTAX), were modeled with a stable package from Veillete (2010), which implements alpha-stable distributions based on Samorodnitsky and Taqqu (1994). The options simulations for capital adequacy were performed in two steps. First, we simulated options with maturity, and then perpetual options. The underlying asset follows a geometric Brownian motion with drifts, as in equation 3.3:

Equation 3.3: Geometric Brownian motion for asset V

$$
d V=\mu V d T+\sigma V d Z
$$

Where $\mathrm{Z}$ is a Wiener process or Brownian motion; $\mu$ (the percentage drift) and $\sigma$ (the percentage volatility) are constants.

Concerning to options with maturity, we used the call options program from Pachamanova and Fabozzi (2010) that implements a Longstaff and Schwartz's algorithm (2001). We calculate the premia aiming at a strike price zero (insurance-like) with the spot price being either 5\%, the Basel index of $8 \%, 11 \%$ (as the Basel Index adopted in Brazil, since 1998), 14\% or $17 \%$.

In the case of perpetual options, we use the same capital requirements parameters with no expiration date, thus no need to predict the crisis timing and it can be exercised in moments of turbulence. We utilized the model proposed by Alvarez and Dixit (2014) which was discussed in Backus (2013), according to Gerber and Shiu (1994) and Ingersoll (1987). Consider an asset pricing in a stationary Markov setting with a state variable $\mathrm{x}$. The ex-dividend value of a claim to the stream of future dividends $\mathrm{d}$ might be expressed as proportional to the asset value. The solution has the form: exercise if $\mathrm{V}\left(\mathrm{x}_{\mathrm{t}}\right)>=\mathrm{V}^{*}$ for some threshold value $\mathrm{V}^{*}$, and wait otherwise. The assumptions are described in equation 3.4 and lead to the valuation equation and the optimum value, in equation 3.5 .

\section{Equation 3.4: The Underlying Asset Assumptions for Perpetual Options}

The dividend $\delta$ is proportional to $\mathrm{V}$ :

The future price of the underlying is lognormal:

$$
d_{t=1}+V_{t+1}=e^{\delta} V_{t+1}
$$$$
\log V_{t+1}-\log V_{t} \sim \mathrm{N}\left(k_{1}, k_{2}\right)
$$ 


\section{Equation 3.5: Perpetual options - Valuation Equation and optimum Value}

$V_{t}=E_{t}\left[m_{t+1}\left(d_{t+1}+V_{t+1}\right)\right]=E_{t}\left[e^{-r} e^{\delta} V_{t+1}\right]=e^{\delta-r} V_{t} e^{k_{1}+\frac{k_{2}}{2}} \Rightarrow \delta-r+k_{1}+\frac{k_{2}}{2}=0$

Determining the constant a:

$$
a=\frac{-k_{1}+\left(k_{1}^{2}+2 k_{2} r\right)^{1 / 2}}{k_{2}}
$$

Optimum Value $(*)$ related to strike price $(\mathrm{k})$ :

$$
V^{*}=[a /(a-1)] k>k
$$

\section{4 .}

\section{Results}

\section{Fed Fund Rates and Treasury Bills}

Figure 3.1 shows the daily fed fund data: rates, variation and volatility. The abrupt decrease of fed fund rates since the sub-prime crisis and simultaneous to the quantitative easing operations is visually verified. Consequently, quite low levels of unconditional volatilities have prevailed and very low yields: example: regarding T-bills, it takes more than 2,000 years to reach a $25 \%$ yield.

Table 3.3 shows the GARCH estimation of the fed fund rates daily returns: the results indicate that they followed a $\operatorname{GARCH}(0,1)$ process with very low unconditional volatility and almost no innovations from the end of September, 2008 to July, 2015. Similar results were found for the T-bills.

Figure 3.1: Fed Funds Daily Data: Rates, Variation and Volatility.

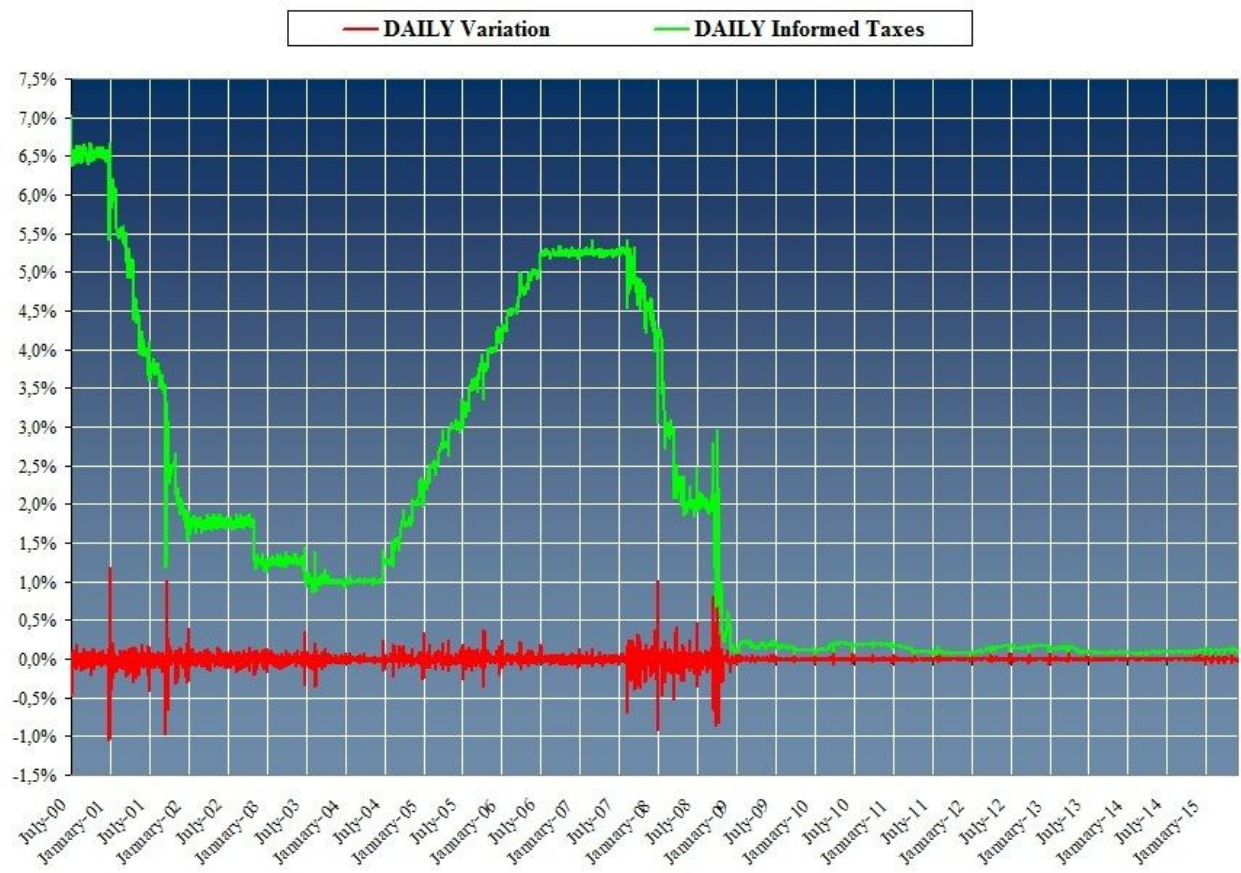




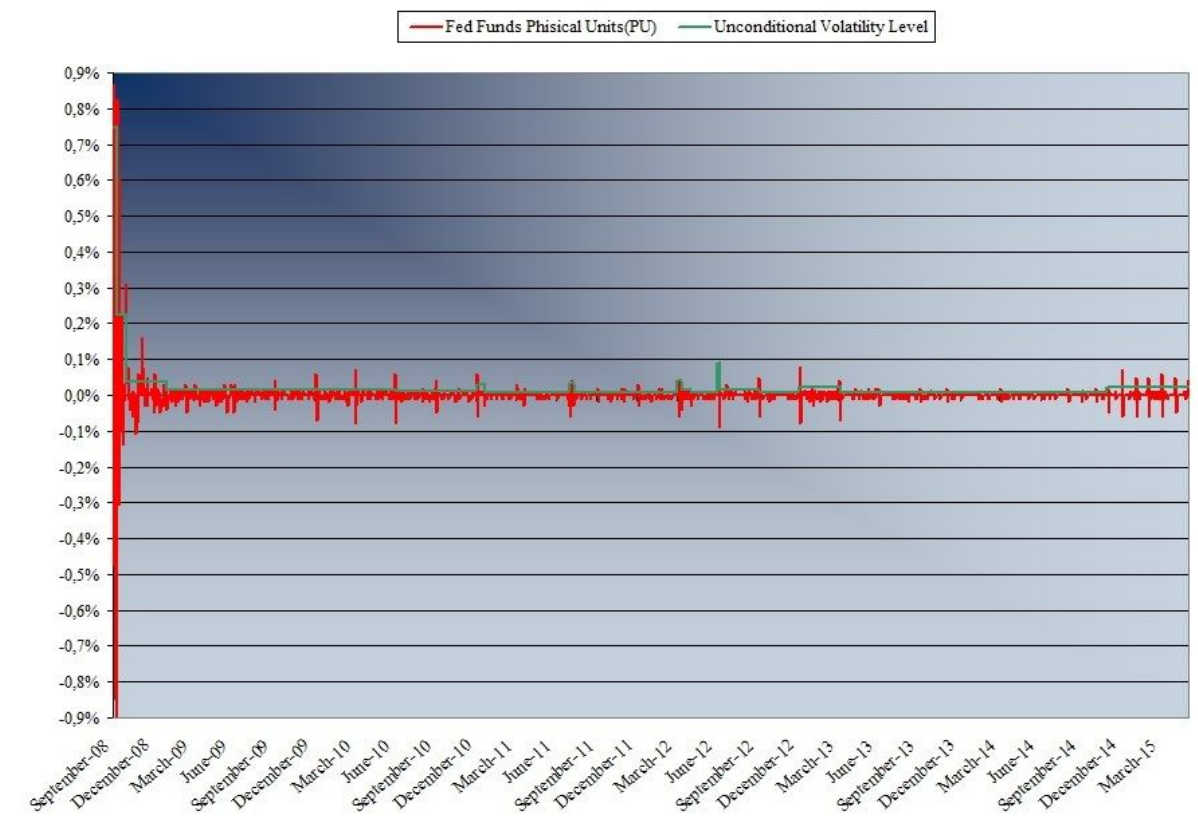

Table 3.3: GARCH Fitting for Fed Funds from September 2008 to June 2015

Note: the coefficients $\mathrm{A} 0$ is constant in the average equation, $\mathrm{C}$ is constant in the conditional variance equation, $\mathrm{Q}$ is the residuals coefficient, $\mathrm{P}$ is the conditional variance coefficient, Lev is the leverage coefficient, and $\mathrm{D}$ is the degree of freedom of the t-student distribution that models the return series.

\begin{tabular}{ccccc}
\hline Variable & Coefficients & Std Error & T-Stat & P value \\
\hline A0 & 0.0000025 & 0.0000015 & 172.911 & 0.0837893 \\
\hline A1 & -0.1887614 & 0.0178334 & -1.058 .471 & 0 \\
\hline C & 0.0000001 & 0.0000012 & 0.07192 & 0.9426676 \\
\hline Q1 & 29.166 .717 & 40.602 .065 & 0.07184 & 0.9427328 \\
\hline P1 & 0.2041743 & 0.0286676 & 712.214 & 0 \\
\hline LEV & -71.784 .611 & 10.011 .919 & -0.0717 & 0.9428413 \\
\hline D & 20.071 .195 & 0.1023185 & 1.961 .639 & 0 \\
\hline
\end{tabular}

\section{Brazilian Rediscount}

Concerning the Brazilian rediscount, the average rediscount from February $14^{\text {th }}, 2000$ to April $30^{\text {th }}, 2015$ was R $\$ 124$ millions (see Figure 3.2), and high volumes of rediscount seldom occurred in Brazil, what is in line with the fact that no systemic bank crisis occurred in Brazil at least in the last 60 years, according to Laeven and Valencia (2008). The Brazilian rediscount daily series was fitted with a Poisson distribution. Table 3.4 shows the probabilities for $\mathrm{k}=0$ to 10 times the average rediscount could happen, according to equation 3.6. 


\section{Equation 3.6: Poisson Probability, Rediscount Greater than Average}

$f(k ; \lambda)=\frac{e^{-\lambda} \lambda^{k}}{k !}$

Figure 3.2: Brazilian Daily Rediscount - Financial Volume

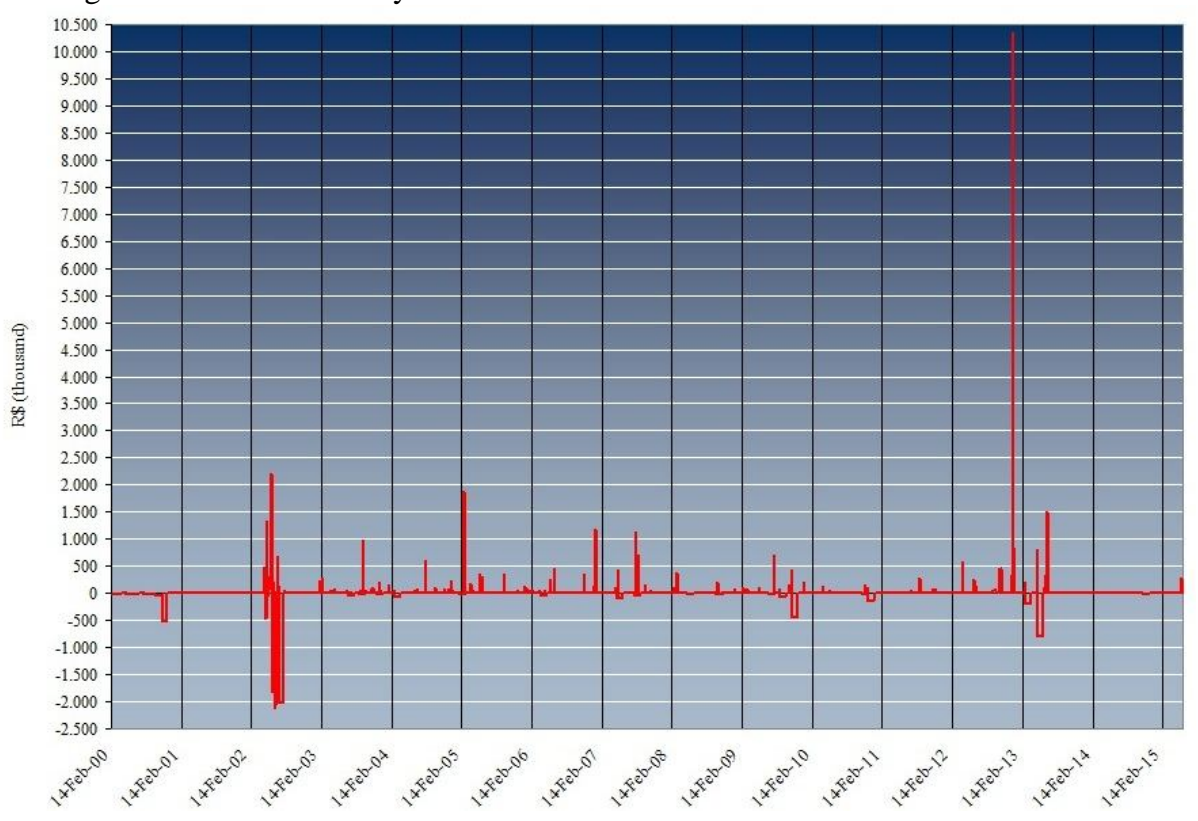

The results show (table 3.4 and figure 3.2) that the likelihood of a rediscount greater than the average is quite insignificant. In fact, the exceptions are: (a) a peak in December, 24 $4^{\text {th }}, 2012$ (end of the year with an abnormally high cash money circulation); and (b) a turbulent period, from April 22 $2^{\text {nd }}, 2002$ to August $5^{\text {th }}, 2002$, which coincides with the unstable Brazilian political scene, in the eve of the presidential election in 2002.

Table 3.4: Poisson pdf , Multiples of Average Rediscount $($ Lambda $=0.1062)$

\begin{tabular}{|c|c|c|c|c|c|c|}
\hline $\mathbf{K}$ & $\mathbf{0}$ & 1 & 2 & 3 & 4 & 5 \\
\hline Probability & 0.8992 & 0.0955 & 0.0051 & 0.0002 & $4.77 \mathrm{E}-06$ & $1.01 \mathrm{E}-07$ \\
\hline $\bar{K}$ & 6 & 7 & 8 & 9 & 10 & \\
\hline Probability & $1.79 \mathrm{E}-09$ & $2.72 \mathrm{E}-11$ & $3.62 \mathrm{E}-13$ & $4.27 \mathrm{E}-15$ & $4.53 \mathrm{E}-17$ & \\
\hline
\end{tabular}




\section{The Brazilian Liquidity Index}

The Brazilian liquidity index (LI) is the ratio between the total net assets that banks have to honor their obligations and the possible loss of liquidity that banks would be subject under stress situations. The Brazilian aggregated LI varied from 1.4 (October, 2008) to 2.8 (January, 2010), with an average of 2.01, which is above the critical value 1 . The Kolmogorov-Smirnov test rejected the null hypothesis of normality at the $1 \%$ significance level.

Table 3.5 exhibits the results for the variance ratio test for a random walk, according to Campbell et al. (1997). The variance ratio test failed to reject the random-walk null hypothesis. A Monte Carlo simulation (with one million combinations) for a geometric mean reverting model confirmed the result, since the speed adjustment factor for the mean-reverting model was less than $2 \%$. The low p-values mean standard normal probabilities, associated to the critical value. The random walk behavior possibly means that banks continuously compensate the occasional increase of stressed cash flow with more liquid assets.

Table 3.5: Variance Ratio Test and Mean Reverting Model Fitting (LI)

\begin{tabular}{ccccccc}
\hline P-value & Critical value & Ratio & Average & Volatility & Speed & OLS \\
\hline 0.3216 & 19.600 & 0.9035 & 1.865 & $5.66 \%$ & $1.91 \%$ & 5.566 \\
\hline
\end{tabular}

Figure 3.3 exhibits the LI, a quadratic polynomial curve fit for LI, the monthly returns and the unconditional volatility levels. The first two series, for graphic scaling reasons, are divided by 10 . The curve fit with quadratic polynomial curve $\left(\mathrm{IL}=\mathrm{p} 1 * \mathrm{x}^{\wedge} 2+\mathrm{p} 2 * \mathrm{x}+\mathrm{p} 3\right)$ has the following coefficients (with $95 \%$ confidence bounds): $\mathrm{p} 1=6.646 \mathrm{e}-005(1.105 \mathrm{e}-005,0.0001219) ; \mathrm{p} 2=-$ $0.01553(-0.02188,-0.00918)$ and $\mathrm{p} 3=2.6(2.447,2.753)$, rather a linear curve, since $\mathrm{p} 1<<\mathrm{p} 2$, concluding that $\mathrm{LI}$ is a random walk with drift process. 
Figure 3.3: LI - Curve Fit, Monthly Returns and Unconditional Volatility

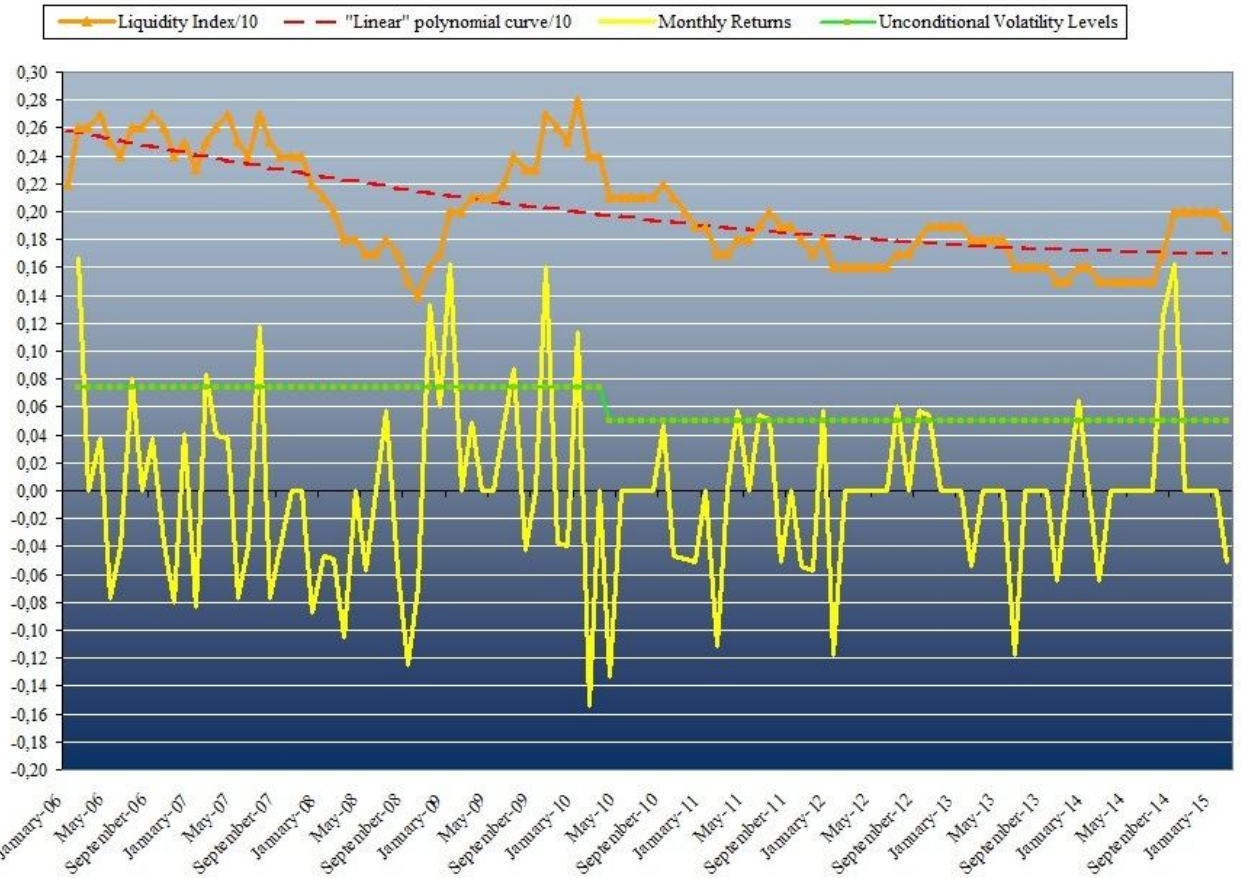

In line with the failure to reject the random-walk null hypothesis, a GARCH modelling resulted in rejection for GARCH coefficients, as seen in Table 3.6.

Table 3.6: GARCH Fit for the Brazilian Liquidity Index

\begin{tabular}{ccccc}
\hline Parameter & $\mathrm{C}$ & $\mathrm{K}$ & GARCH $(1)$ & ARCH (1) \\
\hline Value & 18.237 & 0.0096203 & 0 & 0.93413 \\
\hline T-Statistic & 877.221 & 16.178 & 0.0000 & 22.496 \\
\hline
\end{tabular}

The volatility levels (from the ICSS program) were 7.42\% (January, 2006 to March, 2010) and 4.96\% (April, 2010 to February, 2015). The higher level of the first period may be explained by the influence of the international financial crisis.

Table 3.7 exhibits the stepwise fit regressions for LI with some domestic and foreign variables, showing a possible positive linear relation with the domestic real estate market. As expected, LI has a significant correlation with the Basel index (54.59\%). The Basel Index, the household indebtedness to the national financial system, the global house price index, the currency exchange rate, the monthly inflation and the international reserves are significant at $1 \%$ or $5 \%$. 
Table 3.7: Linear Regressions, Liquidity Index and Financial Variables

\begin{tabular}{lcccc}
\hline \multicolumn{1}{c}{ Variable/Result } & Coeff & Std.Err. & Status & P-value \\
\hline Basel Index & 0.1874 & 0.0306 & In & 0.0000 \\
\hline Household indebtedness & -0.3736 & 0.0566 & In & 0.0000 \\
\hline Household indebt exc housing credit & 0.0000 & 0.1218 & Out & 0.9964 \\
\hline VIX (monthly) & 0.0016 & 0.0031 & Out & 0.6047 \\
\hline Global House Price Index (monthly) & 0.0554 & 0.0264 & In & 0.0409 \\
\hline FIPEZAP & -0.0077 & 0.0090 & Out & 0.3937 \\
\hline PTAX & 0.593 & 0.1554 & In & 0.0000 \\
\hline Rediscount (month-end in balance) & 0.0000 & 0.0000 & Out & 0.5832 \\
\hline Rediscount (monthly average) & 0.0000 & 0.0000 & Out & 0.9602 \\
\hline IPC (monthly inflation) & 0.0133 & 0.0055 & In & 0.0201 \\
\hline New Defaults (SPC) & 0.0000 & 0.0000 & Out & 0.9083 \\
\hline Employment & 0.0174 & 0.03 & Out & 0.5647 \\
\hline International reserves & 0.0000 & 0.0000 & In & 0.0000 \\
\hline SELIC & -0.9274 & 1.5452 & Out & 0.5514 \\
\hline GDP & 0.0000 & 0.0000 & Out & 0.3622 \\
\hline
\end{tabular}

\section{Currency Exchange Rates: U.S. Dollars/Reais and Euro/Reais (PTAX)}

The next figures (3.4. and 3.5) show the daily returns and volatility of the U.S. Dollars/ Brazilian Reais exchange rate (PTAX) from 1994 to 2015. The daily returns of PTAX ranged from $-9.36 \%$ (August $2^{\text {nd }}, 2002$ ) to $10.53 \%$ (January $15^{\text {th }}$, 1999), with a $12.82 \%$ standard deviation for the entire period. The null hypothesis of normality (one-sample Kolmogorov-Smirnov test) was rejected. More than 50 unconditional volatilities levels were found (see the lower part of figure 3.5) favoring the stable modeling over the SWGARCH modeling. 
Figure 3.4: Daily Returns of Exchange Rate (U.S. Dollars/ Brazilian Reais)

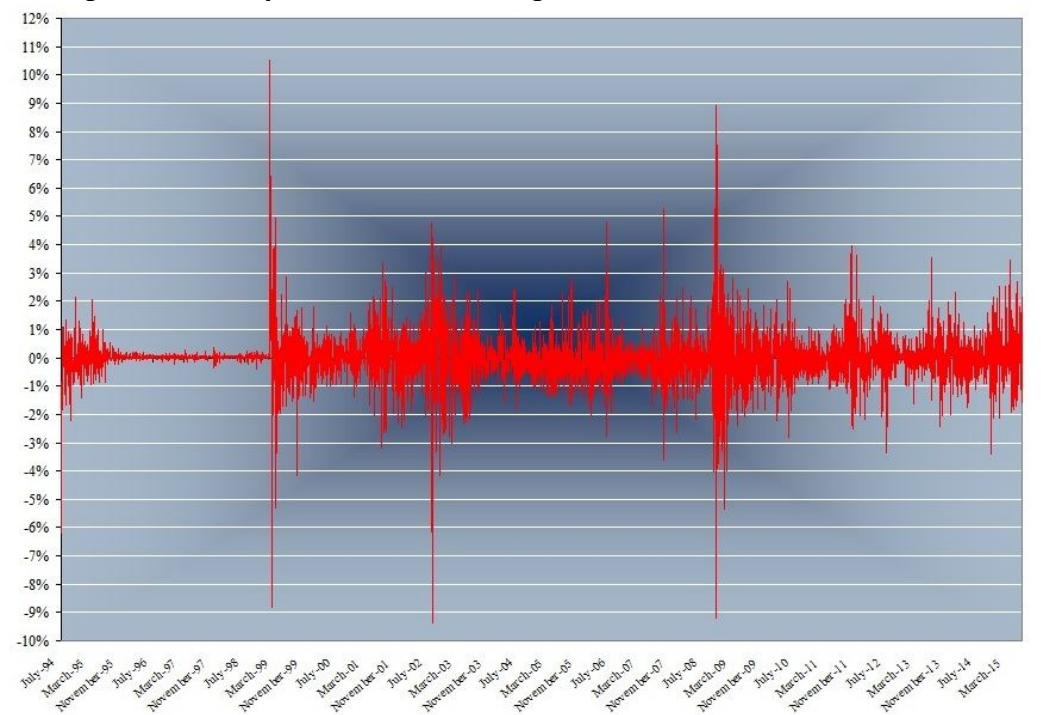

Figure 3.5: Daily Conditional and Unconditional PTAX Volatility
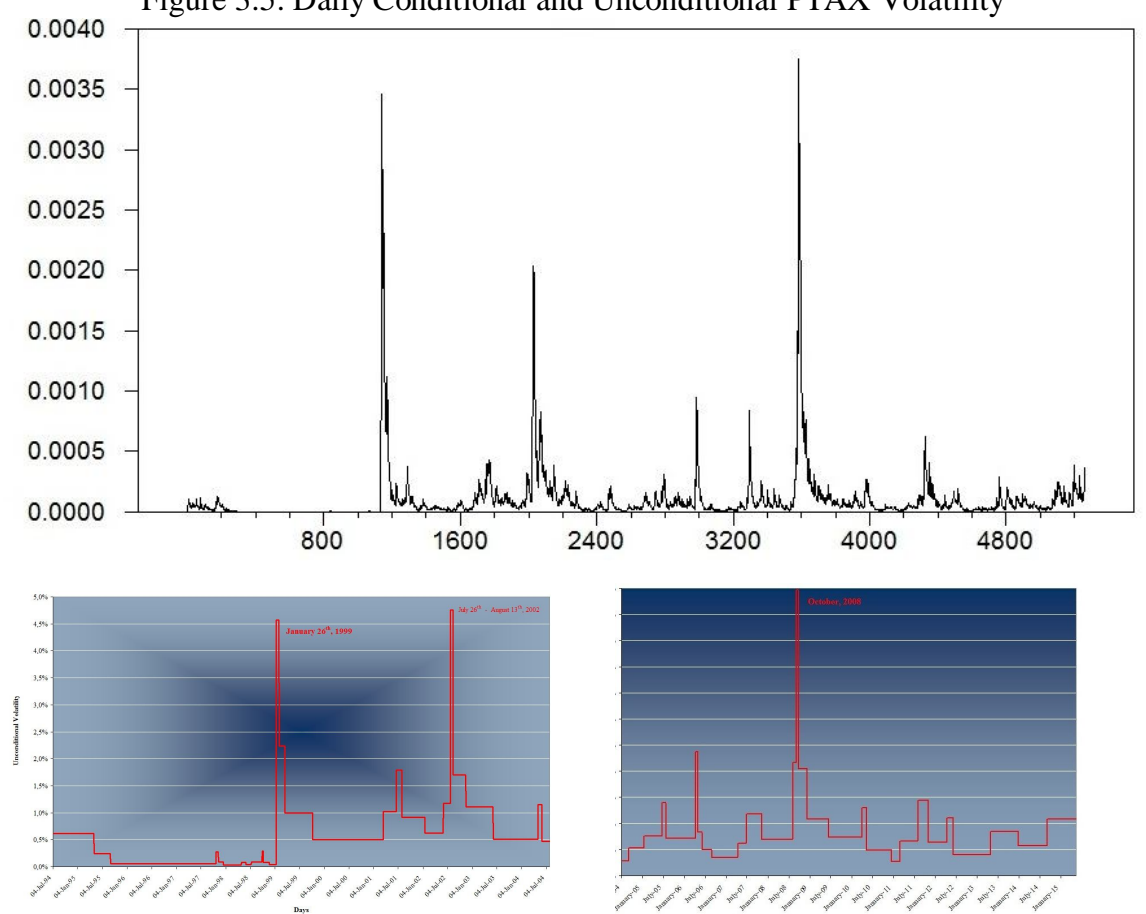

The next table (3.8) exhibits an AR (1)-GARCH $(1,1)$ modeling for the daily returns of the exchange rate (U.S. Dollars/ Brazilian Reais), considering the leverage effect and t-student innovations, with a high persistence of the GARCH parameters, reinforcing the likelihood of volatility level changes. 
Table 3.8: AR (1)-GARCH $(1,1)$ Modeling for PTAX daily returns (1994 to 2015)

Note: The coefficients $\mathrm{A} 0$ is constant in the average equation, $\mathrm{C}$ is constant in the conditional variance equation, $\mathrm{Q}$ is the residuals coefficient, $\mathrm{P}$ is the conditional variance coefficient, Lev is the leverage coefficient, and D is the degree of freedom of the t-student distribution that models the return series.

\begin{tabular}{lccccccc}
\hline Variable & A0 & A1 & C & Q1 & P1 & LEV & D \\
\hline Coeff & $2.53 \mathrm{E}-04$ & 0.0971 & $1.95 \mathrm{E}-09$ & 0.2088 & 0.871 & -0.0982 & 54.307 \\
\hline Std Error & $1.67 \mathrm{E}-05$ & 0.0141 & $1.49 \mathrm{E}-09$ & 0.0159 & $7.51 \mathrm{E}-03$ & 0.0175 & 0.2261 \\
\hline T-Stat & 1.519 .532 & 68.955 & 130.977 & 1.310 .774 & 1.159 .911 & -559.772 & 2.402 .418 \\
\hline Significance & 0 & 0 & 0.190273 & 0 & 0 & $2,00 \mathrm{E}-08$ & 0 \\
\hline
\end{tabular}

As seen in Figure 3.5, the ICSS program returned 55 changes for the daily returns of the exchange rate (U.S. Dollars/Brazilian Reais). Those levels varied from $0.0343 \%$ to $5.472 \%$, a ratio of 159.61 highest/lowest levels. The greatest peaks are in January, 1999, August, 2002 and October, 2008. The same procedure was applied to the daily exchange rate Euro/Brazilian Reais, resulting in 24 unconditional volatility levels that varied from $0,557 \%$ to $4,215 \%$, a ratio of 7.57 highest/lowest. These various levels and high jumps observed favored modeling the daily returns of PTAX series with the alpha stable (STBLFIT) function from Veillete (2010), as seen in table 3.9, instead of volatility switching models.

Table 3.9: Alpha Stable Distribution for the Currency Exchange Rates (PTAX)

Note: $\alpha, \beta, \delta$ and $\gamma$ stand for the characteristic parameter (tail), skewness, scale (equivalent to variance) and location (equivalent to mean). For a normal distribution, the tail value is 2 , the skewness value is zero, the scale is 1 and the mean is zero.

\begin{tabular}{lcccc}
\hline \multicolumn{1}{c}{ Series } & $\alpha$ & $\beta$ & $\delta$ & $\gamma$ \\
\hline Ptax July 2004- June $12^{\text {th }}, 2005$ & 1.3216774 & 0.0018450 & 0.0033897 & $-2.72 \mathrm{E}-06$ \\
\hline Ptax 1994-July 2004 & 0.7565985 & 0.0169553 & 0.0016224 & 0.0002416 \\
\hline Ptax August 2004- June 12 ${ }^{\text {th }}, 2015$ & 1.6023555 & 0.2364137 & 0.0046274 & 0.0001857 \\
\hline Euro: December 31 & & & & \\
\hline
\end{tabular}




\section{Simulating Capital Requirements with Options}

Table 3.10 shows the average time to reach different capital levels (8\%, $11 \%, 14 \%$ and 17\%) departing from 5\%, assuming a geometric Brownian movement in a Monte Carlo simulation with 50,000 combinations. The higher drifts generate higher times to reach the desired capital level.

\begin{tabular}{lccccccc} 
Table 3.10: Average Time to Reach Capital Level Departing from 5\% \\
\hline Capital / Drift & $\mathbf{- 1 . 1}$ & $\mathbf{- 0 . 9}$ & $\mathbf{- 0 . 6}$ & $\mathbf{- 0 . 1}$ & $\mathbf{0}$ & $\mathbf{0 . 3}$ & Average \\
\hline Average time, $\mathrm{M}=8 \%$ & 142.00 & 97.02 & 96.19 & 95.40 & 97.90 & 94.19 & 97.79 \\
\hline Average time, $\mathrm{M}=11 \%$ & 195.25 & 187.83 & 175.41 & 180.10 & 178.58 & 159.46 & 180.59 \\
\hline Average time, $\mathrm{M}=14 \%$ & 289.46 & 259.99 & 252.20 & 261.12 & 259.01 & 194.53 & 258.38 \\
\hline Average time, M=17\% & 354.65 & 345.59 & 325.28 & 329.94 & 328.89 & 267.29 & 327.92 \\
\hline
\end{tabular}

Table 3.11 shows the percentage of simulations reaching a specific level departing from $11 \%$, in a Monte Carlo simulation with 50,000 combinations. We can see that $97.1 \%$ of the simulation departing from $11 \%$ reached capital levels above $17 \%$, or, equivalently, $2.9 \%$ of the simulations never reached $17 \%$. Instead, those simulations are likely to reach the lower levels of $8 \%$ and $5 \%$.

Table 3.11: Reaching a Specific Capital Level Departing from $11 \%$

\begin{tabular}{ccccc}
\hline$<=\mathbf{5 \%}$ & $<=\mathbf{8 \%}$ & $>=\mathbf{1 1 \%}$ & $>\mathbf{1 4 \%}$ & $>=\mathbf{1 7 \%}$ \\
\hline $3.49 \%$ & $23.74 \%$ & $83.97 \%$ & $98.75 \%$ & $97.10 \%$ \\
\hline
\end{tabular}

Table 3.12 shows the European call prices / asset value ratio per strike value varying from $5 \%$ to $17 \%$. The results came from 1,000 Monte Carlo simulations, with each simulation consisting of 50,000 choices. The table shows the threshold values for the call options with maturity, when simulating volatilities from geometric random walks models. For volatilities within the VIX range (from $2.69 \%$ to $23.34 \%$ ), the frequency of call premium/value ratio varies from only $0.186 \%$ under $5 \%$, a reasonable cost (when the strike value is $8 \%$ ) to $60.418 \%$ under the excessive cost of $100 \%$ (when the strike value is $11 \%$ ). 
Table 3.12: Call Prices/Asset Value Ratios, Strike Prices Varying from 5\% to 17\%

\begin{tabular}{cccccc}
\hline $\begin{array}{c}\text { Premium/ } \\
\text { Vo Ratio }\end{array}$ & $5 \%$ & $8 \%$ & $11 \%$ & $14 \%$ & $17 \%$ \\
\hline Under 5\% & $0.194 \%$ & $0.186 \%$ & $0.216 \%$ & $0.196 \%$ & $0.204 \%$ \\
\hline Under 10\% & $0.828 \%$ & $0.8 \%-$ & $0.78 \%$ & $0.898 \%$ & $0.846 \%$ \\
\hline Under 20\% & $3.026 \%$ & $2.88 \%$ & $2.966 \%$ & $2.962 \%$ & $3.02 \%$ \\
\hline Under 30\% & $6.208 \%$ & $6.054 \%$ & $6.032 \%$ & $6.182 \%$ & $6.054 \%$ \\
\hline Under 40\% & $10.226 \%$ & $10.064 \%$ & $9.968 \%$ & $10.058 \%$ & $9.99 \%$ \\
\hline Under 50\% & $14.89 \%$ & $14.83 \%$ & $14.712 \%$ & $14.834 \%$ & $14.742 \%$ \\
\hline Under 60\% & $20.576 \%$ & $20.42 \%$ & $20.484 \%$ & $20.558 \%$ & $20.524 \%$ \\
\hline Under 70\% & $27.486 \%$ & $27.318 \%$ & $27.4 \%$ & $27.376 \%$ & $27.494 \%$ \\
\hline Under $80 \%$ & $35.818 \%$ & $35.69 \%$ & $35.998 \%$ & $35.788 \%$ & $36.022 \%$ \\
\hline Under $90 \%$ & $46.848 \%$ & $46.574 \%$ & $46.662 \%$ & $46.482 \%$ & $46.772 \%$ \\
\hline Under 100\% & $60.282 \%$ & $60.348 \%$ & $60.418 \%$ & $60.306 \%$ & $60.106 \%$ \\
\hline
\end{tabular}

Table 3.13 shows (from a Monte Carlo simulation with 50,000 combinations) how much the rediscount financing is less expensive than regular call options, for each level of RWA of capital requirements, from $5 \%$ to $17 \%$. The price uplifting, comparing options with the usual rediscount, ranged from $42.04 \%$ $($ level $=8 \%)$ to $55.51 \%($ level $=14 \%)$.

Table 3.13: Cost of Rediscount Financing versus Regular Options

\begin{tabular}{ccccc}
\hline $\mathrm{Call} / \mathrm{Vo}=5 \%$ & $\mathrm{Call} / \mathrm{Vo}=8 \%$ & $\mathrm{Call} / \mathrm{Vo}=11 \%$ & $\mathrm{Call} / \mathrm{Vo}=14 \%$ & $\mathrm{Call} / \mathrm{Vo}=17 \%$ \\
\hline $46.54 \%$ & $42.04 \%$ & $55.36 \%$ & $55.51 \%$ & $55.28 \%$
\end{tabular}

\section{Simulating Capital Requirements with Perpetual Options}

In the case of perpetual options, the lender has capital $\dot{\mathrm{M}}$ available at $\mathrm{t}=0$. The company pays the premium at time zero and can exercise the option, paying $\mathrm{K}$ when optimal value $(\dot{\mathrm{M}})$ occurs at time $\mathrm{T}$. By construction, the cost of the perpetual option is greater then the rediscount at a selected interest rate $r$, as seen in equation 3.7 : 
Equation 3.7: Rediscount costs less than perpetual options

$p=M-K \Rightarrow N P V($ Rediscount - PerpOption $)=(M-K)^{*}(1+r)^{-T}-p<0$

A series of Monte Carlo simulations evaluated the perpetual options with optimum value $\dot{M}$ equals to $5 \%, 8 \%, 11 \%, 14 \%$ or $17 \%$ of capital requirements. The random generated values are: the dividend coefficient (set to be less then $5 \%$ ), the volatility (K2) and the interest rate $\mathrm{r}$. The dividend comes from the coefficient dividend $\delta$, from equation 3.4 :

$D I V=\sum V_{t}\left(e^{\delta}-1\right)$

The underlying asset follows a geometric Brownian motion, simulated with 50,000 Monte Carlo combinations, each one with 1,000 time periods. The underlying assets do not the reach the desired value in $0.82 \%$ of the simulations. In the case where the asset value decreases below the desired $\dot{M}$ at time $\mathrm{T}$, the sum of dividends and premium covers the difference, however if the underlying asset vanishes (a default situation), this covering occurs only in $61.44 \%$ of the cases. Table 3.14 shows an example of exercise value and premium of perpetual options simulation for risk weighted assets using minimum capital ratios of 5\%,8\%, 11\%, $14 \%$ and $17 \%$, for a tax rate of $4.57 \%$, volatility $23.34 \%$ and dividend equal $9.1 \%$. $\mathrm{K}$ and $\mathrm{P}$ stand for exercise price and premium, respectively.

Table 3.14: Perpetual Options Simulation Example

\begin{tabular}{ccccc}
\hline $\mathbf{K}(\mathbf{5 \%})$ & $\mathbf{K}(\mathbf{8 \% )}$ & $\mathbf{K}(\mathbf{1 1 \%})$ & $\mathbf{K}(\mathbf{1 4 \% )}$ & $\mathbf{K}(\mathbf{1 7 \% )}$ \\
\hline $1.92 \%$ & $3.07 \%$ & $4.22 \%$ & $5.37 \%$ & $6.52 \%$ \\
\hline $\mathrm{P}(5 \%)$ & $\mathrm{P}(8 \%)$ & $\mathrm{P}(11 \%)$ & $\mathrm{P}(14 \%)$ & $\mathrm{P}(17 \%)$ \\
\hline $3.08 \%$ & $4.93 \%$ & $6.78 \%$ & $8.63 \%$ & $10.48 \%$ \\
\hline
\end{tabular}

If dividend $=0$, then $\mathrm{a}=1, \mathrm{k}=0$ and the premium $\mathrm{V}^{*}$ can be $5 \%, 8 \%, 11 \%$, $14 \%$ or $17 \%$. Again, as shown in table 3.13 , in all cases, the premium of the perpetual option costs more than the rediscount paid by calculating their Net Present Values (NPV), based on Koller et al (2010). 


\section{5 Discussion}

This chapter evaluated an alleged dichotomy: the simultaneous need for liquidity regulations and for a lender of last resort (LOLR), discussed, for instance, in Carlson et al. (2015). Although the liquidity concept is quite a lot older than the nowadays financial risks concepts of market, credit and operational risks, the main Basel III recommendations for liquidity risk became operational only in 2015, giving rise for this kind of debate.

In a necessary search for an effective contextualization of the question with the international financial crisis and the recommendations from the Basel III agreement, we performed four groups of analysis, described in the results section. We rebate the dichotomy and innovate both by showing that third alternatives to capital requirements are theoretically viable through perpetual options and by identifying that the Brazilian Liquidity Index is a random walk process, possibly meaning that banks continuously compensate the occasional increase of stressed cash flow with more high liquid assets.

Concerning US banking regulation policy, the practice of lending as last resort with penalty looks like being out of date: to lend at a low rate is in line with the quantitative easing approach of the Federal Reserve, and the use of rediscount does not work any longer as a warning flag.

Carlson et al. (ibid) stated that "solvency concerns can cause creditors to pull away from troubled institutions". That can be interpreted as: (a) the liquidity is demanded at D-1 troubled day; (b) the key word of the LOLR acronym is LAST and (c) LOLR is connected to centralizing system risk control as in Rochet and Tirole (1996). The coexistence of capital requirements for liquidity risk and last resort lending concerns to: (i) the portfolio selection prevails over any kind of regulation concerns - there is also a small possibility of adding components in this natural two component portfolio; (ii) the coherence of risk measure, as in Arzen et al. (1999) and (iii) the need to use reserves for unconventional monetary policy, as seen in Araújo et al. (2015). 
With regard to options with maturity, users need to forecast crisis timing and the higher capital is required the less attractive they are, as seen from the geometric random models used in the simulations. The higher the capital allocated for the risk weighted assets, the costly the option price is, suggesting the existence of a ceiling/exhaustion point for the capital requirements approach: as the proposed options alternative also stay pegged to a percentage level like the capital requirements, another contribution of the option model is to give a general view of impact of the growing capital requirements. This part of the first pillar of the Basel III agreement - which is the most important and most controversial pillar is directly tied to the increase of the risk weighted assets, leaving less room to alternative models.

The perpetual options approach, from Alvarez and Dixit (2014), could be either an alternative or a complement to the permanently allocated capital when simulating the underlying assets following a geometrical Brownian motion: theoretically feasible solutions were found, more costly for borrowers than the usual rediscount operations, and not always warranted.

What if the underlying asset value decreases at maturity under the desired strike price? Simulations show that the sum of dividends and premium covers the difference, but only in $61.44 \%$ of the simulations if the minimum value of the underlying asset is unavailable (defaulted to zero). In practice, due to the large amount of money involved in real life, the options approach could be applied to smaller banks rather than to the "too big to fail" banks, and also for capital requirements related to market and credit risk.

There is always an unavoidable timing problem: reach the capital level on time, a crucial reason not to discard perpetual options as alternative/complement for the liquidity capital requirements prescribed in the Basel III Accord. 


\section{4 \\ Hedging against Price Bubbles through Options with Volatility Regime-Switching Risk in the Brazilian Real Estate Market (2008-2015)}

\section{1}

\section{Introduction}

Do the high price levels in the Brazilian real estate market unfold a real estate bubble? How can the effects of bubble bursting be mitigated through financial instruments? Whether confirming or not the real estate bubble hypothesis, this chapter proposes the developing of real estate put options (abandon options) in order to hedge against real estate assets value devaluations. This is, in a broad sense, a capital requirements approach, similar to the pillar 1 of the Basel III agreement. Since 2010, it is feasible to simulate real estate options, due to the monthly disclosure of the FIPE-ZAP index, a Brazilian real estate database.

We evaluated the existence of stylized facts in the Brazilian real estate market, such as price bubbles and price volatility clustering, from 2008 to 2015 . The alleged overvaluation of the real estate prices, especially in the large urban centers of Rio de Janeiro and São Paulo, suggested a price bubble hypothesis for real estate assets, a hypothesis related even to economic boom scenarios, from 2006 to 2008 and from 2009 to the second quarter of 2011: bad news frequently came to light, reflected in the high fluctuations of the stock prices of real estate companies listed in the BM\&FBOVESPA stock exchange..

The Brazilian real estate market is considered to be very fragmented; therefore a few real estate companies listed in the Stock Exchange do not describe this economic sector. At first, a highly fragmented market means plenty of choice for the consumer/household side of the economy. However, this picture lacks a clear idea of the real estate market and does not deal with a recurring household asset hedging problem, when real estate assets loose dramatically their value or when the consumer goes to default. 
Fortunato et al (2008), concerning that the Brazilian Consumer Code enables contract terminations and the resumption of alienated products, calculated the value of abandon options, based on their own price survey, since no regular real estate index was available at that time.

On the other hand, Brazilian financial assets historically exhibited greater volatility than equivalent European and U.S. assets, therefore a persistent high volatility can be also the case for real estate assets, reinforced by the bubble hypothesis. The real estate bubbles happen in several countries and, according to Glaeser and Nathanson (2014), excess variance is less endemic than in other asset markets, and shows up primarily in brief outbursts.

There are lessons taken from the recent U.S. real estate bubble, considered to be one of the starting points of the international financial crisis that began in 2007. According to Cynamon and Fazarri (2008), early crisis warning signs could be observed when looking through the consumer/household side of the U.S. Economy and its persistent excess of personal expenses based on income. The household consumption stayed over 94\% of the household income since 1992 and over $96 \%$ since 1999, with a sharp decline from 2007, precisely the beginning of the global financial crisis. The financial deregulation was also a key issue, according to Eichengreen (2009).

Consequently, the main international financial organizations are making efforts to develop a more effective set of preventive regulation, such as the Basel III agreement (see BIS, 2011). Two main points arise:

(i) The BIS focus its market risk recommendations (BIS, 1996) on four broad financial risk factor categories (interest rates, currency exchange rates, equity prices and commodity prices), so that real estate risk is not a specific category.

(ii) Mitigating financial losses can be a feasible but a hard objective to reach, since it is impossible to prevent all sorts of crises, and BIS (2011) acknowledges the unpredictable nature of future crises.

However, taking into account that financial crises can be originated from any sort of economic sectors, the real estate market is a qualified candidate for crisis source, as seen in several countries.

This chapter comprises the following sections: bibliographic review, data and methodology, results and discussion. 


\section{2 Review on Bubbles, Financial Crises and Financial Time Series}

A recurring question in the market and academic literature is whether a high asset price can be either ex-ante detected as a bubble about to burst or only recognized as such ex-post (after bursting). Shiller (2006) postulates that bubbles result from feedback mechanisms in prices that amplify some initial precipitating factors. Bubbles are usually classified as rational or irrational. According to Scheinkman (2013), a rational bubble is characterized by a continuous rise of an asset's price. Investors may hold the asset at the current price, because they believe that they are compensated for any risk of the bubble bursting by a suitable expected rate of price increase.

Nevertheless, Scheinkman (ibid.) stated that there are two reasons to dismiss the relevant differences between types of bubbles. The first is learning: the irrational agents should eventually learn that the signal they are using is useless. The second is survivorship, following Friedman (1966): irrational agents loose wealth on average and thus have a vanishing influence on market.

In this context, Simiano Nunes and Da Silva (2009) highlighted three specific types: (i) explosive bubbles that occur in the long-run equilibrium of absence between the share price and the payment of dividends; (ii) bubbles bursting periodically, which are those that exceeded a certain threshold value, decay to a value close to zero, but grow back slowly to the long-term alignment between the share price and dividends; and (iii) intrinsic bubbles arise merely from excessive reaction of the share price in relation to the variation of dividends, with no influence from extrinsic factors.

Some authors, like Evanoff et al (2012), stipulated the bubble size: a burst is defined as a peak to trough price change that is in the most negative quartile of price decreases in a sample, stating for equity markets at least a $37 \%$ correction from peak to trough. A practical example is found in the Financial Stability Report from Brazilian Central Bank (2015): for real estate prices, the bubble correction shall not exceed 55\% from which troubled institutions would arise, as seen in Figure 4.1. 


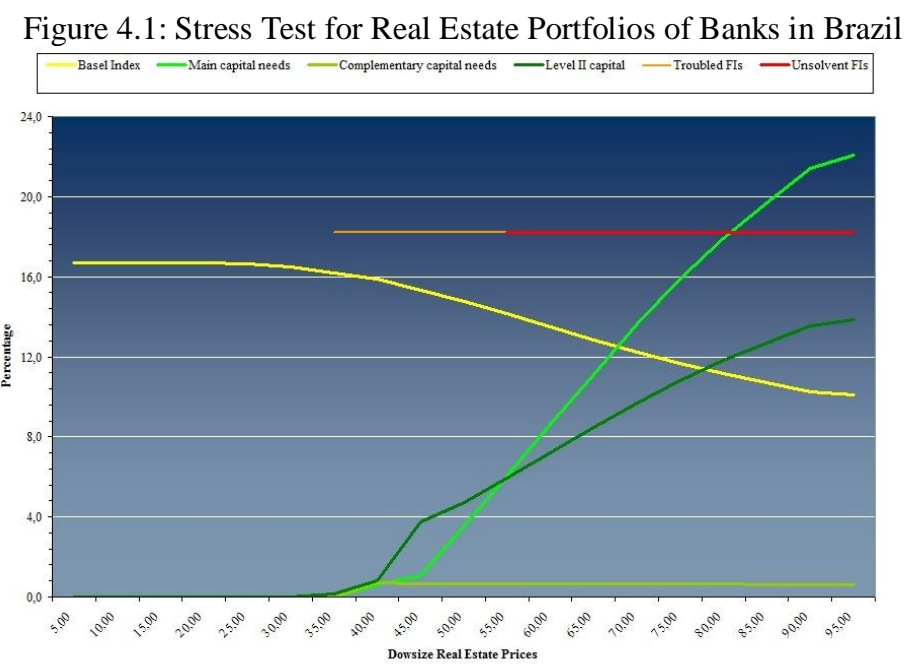

Source: Brazilian Central Bank (2015).

There are some take-away lessons about asset price bubbles learned from the recent global financial crisis. Evanoff et al (2012) itemized four aspects. First, sharp prolonged increases in the prices of important assets, followed by equally sharp but quicker declines in prices, occur frequently. Second, the burst of housing bubbles is frequent and dangerous. Third, the wrong way risks (where the exposure increases when the credit quality of the counterparty deteriorates) are frequent during crises. Fourth, the financial stability tools need to target sectors in which bubbles are emerging. Out of many ways to evaluate real estate bubbles, a simple one is shown in equation 4.1:

\section{Equation 4.1: Real Estate Present Value}

$$
P_{t}=\sum_{i=1}^{N} E_{t}\left[\left(\frac{1}{1+r_{t}}\right)^{i} D_{t+i}\right]
$$

where $P_{t}$ is the price of the property at the date of acquisition, $r_{t}$ is the opportunity cost of investing in real estate, $D_{t}$ is the flow of net revenues derived from the ownership of the property given by the value of the rent (or other income and costs) and $E_{t}$ is the conditional expectation the information available in period t. Comparing the fundamental (right side of equation 1) with the selling (market) value, there is an estimation whether certain assets are expensive or cheap. 
According to Marçal et al (2012), when the metric is the increase in household income or the rent in Sao Paulo associated to CDI (short term interest rate), there is a weak bubble evidence, which becomes stronger when simulating Net Present Values (NPV) from the São Paulo's FIPE-ZAP real estate index using rental prices as dividend in a valuation approach - see Koller et al. (2010). Figure 4.2 shows the NPV of real estate assets in Sao Paulo from 2008 to 2015. Most NPVs have been increasingly negative, suggesting a clear selling overprice related to rental prices.

Figure 4.2: Net Present Value of FIPE-ZAP Real Estate in Sao Paulo SP1D, SP2D, SP3D, SP4D and SPTotal mean real estate properties in Sao Paulo with 1, 2, 3, 4 or more rooms and all properties, respectively. The index base is 100 in August, 2010.

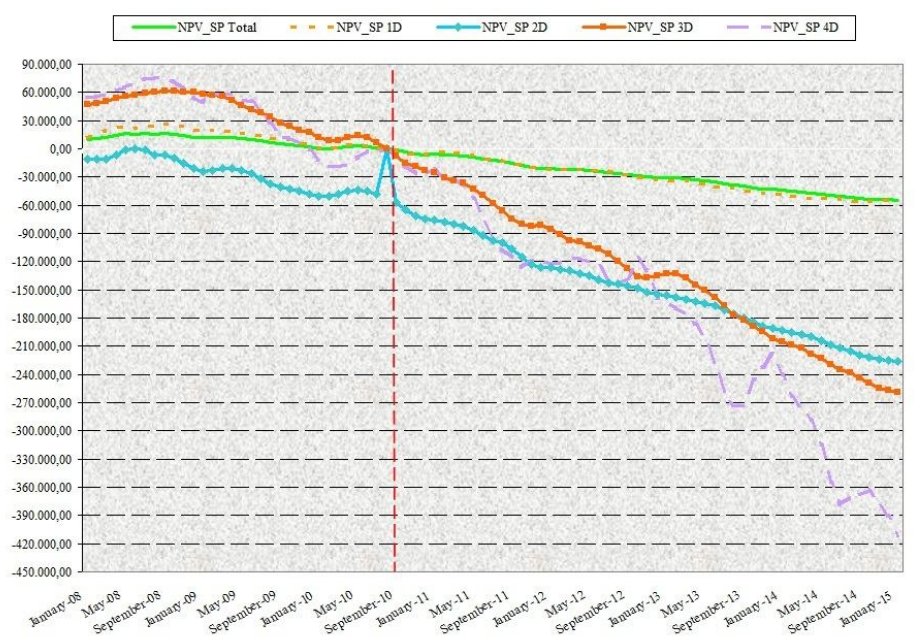

Bubbles are easily associated with self-fulfilling prophecies, a phenomenon initially described from a sociological point of view by Merton (1968): "The selffulfilling prophecy is, in the beginning, a false definition of the situation evoking a new behavior which makes the original false conception come 'true'.

This is the focus of Azariadis (1981), where expectations lead to economic fluctuations in the level of business activity. There are some Brazilian references for bubbles in inflation (HOLANDA BARBOSA and SALLUM, 2002), currency exchange rates (OREIRO, 2001), stock market (SIMIANO NUNES and DA SILVA, 2009). Martin et al. (2004) identify rational speculative bubbles from Markovian regimes, and claim that financial returns can be described as function of two regimes - bull markets and bear markets. According to Van Norden and Schaller (1996) the main rational bubble models lead to regime change. 
One main concern on crises and bubbles is the contagion effect, when, for instance, a bubble burst induces other bubbles bursts. Cynamon and Fazzari (2008), Eichengreen (2009), and many other authors deal with crisis transmission. Stumpner (2013) shows that trade (a real sector of the economy) was an important channel of the geographic spread of the U.S. crisis (2007 onwards). See also BIS and Hyun Jo (2012) for financial contagion, when the failure of some financial institutions impacts other financial institutions.

Many previous works report, as stylized facts for financial time series, volatility clustering and autoregressive conditional heteroscedastic (ARCH) effects. For a review of the ARCH and generalized ARCH (GARCH) effects, see Engle (1982) and Bollerslev (1986). The existence of volatility clusters suggests either an approach under the viewpoint of changes in volatility regimes or an approach under the standpoint of volatility leaps.

Concerning to time series with leaps, Kim et al (2011) provide a quick overview of the Lévy processes literature. A previous identification of the unconditional volatility levels is considered, in order to verify if there are levels of unconditional volatility, through the determination of the discrete changes in the unconditional variance investigated with the ICSS (Iterative Cumulative Sum of Squares) algorithm, from Inclán and Tiao (1994).

The time series subject to changes in regime grew relevance with Hamilton's (1989 and 1990) switching regimes models. The EM (Estimation Maximation) algorithm estimates parameters through maximum likelihood estimation (MLE) and can be adapted to non-normal distributions. The estimates of the model parameters are consistent, unbiased and efficient (DEMPSTER, LAIRD \& RUBIN, 1977).

Hamilton and Susmel (1994) and Cai (1994) introduced the SWARCH (switching autoregressive conditional heteroskedasticity) models, a generalization of the ARCH model of Engle (1982) allowing discrete changes in its level parameters through a Markov process.

Haas et al. (2004) specify the switching generalized autoregressive conditional heteroskedasticity (SWGARCH) model, which combine GARCH with regime switching. In the model specification, from Haas et al. (2004), the regime variances only depend on past shocks and their own lagged values - the pathdependency restriction was removed. This specification is analytically treatable, 
allows a separation of the process of conditional variance and offers direct parameter estimation through maximum likelihood.

Dixit and Pindyck (1994) present an overall review of real options methodologies. Titman (1985) and Williams (1991) pioneered the theory of real options for real estate assets. The authors searched the time and optimal scale of the (re) development of vacant properties. For the specific case of the Brazilian real estate options, Fortunato et al (2008) reported the difficulties of developing real estate options based on scattered sources. Nowadays, the FIPE-ZAP real estate index provides data for the cities of São Paulo and Rio de Janeiro since January 2008, but only quarterly average data are monthly released.

Driffill et al (2013) stated that accounting for Markov switching risk results in a delay in the expected timing of the investment while the regime-specific factor risk premium make the possibility of a regime shift more pronounced. Referring to Hamilton (1989), they suggest the use of Markov switching models to best fit variables such as real options volatility. The authors emphasized the scarce literature on real options with Markov switching models.

\section{3. \\ Data and Methodology}

The main data is the FIPE-ZAP real estate index, calculated by Fundação Instituto de Pesquisas Econômicas (FIPE) and Zap Imóveis (a real estate company) and available since January 2008. The FIPE-ZAP index consists of real estate rental and sales prices in selected Brazilian cities: Belo Horizonte, Brasília, Campinas, Contagem, Curitiba, Florianópolis, Fortaleza, Goiânia, Guarujá, Guarulhos, Niterói, Osasco, Porto Alegre, Praia Grande, Recife, Rio de Janeiro, Salvador, Santo André, Santos, São Bernardo do Campo, São Caetano do Sul, São Paulo, São Vicente, Vila Velha and Vitória.

The FIPE-ZAP compound index covers a weighted index of the seven biggest Brazilian cities while the broad index contains all cities covered. All indexes are calculated based on the advertisements published on the ZAP web page. The FIPE-ZAP index considers apartments announcements and takes into account the location (neighborhood), number of bedrooms and floor area. Its methodology is available on the link: http://www.fipe.org.br/web/index.asp. Data have been collected and stored on a daily basis since January 2008. Table 4.1 
shows the FIPE-ZAP indexes according to the city (Sao Paulo and Rio de Janeiro) and number of rooms: 1, 2, 3 and 4+ (four or more rooms). The monthly prices are 3-months moving averages.

Table 4.1: Examples of FIPE-ZAP Real Estate Index

\begin{tabular}{ll}
\hline \multicolumn{1}{c}{ Description } & \multicolumn{1}{c}{ Description } \\
\hline São Paulo: Total (all properties) & Rio de Janeiro: Total (all properties) \\
São Paulo: 1D (one room) & Rio de Janeiro 1D (one room) \\
\hline São Paulo: 2D (two rooms) & Rio de Janeiro: 2D (two rooms) \\
São Paulo: 3D (three rooms) & Rio de Janeiro: 3D (three rooms) \\
\hline São Paulo: 4D (four or more rooms) & Rio de Janeiro: 4D (four or more rooms) \\
\hline
\end{tabular}

Besides the FIPE-ZAP index, we also collect macroeconomic variables such as the monthly GDP (to predict the put option strike price and deflate the Ibovespa stock market index), consumer price index - IPC (to deflate both the Ibovespa and FIPE-ZAP), Ibovespa, inter-banking interest rate (CDI), consumer confidence index, and employment rate. Table 4.2 shows the main data used and their source.

Table 4.2: Main Data and Source

\begin{tabular}{ccc}
\hline Series & Acronym & Source \\
\hline FIPE-ZAP & FZ & FIPE \\
\hline Monthly GDP & GDP & Central Bank of Brazil \\
\hline Ibovespa Index & IBOV & Central Bank of Brazil \\
\hline Monthly inflation & IPC & FIPE \\
\hline Consumer Confidence Index & CCI & Central Bank of Brazil \\
\hline Formal Employment Rate & FME & Central Bank of Brazil
\end{tabular}

We also collect information on the real estate companies listed on BMF\&BOVESPA stock exchange. The selected companies were: Cyrela, MRV, GAFISA, Even, Tecnisa, Rossi Residencial and Tenda. All of them except Tenda belong to the "New Market", a listing segment that requires better governance practices. Table 4.3 shows the companies and their share on the corporate governance index of New Market. 
Table 4.3: Real Estate Companies, BMF\&BOVESPA's Governance Index

\begin{tabular}{lcll}
\hline \multicolumn{1}{c}{ Stock } & Share (\%) & Stock & Share (\%) \\
\hline CYRELA REALT & 0.814 & EVEN & 0.262 \\
\hline MRV & 0.562 & TECNISA & 0.121 \\
\hline GAFISA & 0.272 & ROSSI RESID & 0.115 \\
\multicolumn{4}{c}{ Source: BMF\&BOVESPA (2012). }
\end{tabular}

Our analyses consisted of two parts. First, we evaluate the real estate market in Brazil. Then, we analyze the monthly returns of FIPE-ZAP index, its volatility and simulate put options. Three types of tests were performed: changes of volatility regimes, SWGARCH simulations and American put simulations. Table 4.4 summarizes the chosen methods.

Table 4.4: Main Algorithms used in this chapter

\begin{tabular}{|c|c|c|c|}
\hline OPERATION & ALGORITHM & SOURCE & SOFTWARE \\
\hline Unconditional Volatility & $\overline{\mathrm{ICSS}}$ & Inclán and Tiao (1994) & RATS \\
\hline GARCH+ & SWGARCH & Haas et al (2004) & MATLAB \\
\hline \multicolumn{4}{|l|}{ Levels } \\
\hline \multirow[t]{2}{*}{ Real Options } & American put & Drifill et al (2013) & Microsoft \\
\hline & & $\begin{array}{l}\text { Longstaff and Schwartz } \\
(2001)\end{array}$ & VBA+@Risk \\
\hline
\end{tabular}

\section{Equation 4.2: Equation of Returns}

Monthly return $=R_{m}=\operatorname{Ln}\left(\frac{\text { FIPEZapIndex }}{m}\right)$

The determination of the discrete changes in the unconditional variance can be evaluated with the ICSS - Iterative Cumulative Sum of Squares algorithm, from Inclán and Tiao (1994). The time series presents a stationary variance over the initial period; a sudden change in variance occurs some time later, possibly caused by some political and/or economic shock; and the variance becomes stationary again, at another level, until another sudden change occurs. This process is repeated creating a temporal series of observations with an unknown number of sudden changes in variance. 


\section{Equation 4.3: AR/GARCH for Sudden Changes in the Unconditional Volatility}

$$
\begin{gathered}
A R(1): R m_{t}=A_{0}+A_{1} R m_{t-1}+u_{t} \\
\operatorname{GARCH}(1,1): v_{t}=C+p v_{t-1}+q u_{t-1}^{2}+\operatorname{LevI}_{t-1} u_{t-1}^{2}
\end{gathered}
$$

Conditions : $\mu_{t}=\sqrt{v_{t}} \varepsilon_{t} ; \varepsilon_{t}=t ; \mu=0 ; \sigma^{2}=1 ; d f=D(t-$ student $) ; I_{t}=1\left(u_{t}<0\right) ; I_{t}=0\left(u_{t} \geq 0\right)$ where the coefficients $\mathrm{A}_{0}$ is constant in the average equation, $\mathrm{C}$ is constant in the conditional variance equation, $\mathrm{Q}$ is the residuals coefficient, $\mathrm{P}$ is the conditional variance coefficient, Lev is the leverage coefficient, and D is the degree of freedom of the t-student distribution that models the return series. After running the GARCH model, the program runs the ICSS algorithm, where the variance of a given sequence of observations is verified retrospectively, in order to use all the information on the series to indicate the points of variance change.

\section{Equation 4.4: ICSS algorithm variables}

$$
C_{k}=\sum^{k} \varepsilon_{t}^{2}, k=1, \ldots, T
$$

Is the cumulative sum of squares of a series of uncorrelated random variables with mean zero and variance $\sigma_{t}^{2}$.

$$
D_{k}=\left(C_{k} / C_{T}\right)-k / T \text {, where } k=1, \ldots, T \text { and } D_{0}=D_{T}=0 .
$$

The plot of Dk against $\mathrm{k}$ will oscillate around zero for series with homogeneous variance. When there is a sudden change in variance, the plot of Dk will exhibit a pattern going out of some specified boundaries with high probability. These boundaries can be obtained from the asymptotic distribution of Dk assuming constant variance.

Let $\mathrm{k}^{*}$ be the value of $\mathrm{k}$ at which $\max \mathrm{k}|\mathrm{Dk}|$ is attained if the maximum absolute value exceeds a pre-determine boundary, concluding that there is a change point near $\mathrm{k}^{*}$ and estimate $\mathrm{k}^{*}$ as an estimate of the change point.

With regards to time series subject to changes in regime, the SWGARCH models combine GARCH with regime switching. In the Haas et al. (2004, p. 497) model specification, the regime variances only depend on past shocks and their own lagged values - the path-dependency restriction was removed. This specification is analytically treatable, allows a separation of the process of conditional variance and offers direct parameter estimation through maximum likelihood. 


\section{Equation 4.5: Conditional Variance for a SWGARCH $(k, p, q)$ Model}

$v_{t, k}=\alpha_{0}+\sum_{i=1}^{q} \alpha_{i} u_{t-i}^{2}+\sum_{j=1}^{p} \beta v^{v_{t-j, k}}$

Residuals: $u_{t}=\sqrt{v_{t}} \varepsilon_{t}$, Either $\varepsilon_{t} \sim N\left(0, \sigma_{s t}\right)_{\text {or }} \varepsilon_{t} \sim t-$ student

Where $v_{t, k}$ stands for the $k$-regime variance at period $t ; \alpha_{0}, \alpha_{i}, \beta_{j}$ are constants.

From the Markov chain properties, the duration of each regime can be easily derived. Defining, in equation 4.6, D as the duration of a specific regime and pjj the probability of staying in the same regime $\mathrm{j}$ from time $\mathrm{t}$ to time $\mathrm{t}+1$ :

\section{Equation 4.6: Expected Regime Duration (by induction).}

$$
\mathrm{E}(\mathrm{D})=\sum_{j=1}^{\infty} j P[D]=\left(1-\mathrm{p}_{\mathrm{jj}}\right)+2 \mathrm{p}_{\mathrm{jj}}\left(1-\mathrm{p}_{\mathrm{jj}}\right)+3 \mathrm{p}_{\mathrm{jj}}\left(1-\mathrm{p}_{\mathrm{jj}}\right)+\ldots=1 /\left(1-\mathrm{p}_{\mathrm{jj}}\right) .
$$

If $\mathrm{p}_{\mathrm{jj}}=0.5$, then $\mathrm{E}(\mathrm{D})=2$ time periods. The American put options simulations utilize Pachamanova and Fabozzi’s (2010) software that follows Longstaff and Schwartz (2001).

\section{4. Results}

This section consists of two parts. First, we present an analysis of the real estate market in Brazil. The second part analyses the volatilities of the FIPE-ZAP index and simulate the real estate put options.

\section{Real Estate Market in Brazil}

The real estate credit market/GDP ratio in Brazil is lower than other countries (see Figure 4.3). Even with the growing share of Brazilian household expenditures with real estate assets in recent years (see Figure 4.4), the conjuncture is far from the quite high levels of household expenditures in other countries, as seen in Cynamon and Fazzari (2008) although vulnerability still is a main issue (see Blejer and Schumacher, 1998). 
Figure 4.3: Real Estate Credit/GDP Ratio

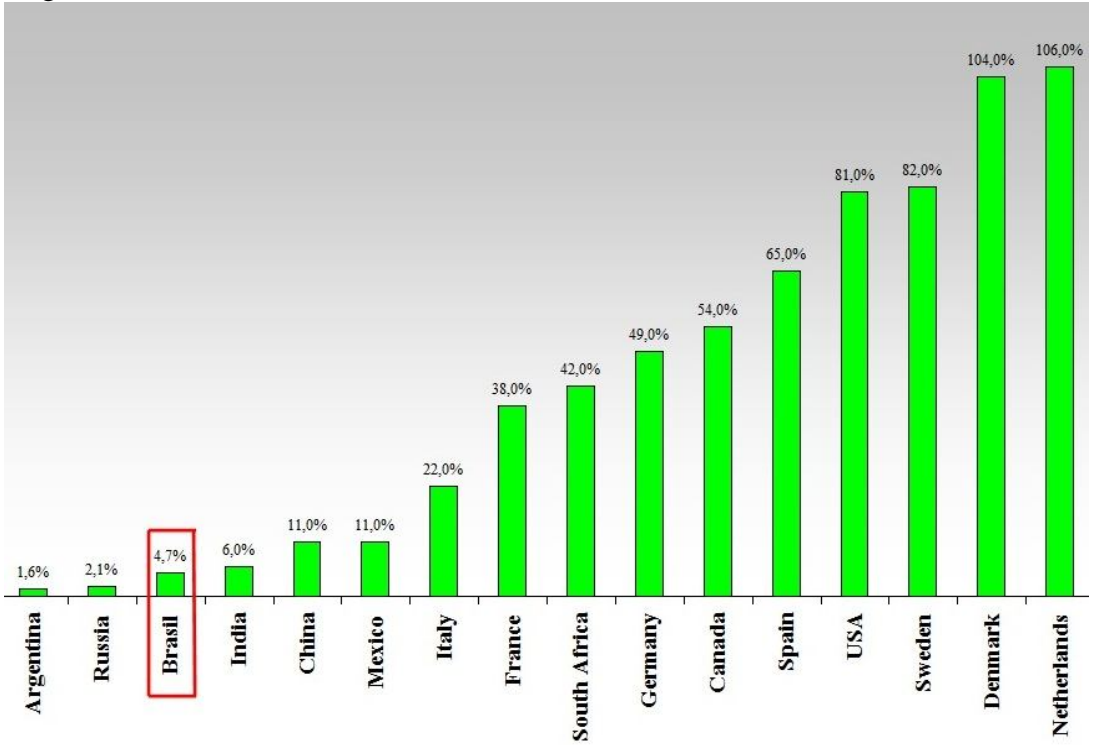

Source: ABECIP Brazilian Association of Mortgage Entities (2011).

Figure 4.4: Real Estate Loans x GDP Compared to Household Expenditures

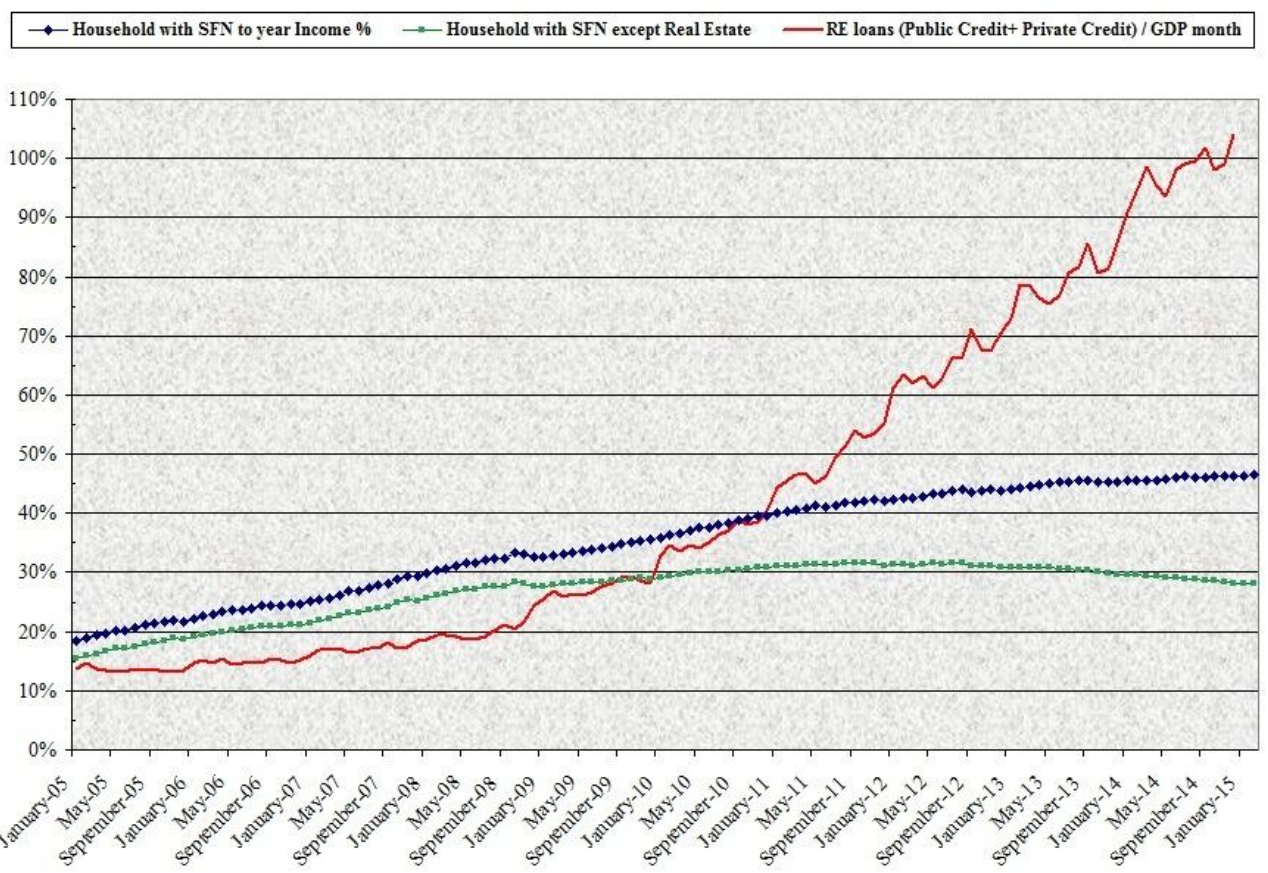

Source: ABECIP Brazilian Association of Mortgage Entities (2011). 
The market value of companies listed on BM\&FBOVESPA has undergone major changes since 1996, as seen in figure 4.5. There is a sharp decline of firm values in 2008, when the global financial crisis reached (to a limited extension) Brazil. From 2011 on, the overall firm value decreased related to inflation and GDP, in line with the slow GDP growth in Brazil. Meanwhile, the real estate loans/GDP ratio continued to growth. Moreover, the prices of real estate properties have increased until 2014, in spite of economic oscillations.

Figure 4.5: Firm's Market Value (BMF\&BOVESPA) Deflated by Inflation / GDP

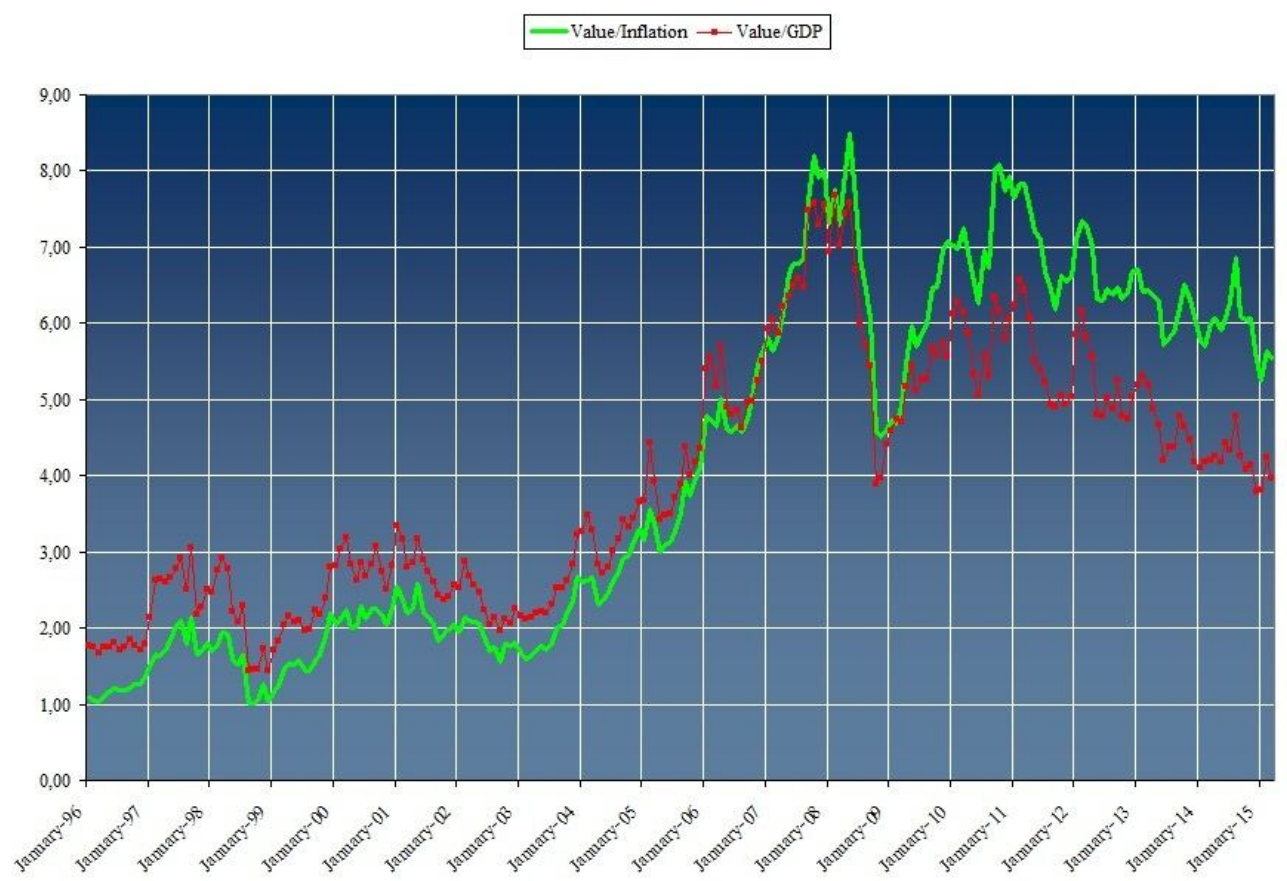

Next, we perform stepwise fit regressions using FIPE-ZAP indexes as dependent variables and the following independent variables: GDP, IPC, Ibovespa, CDI, consumer confidence, and employment rate.

Table 4.5 shows the p-values of the stepwise fit regressions results for FIPEZAP relative to monthly GDP and inflation from February 2008 to January 2015. We can see that there is no significant relation between FIPE-ZAP and monthly GDP and inflation. The only significant result at 10\% level was for the SPD4 and RJD4 series (flats with 4 or more rooms) and three months and five months lagged inflation. The regressions with the consumer confidence index and employment rate showed positive coefficients for lag $=2$ months. 
Table 4.5: FIPE-ZAP Fit Regression with Lagged Monthly Inflation and GDP RJ and SP stand for Rio de Janeiro and São Paulo and Dx is the number of rooms (from 1 to 4 or more) per flat. Total is the overall city index. The table shows the p-value of the coefficients. * indicates significant at $10 \%$ level.

\begin{tabular}{lllllllllll}
\hline Series/ & GDP & GDP & GDP & GDP & GDP & IPC & IPC & IPC & IPC & IPC \\
Regressor & $\mathbf{t}-1$ & $\mathbf{t}-2$ & $\mathbf{t}-3$ & $\mathbf{t}-4$ & $\mathbf{t - 5}$ & $\mathbf{t}-1$ & $\mathbf{t}-2$ & $\mathbf{t}-3$ & $\mathbf{t}-4$ & $\mathbf{t}-5$ \\
\hline RJD1 & $52.43 \%$ & $58.60 \%$ & $43.09 \%$ & $68.73 \%$ & $94.65 \%$ & $82.55 \%$ & $76.34 \%$ & $94.60 \%$ & $42.56 \%$ & $10.34 \%$ \\
\hline RJD2 & $28.52 \%$ & $80.63 \%$ & $86.04 \%$ & $82.39 \%$ & $19.08 \%$ & $66.69 \%$ & $93.91 \%$ & $71.38 \%$ & $30.68 \%$ & $18.72 \%$ \\
\hline RJD3 & $42.91 \%$ & $96.26 \%$ & $83.56 \%$ & $91.56 \%$ & $41.34 \%$ & $95.61 \%$ & $57.89 \%$ & $57.77 \%$ & $45.47 \%$ & $36.26 \%$ \\
\hline RJD4 & $90.25 \%$ & $79.33 \%$ & $80.97 \%$ & $45.05 \%$ & $24.61 \%$ & $84.85 \%$ & $84.82 \%$ & $63.02 \%$ & $22.74 \%$ & $7.55 \% *$ \\
\hline RJTOTAL & $40.85 \%$ & $76.71 \%$ & $85.75 \%$ & $73.68 \%$ & $43.02 \%$ & $79.47 \%$ & $76.36 \%$ & $74.23 \%$ & $33.91 \%$ & $13.99 \%$ \\
\hline SPD1 & $12.56 \%$ & $83.59 \%$ & $61.16 \%$ & $58.05 \%$ & $45.66 \%$ & $50.51 \%$ & $63.34 \%$ & $86.16 \%$ & $98.75 \%$ & $35.50 \%$ \\
\hline SPD2 & $12.08 \%$ & $36.58 \%$ & $71.35 \%$ & $74.67 \%$ & $81.28 \%$ & $86.93 \%$ & $36.29 \%$ & $31.56 \%$ & $53.37 \%$ & $60.74 \%$ \\
\hline SPD3 & $24.81 \%$ & $68.25 \%$ & $81.48 \%$ & $59.52 \%$ & $93.99 \%$ & $87.12 \%$ & $98.10 \%$ & $81.33 \%$ & $66.06 \%$ & $35.91 \%$ \\
\hline SPD4 & $27.29 \%$ & $19.08 \%$ & $18.86 \%$ & $94.66 \%$ & $48.51 \%$ & $48.39 \%$ & $20.14 \%$ & $\mathbf{8 . 4 1 \%}$ & $34.11 \%$ & $28.56 \%$ \\
\hline SPTOTAL & $10.25 \%$ & $47.31 \%$ & $83.52 \%$ & $64.24 \%$ & $65.23 \%$ & $64.55 \%$ & $97.34 \%$ & $91.47 \%$ & $83.53 \%$ & $36.06 \%$ \\
\hline
\end{tabular}

Table 4.6 shows the results of the regressions of FIPE-ZAP index in Rio de Janeiro relative to the formal employment rate in Brazil and Rio de Janeiro, from February 2008 to January 2015. There is a direct relation with the formal employment rate in Rio de Janeiro (lags zero, 1, 2, 3 and 10) and Brazil (mainly $\operatorname{lag} 2$ ).

Table 4.6: Regressions with Lagged Employment Rate, Rio and Brazil RJ stands for Rio de Janeiro, BR for Brazil and Dx is the number of rooms (from 1 to 4) per flat. Total is the overall city index.The p-values for the null hypothesis are shown between brackets.

\begin{tabular}{lccccc}
\hline LAG/Series & RJD1 & RJD2 & RJD3 & RJD4 & RJTOTAL \\
\hline BRt-2 & 0.498 & & & & \\
& $(1.2500 \%)$ & & & & \\
\hline BR t-25 & & -0.723 & & -0.719 & -0.747 \\
& $(0.0028 \%)$ & & $(0.1300 \%)$ & $(0.0168 \%)$ \\
\hline RJ t & 1.050 & 0.883 & 1.121 & 1.019 \\
& & $(0.0004 \%)$ & $(0.0348 \%)$ & $(0.0145 \%)$ & $(0.0086 \%)$ \\
\hline RJ t-1 & 1.186 & & 1.087 & 1.087 \\
& & $(0.0001 \%)$ & & $(0.0319 \%)$ & $(0.0049 \%)$ \\
\hline
\end{tabular}

\begin{tabular}{lcc}
\hline RJ t-2 & \multicolumn{3}{c}{0.620} \\
& \multicolumn{3}{c}{$(1.8300 \%)$} \\
\hline RJ t-3 & 0.969 & \\
& $(0.3700 \%)$ & 0.546 \\
& & $(4.0600 \%)$ \\
\hline RJ t-10 & & \\
& & \\
\hline
\end{tabular}


Table 4.7 shows the correlations of selling and rental prices of real estate in Sao Paulo. The suffix "R" stands for rental prices. As expected, most correlations are positive, however there are a few negative correlations between selling prices (3D and 4D) and rentals.

Table 4.7: Correlations of Selling and Rental Real Estate Prices in Sao Paulo RJ and SP stand for Rio de Janeiro and São Paulo and Dx is the number of rooms (from 1 to 4) per flat. Total is the overall city index. The suffix " $R$ " stands for rental prices.

\begin{tabular}{|c|c|c|c|c|c|c|c|c|c|c|}
\hline & SPTotal_R & SP1D_R & SP2D_R & SP3D_R & SP4D_R & SPTotal & SP1D & SP2D & SP3D & SP4D \\
\hline SPTotal_R & $100.00 \%$ & & & & & & & & & \\
\hline$\overline{\text { SP1D_R }}$ & $87.40 \%$ & $100.00 \%$ & & & & & & & & \\
\hline SP2D_R & $86.83 \%$ & $57.75 \%$ & $100.00 \%$ & & & & & & & \\
\hline SP3D_R & $65.58 \%$ & $41.87 \%$ & $51.13 \%$ & $100.00 \%$ & & & & & & \\
\hline SP4D_R & $31.32 \%$ & $9.26 \%$ & $25.20 \%$ & $29.76 \%$ & $100.00 \%$ & & & & & \\
\hline SPTotal & $27.43 \%$ & $4.54 \%$ & $24.34 \%$ & $52.76 \%$ & $46.98 \%$ & $100.00 \%$ & & & & \\
\hline SP1D & $46.42 \%$ & $29.33 \%$ & $40.13 \%$ & $47.21 \%$ & $45.80 \%$ & $81.39 \%$ & $100.00 \%$ & & & \\
\hline SP2D & $22.63 \%$ & $4.11 \%$ & $17.28 \%$ & $50.65 \%$ & $36.55 \%$ & $91.74 \%$ & $62.99 \%$ & $100.00 \%$ & & \\
\hline SP3D & $19.57 \%$ & $-6.09 \%$ & $20.64 \%$ & $52.41 \%$ & $41.71 \%$ & $90.60 \%$ & $58.41 \%$ & $80.09 \%$ & $100.00 \%$ & \\
\hline SP4D & $-13.33 \%$ & $-29.19 \%$ & $-10.70 \%$ & $17.35 \%$ & $35.44 \%$ & $73.87 \%$ & $45.53 \%$ & $59.21 \%$ & $72.85 \%$ & $100.00 \%$ \\
\hline
\end{tabular}

\section{FIPE-ZAP Volatility and Put Options Modeling}

The tests for the real estate option volatilities consisted of analyzing changes of volatility regimes, SWGARCH estimations and American put simulations. All the series were submitted to the Kolmogorov-Smirnov test, which rejected the null hypothesis of normality.

Table 4.8 shows the GARCH fitting for FIPE-ZAP index in Rio de Janeiro and São Paulo. The results for GARCH $(1,1)$ fitting indicate that all series but SPD4 exhibit a high persistence of shocks: the sum of the ARCH+GARCH coefficients are 1 or near 1 , no matter the nature of the conditional distribution of innovations (either normal or t-student). 
Table 4.8: GARCH Fitting for FIPE-ZAP Index in Rio de Janeiro and São Paulo

RJ and SP stand for Rio de Janeiro and São Paulo and Dx is the number of rooms (from 1 to 4) per flat. Total is the overall city index.

\begin{tabular}{lcclllll}
\hline $\begin{array}{c}\text { Series/ } \\
\text { Parameters }\end{array}$ & $\begin{array}{c}\text { ARCH } \\
(\mathbf{1})\end{array}$ & $\begin{array}{c}\text { GARCH } \\
\mathbf{( 1 )}\end{array}$ & SUM & $\begin{array}{c}\text { Series/ } \\
\text { Parameters }\end{array}$ & $\begin{array}{c}\text { ARCH } \\
(\mathbf{1})\end{array}$ & $\begin{array}{c}\text { GARCH } \\
(\mathbf{1})\end{array}$ & SUM \\
\hline RJD1 & 0.391 & 0.576 & 0.967 & SPD1 & 0.528 & 0.316 & 0.845 \\
\hline RJD2 & 0.930 & 0.000 & 0.930 & SPD2 & 1.000 & 0.000 & 1.000 \\
\hline RJD3 & 1.000 & 0.000 & 1.000 & SPD3 & 1.000 & 0.000 & 1.000 \\
\hline RJD4 & 0.717 & 0.220 & 0.937 & SPD4 & 0.426 & 0.042 & 0.468 \\
\hline RJTOTAL & 0.965 & 0.000 & 0.965 & SPTOTAL & 0.771 & 0.144 & 0.915
\end{tabular}

Then we analyze the changes of unconditional volatility levels. Table 4.9 shows the ICSS (TIAO and INCLAN, 1994) results for the volatility levels for São Paulo and Rio de Janeiro. There are clear changes in the unconditional volatility level in some series.

Table 4.9: Unconditional Volatility Levels of FIPE-ZAP Index RJ and SP stand for Rio de Janeiro and São Paulo and Dx is the number of rooms (from 1 to 4) per flat. Total is the overall city index.

\begin{tabular}{llllllll}
\hline Series & Start & End & $\begin{array}{l}\text { Volatility } \\
\text { Level }\end{array}$ & Series & Start & End & $\begin{array}{c}\text { Volatility } \\
\text { Level }\end{array}$ \\
\hline RJD1 & Jan-08 & Feb-15 & $0.56 \%$ & SPD1 & Jan-08 & Feb/09 & $0.91 \%$ \\
\hline RJD2 & Jan-08 & Jan-11 & $0.36 \%$ & SPD2 & Jan-08 & Jul-09 & $0.45 \%$ \\
\hline RJD2 & Feb/11 & Feb-15 & $0.19 \%$ & SPD2 & Aug-09 & Feb-15 & $0.22 \%$ \\
\hline RJD3 & Jan-08 & Apr-12 & $0.36 \%$ & SPD3 & Jan-08 & Jul-11 & $0.30 \%$ \\
\hline RJD3 & May-12 & Feb-15 & $0.14 \%$ & SPD3 & Aug-11 & Feb-15 & $0.12 \%$ \\
\hline RJD4 & Jan-08 & Jun-11 & $0.25 \%$ & SPD4 & Jan-08 & Aug-11 & $0.46 \%$ \\
\hline RJD4 & Jul-11 & May-12 & $1.17 \%$ & SPD4 & Sep-11 & Feb-15 & $0.27 \%$ \\
\hline RJD4 & Jun-12 & Feb-15 & $0.19 \%$ & & & & SPD1 \\
\hline RJTOTAL & Jan-08 & Oct-11 & $\mathbf{0 . 3 0 \%}$ & SPTOTAL & Jan-08 & Aug-11 & $\mathbf{0 . 2 9 \%}$ \\
\hline & Nov-11 & Feb-15 & $\mathbf{0 . 1 7 \%}$ & & Sep-11 & Feb-15 & $\mathbf{0 . 1 5 \%}$ \\
\hline
\end{tabular}

Figure 4.6 shows the unconditional volatility levels generated from the ICSS algorithm (INCLAN and TIAO, 1994). All series, except RJD1, exhibited unconditional volatility level changes. The peak volatility for RJ4D could represent a temporary change in the demand for luxury flats in Rio de Janeiro. 
Figure 4.6: Unconditional Volatility Levels of Real Estate Selling Prices

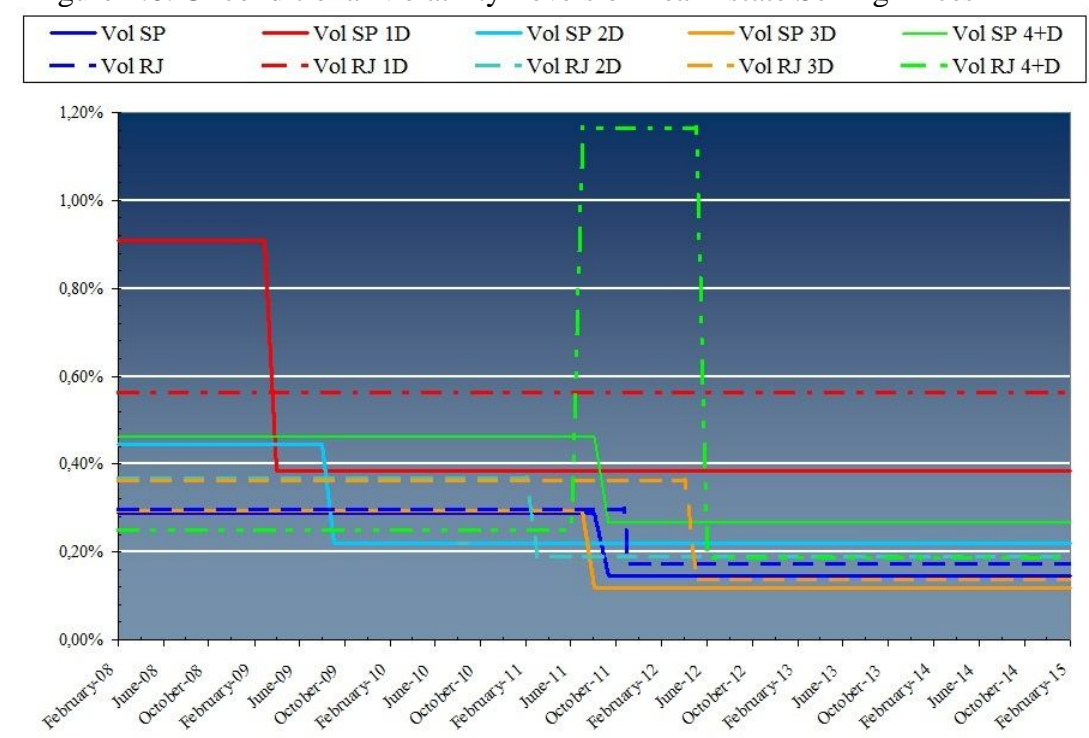

After the SWGARCH simulations, due to both parameter parsimony and to the two unconditional volatility levels output from the ICCS program, a two volatility level model was chosen: an ARMA $(1,1)-S W G A R C H(2,1,1)$. In the first tests, the best results were obtained when all probabilities were set to $50 \%$ (duration $=2$ months). The other parameters were simulated through Monte Carlo simulations (4 million combinations), aiming at a maximum likelihood estimation. The best result for the one-room-flat-São-Paulo index is exhibited in Table 4.10. The persistence of the ARCH-GARCH coefficients downsized to $60 \%$. The monthly unconditional volatilities are considerably low.

Table 4.10: SWGARCH for Sao Paulo Single Room Monthly Index (SPD1)

Note: $\mathrm{CT}=\mathrm{ARMA}(1,1)$ constant; $\mathrm{AR}=\mathrm{AR}$ coefficient for $\operatorname{ARMA}(1,1)$; $\mathrm{MA}=\mathrm{MA}$ coefficient for ARMA $(1,1)$; CT1=unconditional volatility level 1; CT2=unconditional volatility level 2; A1 = ARCH coefficient for volatility level 1; A2= ARCH coefficient for volatility level 2; G1= GARCH coefficient for volatility level 1; G2= GARCH coefficient for volatility level 2; MLE = Maximum Likelihood Estimator.

\begin{tabular}{lccccc}
\hline Parameters & CT & AR & MA & CT1 & CT2 \\
\hline Estimation & 0.7615 & $96.42 \%$ & $10.67 \%$ & $1.25 \%$ & $0.20 \%$ \\
\hline Parameters & A1 & A2 & G1 & G2 & MLE \\
\hline Estimation & $1.15 \%$ & $0.11 \%$ & $1.99 \%$ & $59.19 \%$ & 925.523 \\
\hline
\end{tabular}


Next, we simulated American puts working as abandon options. For the sensibility tests, the minimum and maximum standard deviation values ranged from $0.12 \%$ to $1.17 \%$ a.m. The interest rate ranged from $1 \%$ to $20 \%$ a.m. The initial values of the underlying asset were the FIPE-ZAP index of a specific date, city (São Paulo or Rio de Janeiro) and type of flat. Strike values were either a future value from the same specific FIPE-ZAP index or a forecast based on monthly GDP.

Table 4.11 shows the average ratio premium/asset price for São Paulo single room flats (SPD1). In order to verify if the premium is reasonable compared with the underlying asset price, $10 \%$ was set as a threshold for the premium/asset value ratio. The average premium/asset value is above $10 \%$ for most cases for the São Paulo single room series, except for options with expiration time shorter than a year. The ratio premium/asset values do not vary significantly within the volatility range level found (from $0.12 \%$ to $1.17 \%$ ). The simulated options are considerably more sensible to expiring time than to volatility and interest rate.

Table 4.11: Average Option Value/Real Estate Price for 1-Room Flat (SP)

\begin{tabular}{lcccc}
\hline Years & Up to 1 year & 1 to 2 years & 2 to 3 years & 3 to 4 years \\
\hline Premium/Asset & $7.04 \%$ & $29.56 \%$ & $58.52 \%$ & $94.57 \%$ \\
\hline \hline Years & 4 to 5 years & 5 to 6 years & 6 to 7 years & 7 to 8 years \\
\hline Premium/Asset & $134.30 \%$ & $177.27 \%$ & $218.54 \%$ & $248.39 \%$ \\
\hline
\end{tabular}

Figure 4.7 shows the option value/real estate price ratio for São Paulo and Rio de Janeiro. The volatility change did not impact significantly the American put premium. Only $27.3 \%$ of the cases exhibit a premium under a plausible $10 \%$ threshold, while in $5 \%$ of all simulations the premium cost more than the asset price. 
Figure 4.7: Option Value/Real Estate Price for São Paulo and Rio de Janeiro

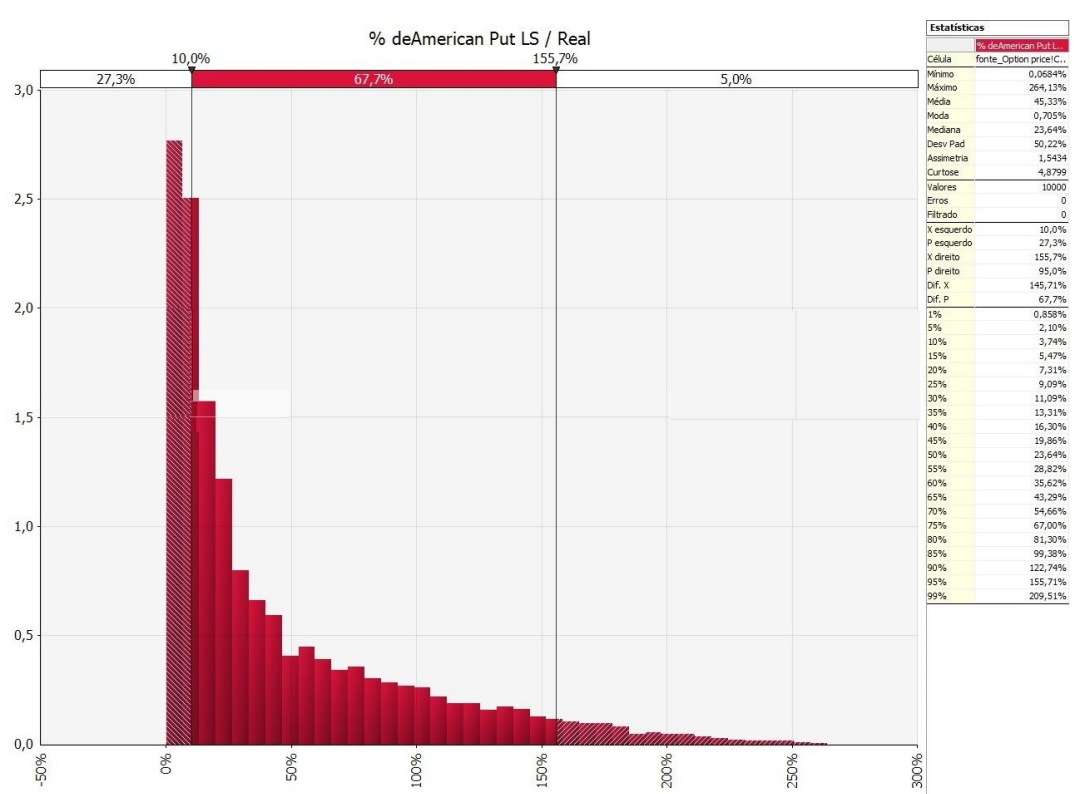

Figure 4.8 shows the simulation of the option value/real estate price ratio predicting strike prices with monthly GDP. As the results indicated that only $23.1 \%$ of the extrapolated strike prices are higher than the real strike values (available from the FIPE-ZAP index), we concluded that the GDP growth does not work as a good strike price predictor. The bullish market offer few opportunities to exercise the put options, since $71.9 \%$ values of the real estate index are greater than the prediction based on GDP linear growth. 
Figure 4.8: Predicting Strike Prices from Monthly GDP (São Paulo and Rio)

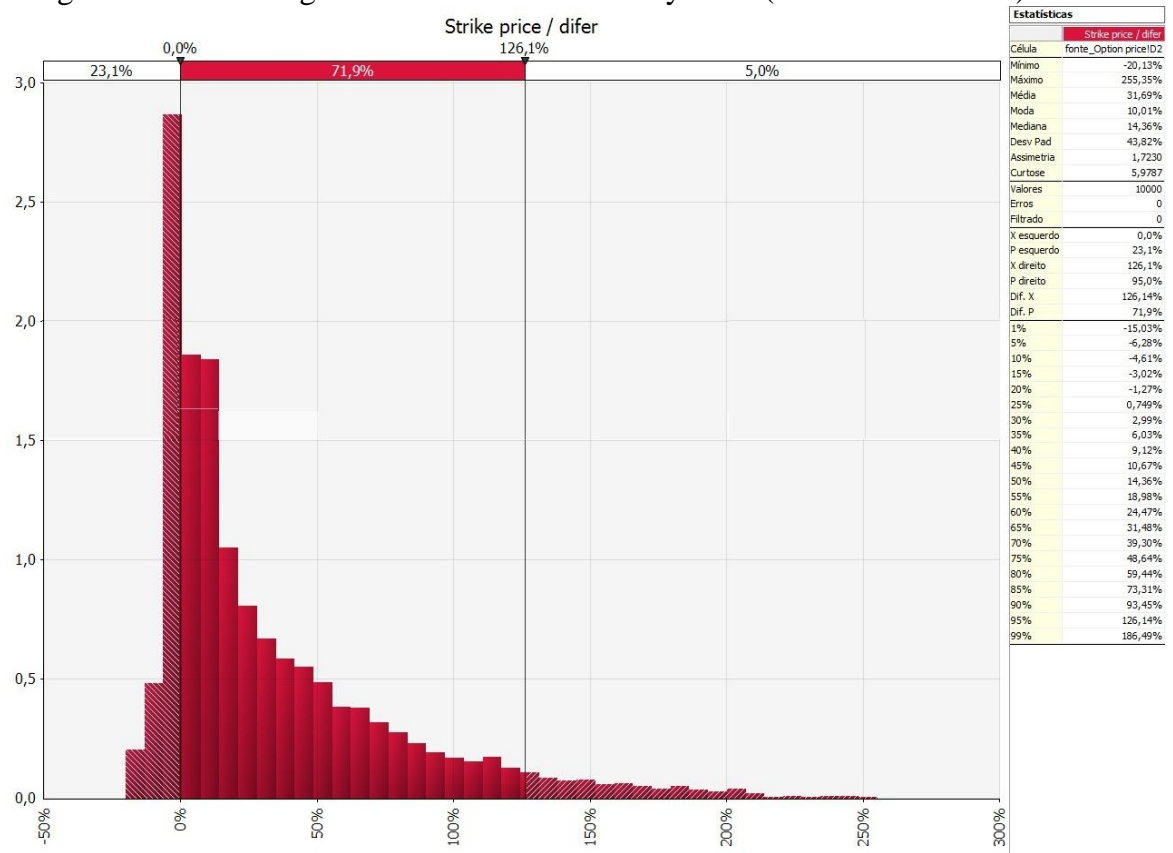

4.5.

Discussion

This chapter evaluated the selling prices of the Brazilian real estate market from January, 2008 to February, 2015. The frequently claimed real estate price overvaluation, especially in large urban centers such as Rio de Janeiro and São Paulo, suggested a price bubble hypothesis. The small Brazilian ratio between real estate credit market/GDP, compared to other countries, makes this hypothesis, at first glance, not a huge concern, although financial vulnerability still remains a main issue (see BLEJER and SCHUMACHER, 1998).

On the other hand, it seems that a strong relation between real estate markets and economic cycles exist. Whatever the case, consumers/householders may desire protection against sharp devaluations of their real estate assets. In short, the evidence of economic cycles suggesting levels in the volatility of real estate assets, the household hedging needs and the existence of a Brazilian real estate index offered the opportunity to create and simulate real abandon options with volatility regime-switching risk - an approach from Driffill et al (2013) - that may help to mitigate the real estate market risk. 
Since 2010, the FIPE-ZAP joint venture releases a monthly index disclosing real estate selling and rental price levels for the two biggest Brazilian cities: São Paulo and Rio de Janeiro (mark-to-market quotations), enabling the creation and simulation of real estate options. This index turned to be a great contribution: previously no regularly disclosed information over real estate prices was available, as we inferred from Fortunato et al (2008). On the other hand, the monthly time series is rather new so that there is few data available, even concerning the cities of São Paulo and Rio de Janeiro, therefore the simulations do not generate a rather critical mass of information. Also, the prices are 3-months moving averages, a quarterly time frame of mark-to-market prices. Nevertheless, monthly information of real estate data can enable the monitoring of this key economic sector better than evaluating stocks from a few real estate companies listed in the Brazilian stock exchange. Future works may contemplate the use of weekly and/or daily data from the FIPE-ZAP database.

Our results indicate that the FIPE-ZAP index is related to consumer confidence and to the formal employment rate. The higher volatility until the second quarter of 2012 meant a short boom period after the negative effects of the international crisis in 2008. The lower volatility, since the second quarter of 2012 suggests an adjustment period, with possible recession indication from the third quarter of 2014. Since the real estate was a bullish market until the third quarter of 2014 , most of the put options would be not exercised.

The bubble golden rule from Evanoff et al (2012), which stipulates a $37 \%$ sharp price decline to detect bubbles, did not apply to the FIPE-ZAP index, and the small GDP growth since 2011 suggested instead good buying opportunities in the bullish real estate market. Alternative to a bubble burst, the real estate market may face gradual price realignment.

While we identified volatility clustering as a stylized fact in the real estate market in Brazil, neither a high probability bubble burst risk nor a Markov switching risk resulting in delays in the expected timing of the investment according to Driffill et al (2013) - could be confirmed as stylized facts in the present analysis. 
The switching models seems well fitted to the scenario approach usual in real options analysis. The American put option can be adapted to assign a specific volatility to each path. A multi-level approach from switching regimes models can be more convenient for real estate valuations than alternatives with levy processes that, instead of volatility switching, deals with fat tails and jumps.

Although the Markovian regime-switching approach is at least 20 year old, there is a gap on its use in the real estate market. While creating real estate options may be of no use when there are few chances to exercise them in a bullish market environment; on the other hand, abandon options for real estate assets could be an effective consumer protection, in line with the Basel III pillar 1 approach (capital requirements), applied to the household side of the economy. 


\section{Conclusions}

This thesis tried to answer the following question: Basel III: Towards a Safer Financial System? As a result of Basel's III complexity, its transient features, and taking account of the myriad of candidates for contributing factors to financial crises, there are many opportunities for researching on Basel's recommendations.

We focused on three concerns: testing the validity of some key Basel III innovations; liquidity risk regulation and possible alternatives; and crises early warnings. Those concerns resulted in three chapters: 1) Backtesting Basel III: Evaluating the Market Risk of Past Crises in Brazil through the Current Regulation; 2) The Liquidity Regulation versus the Lender of Last Resort: a Dichotomy? (Pricing Options for Capital Adequacy); and 3) Hedging against Price Bubbles through Options with volatility Regime-Switching Risk in the Brazilian Real Estate Market (2008-2015).

The three chapters contributed to the literature by applying to the Brazilian financial environment recent econometric methodologies and approaches, taken from Broda et al (2013), Alvarez and Dixit (2014), and Drifill et al. (2013), respectively.

The first chapter analyzed whether the effects of past crises could be mitigated if the Basel III recommendations were already implemented. It innovates by analyzing the question simultaneously with two known approaches: the capital requirements (BIS) and the early warning approach (IMF). The main conclusions are: (i) there is no methodology capable to forecast crises with a high degree of accuracy; neither the early warning approach nor the capital adequacy are fit to deal with the surge of quite high volatility levels that demand quite high capital requirements; (ii) to circumvent either the lack of historical information or the lack of optimal window for stress patterns, it innovates by proposing the calibration of the Stressed VaR with a historical VIX, working as a volatility scale; (iii) other statistical distributions, apart from the standard normal curve 
prescribed in almost all Basel's recommendations, shall be considered, and it innovates with the use of SWGARCH models with stable density innovations; (iv) the daily oscillation limits may have a significant role on crisis mitigation.

The second chapter analyzed a supposed dichotomy in the field of banking regulation: the liquidity risk regulation versus the lender of last resort (LOLR) institute. Why does the financial system need both alternatives simultaneously? Beyond rebating this dichotomy, the main contributions are: first, the simulation of call options without maturity, as in Alvarez and Dixit (2014), originated from any kind of lender (not necessarily a LOLR) offer a theoretically feasible alternative/complement to capital requirements, with underlying assets modelled with geometric Brownian motion, although more costly than the usual rediscount contracted from Central Banks. Second, we verified that the Brazilian liquidity index is a random walk process, meaning a constant effort to keep this index at a safer level.

The third chapter took into account that, as financial crises can be originated from any economic sector, the real estate market is a qualified candidate for crises source, as it happened in several countries. Concerning the Brazilian scenario, confirming or not a real estate bubble hypothesis (from 2008 to 2015), we propose that mitigation efforts can be more effective with the development of abandon options that may hedge against real estate assets devaluations. The main contribution and innovation is the simulation of real options with regimeswitching volatility hedging against real estate price downfalls, based on monthly returns of the FIPE-ZAP real estate index.

Last but not least, "Basel III: towards a Safer Financial System" is a statement of direction as well as a work in progress which offers many opportunities for writing academic texts concerning the analysis and improvement of the Basel Accords. 


\section{References}

ABIAD, A. Early warning systems: A survey and a regime switching approach. Washington, D.C: IMF Working Papers, 2003.

AGÉNOR, P. R.; PEREIRA, L. A. S. Macroprudential regulation and the monetary transmission mechanism. Brasília, Brasil: Banco Central do Brasil Working Paper, n. 254, 2011.

ALVAREZ, F.; DIXIT, A. A real options perspective on the future of the Euro. Journal of Monetary Economics, v. 61, p. 78-109, 2014.

ARAÚJO, A.; SCHOMMER, S.; WOODFORD, M. Conventional and unconventional Monetary Policy with Endogenous Collateral Constraints. American Economic Journal: Macroeconomics, v. 7, n. 1, January 2015.

ARTZNER, P.; DELBAEN, F.; EBER, J. M.; HEATH, D. Coherent Measures of Risk. Mathematical Finance, v. 9, p. 203-228, 1999.

AZARIADIS, C. Self-Fulfilling Prophecies. Journal of Economic Theory, December 1981, p. 380-396, 1981.

BACKUS, D. Discussion of Alvarez and Dixit: A Real Options Perspective on the Euro. The Stern School of Business, New York University and NBER, 2013.

BAGEHOT, W. Lombard Street: a Description of the Money Market. London: H. S. King, 1873.

BAUWENS, L.; PREMINGER, A.; ROMBOUTS, J. Theory and inference for a Markov switching GARCH model. Econometrics Journal, v. 13 (2), p. 218-244, 2010.

BEKAERT, G.; HARVEY, C. R. Emerging Equity Market Volatility. Journal of Financial Economics, v. 43, p. 29-77, 1977.

BIS. Amendment to the capital accord to incorporate market risks. Basel: Basel Committee Publications, Bank for International Settlements, 1996. . Revisions to the Basel II Market Risk Framework. Basel: Basel Committee Publications, Bank for International Settlements, 2009.

.Basel III: A Global Regulatory framework for more Resilient Banks and

Banking Systems. Basel: Basel Committee Publications, Bank for International Settlements, 2011.

Fundamental review of the trading book: consultative document. Basel:

Basel Committee Publications, Bank for International Settlements, 2012. 
Fundamental review of the trading book: A revised market risk

framework. Basel: Basel Committee Publications, Bank for International Settlements, 2014.

; HYUN JO, J. Managing Systemic Risk from the Perspective of the financial network under macroeconomic distress. Basel: Basel Committee Publications, Bank for International Settlements, 2012.

BLACK, F.; SCHOLES, M. The Pricing of Options and Corporate Liabilities. Journal of Political Economy 81 (3): p. 637-654, 1973.

BLEJER, M. I.; SCHUMACHER, L. Central Bank vulnerability and the credibility of commitments: A value-at risk approach to currency crises (p. 39). Washington, D.C.: IMF Working Paper, 1998.

BOLLERSLEV, T. Generalized autoregressive conditional heteroskedasticity. Journal of Econometrics, 31, p. 307-327, 1986.

BORDO, M. D. The Lender of Last Resort: Alternative Views and Historical Experience. Federal Reserve Bank of Richmond Economic Review, January/February, p. 18-29, 1990.

BRAZILIAN CENTRAL BANK. Financial Stability Report. "Relatório de Estabilidade Financeira". Brasília, Brasil: Banco Central do Brasil, 2014.

Financial Stability Report. "Relatório de Estabilidade Financeira". Brasília, Brasil: Banco Central do Brasil, 2015.

BRENNER, M.; FAND GALAI, D. New Financial Instruments for Hedging Changes in Volatility. Financial Analysts Journal, July/August 1989. $<$ http://people.stern.nyu.edu/mbrenner/research/FAJ_ articleon_Volatility_Der.pdf $>$. 1989.

BROCK, W.; HSIEH, D.; LEBARON, B. Nonlinear dynamics, chaos, and instability: Statistical theory and economic evidence. Cambridge: The MIT Press, p. 82-129. 1992.

BRODA, S. A.; HAAS, M.; KRAUSE, J.; PAOLELLA, M. S.; STEUDE, S. C. Stable Mixture GARCH models. Journal of Econometrics, ISSN 0304-4076, v. 172, n. 2, p. $292-306,2013$.

BRUNNERMEIER, M. K.; PEDERSEN, L. H. Market Liquidity and Funding Liquidity. <http://www.princeton.edu>. Princeton, NJ: 2009.

CAI, I. A markov model of switching-regime ARCH. Journal of Business and Economic Statistics, v. 12, p. 309-316, 1994.

CAMPBELl, J. Y.; LO, A. W.; MACKINLAY, A. C. The Econometrics of Financial Markets. Princeton, NJ: Princeton University Press, 1997.

CARLSON, M.; BURCU DUYGAN-BUMP, B.; NELSON, W. R. Why do we need both liquidity regulations and a lender of last resort? A perspective from Federal Reserve lending during the 2007-09 US financial crisis. Basel: BIS Working Papers. n. 493, 2015. 
CARUANA, J. Basel III: Towards a Safer Financial System. Basel: BIS, 2010.

CHRISTENSEN, S. A Method for Pricing American Options Using Semi-Infinite Linear Programming. Mathematical Finance, v. 24, n. 1, p. 156-172, January 2014.

COLlETAZ, G.; HURLIN, C.; PERIGNON, C. The Risk Map: A new tool for validating risk models. Journal of Banking \& Finance, v. 37, Issue 10, p. 3843 3854, October 2013.

CYNAMON, B. Z.; FAZZARI, S. Household Debt in the Consumer Age: Source of Growth-Risk of Collapse. In: Capitalism and Society. The Berkeley Electronic Press, 2008.

DEMPSTER, A.; P., LAIRD, N.; M., RUBIN, D. B. Maximum likelihood from incomplete data via the EM algorithm. Journal of the Royal Statistical Society, v. 39, p. 1-8, 1977.

DIEBOLD, F. X. Modeling the persistence of conditional variances: A comment. Econometric Reviews, v. 5, p. 51-56, 1986.

Modeling volatility dynamics. Diebold's web page: <http://www.ssc.upenn.edu/ fdiebold/>. 1996.

DIXIT, A.; PINDYCK, R. Investment under Uncertainty. Princeton, NJ: Princeton University Press, 1994.

DORNBUSH, R. Capital controls: An idea whose time is gone. In: KENE, P. (Ed.), Symposium on capital controls, Princeton: Princeton Essays in International Finance, Princeton University Press, 1998.

DRIFFILL, J.; KENC, T.; SOLA, M. Real Options with Priced Regime-Switching Risk. International Journal of Theoretical and Applied Finance, n. 16, 1350028, 2013.

EICHENGREEN, B. Financial Crises: Analysis, Prevention and Management (Crises Financeiras: Análise, Prevenção e Gestão). Translation from Helga Hoffmann. Rio de Janeiro: Campus, 2003.

Anatomy of the Financial Crisis (Anatomia da Crise Financeira). Site: <http://www.voxeu.org/article/anatomy-financial-crisis>. 2009.

ENGLE, R. F. Autoregressive conditional heteroskedasticity with estimates of the variance of United Kingdom inflation. Econometrica, v. 50, p. 987-1007, 1982.

.; GRANGER, C. W. J. Co-Integration and Error-Correction: Representation, Estimation, and Testing. Econometrica, v. 55, p. 251-276, 1987.

EVANOFF, D.; KAUFFMAN, G.; MALLIARIS, A. Asset Price Bubbles: Lessons from the Recent Financial Crisis. World Financial Review (Web), 2012.

FORTUNATO, G.; BRANDÃO, L. E. T.; ROZENBAUM, S.; REBELLO, A. P. Abandonment option value in residential real estate developments. "Valor da opção de abandono em lançamentos imobiliários residenciais". Curitiba, Brasil:

RAC Eletrônica, v. 2, n. 3, p. 531-545, September./December, 2008. 
FRIEDMAN, M. Essays in positive economics, Chicago: University of Chicago Press, v. 231. 1996.

GERBER, H.; SHIU, E. Martingale approach to pricing perpetual American options. Astin Bulletin, n. 34, p. 195-220, 1994.

GLAESER, E. L.; NATHANSON, C. G. Housing Bubbles. Site: $<$ http://real.wharton.upenn.edu/ duranton/Duranton_Papers/Handbook/Housing_b ubbles.pdf>. 2014.

GOODHART, C. A. E. The Evolution of Central Banks. London: London School of Economics and Political Science, 1985.

p. 75-89, 1987.

Why do Banks Need a Central Bank? Oxford Economic Papers, v. 39,

GRAY, S. F. Modeling the conditional distribution of interest rates as a regimeswitching process. Journal of Financial Economics, v. 42, p. 27-62, 1996.

HAAS, M.; MITTNIK, S.; PAOLELLA, M. A new approach to markovswitching GARCH models. Journal of Financial Econometrics, v. 2(4), p. 493530, 2004.

HAGENDORFF, J.; VALLASCAS, F. Regulatory Capital: Risk weights and the implications for Basel III. "Capital regulamentar: Ponderadores de risco e as implicações para Basiléia III". Published in: www.voxeu.org.br. Translation to portuguese: Associação Brasileira de Bancos (ABBC), 2013.

HALL, P.; YAO, Q. Inference in ARCH and GARCH models with heavy-tailed errors. Econometrica, v. 71, n. 1, p. 282-317. January 2003.

HAMILTON, J. D. A New Approach to the Economic Analysis of Nonstationary Time Series and the Business Cycle. Econometrica, v. 57, p. 357-384, 1989. Analysis of Time Series Subject to Changes in Regime. Journal of Econometrics, v. 45, p. 39-70, 1990. .; SUSMEL, R. Autoregressive conditional heteroscedasticity and changes in regime. Journal of Econometrics, v. 64, p. 307-333, 1994.

HOLANDA BARBOSA, F.; SALLUM, E. M. Hyperinflation: a theoretical framework. "Hiperinflação: um arcabouço teórico". Rio de Janeiro, Brasil: Revista Brasileira de Economia, v. 56, n. IV, 2002.

HULL, J. Options, Futures and other Derivatives. NJ: Prentice Hall, 8th edition, 2012.

INCLÁN, C.; TIAO, G. C. Use of Cumulative Sums of Squares for Retrospective Detection of Changes of Variance. Journal of the American Statistical Association, v. 89, p. 913-923, 1994.

INGERSOLL, J. E. Jr. Theory of Financial Decision Making. Totowa, New Jersey: Rowan and Littlefield, 1987. 
JORION, P. Value at Risk: The New Source Reference for Market Risk Control. (Value at Risk: A Nova Fonte de Referência para o Controle do Risco de Mercado). São Paulo, Brasil: BM\&F, 1998.

JP MORGAN. RiskMetrics. New York, N.Y.: JP Morgan Technical Document, 1996.

KIM, Y. S.; RACHEV, S. T.; BIANCHI, M. L.; FABOZZI, F. J. Time Series Analysis for Financial Market Meltdowns. Journal of Banking and Finance v. 35, p. 1879-1891, 2011.

KOLLER, T.; GOEDHART, M.; WESSELS, D. Valuation: Measuring and Managing the Value of Companies. New York: John Wiley, Fifth Edition, 2010.

KUPIEC, P. Stress Testing in a Value at Risk Framework. The Journal of Derivatives, fall 1998, v. 6, n. 1, p. 7-24, 1998.

LAEVEN, L.; VALENCIA, F. Systemic Banking Crises: A New Database. Washington: IMF Papers, 2008.

LAMOUREUX, C. G.; LASTRAPES, W. D. Persistence in variance, structural change and the GARCH model. Journal of Business and Economic Statistics, 68: p. 225-234, 1990.

LITTERMAN, R.; SCHEINKMAN, J. Common Factors affecting Bond Returns. Journal of Fixed Income, v. 1, p. 54-61, 1991.

LONGSTAFF, F. A.; SCHWARTZ, E. Valuing American Options by Simulation: a Simple Least-Squares Approach. Review of Financial Studies, v. 14 (1), p. 113-147, 2001.

MANDELBROT, B. New Methods in Statistical Economics. Journal of Political Economy, v. 71, n. 5, p. 421-440, 1963.

MARÇAL, E. F.; GALA, P.; MORI, R. CEMAP Letter: Bubble in the Real Estate Market in São Paulo? Evidence Based in Econometric Tests. "Carta CEMAP: Bolha no Mercado Imobiliário em São Paulo? Evidência Baseada em Testes Econométricos". São Paulo, Brasil: Centro de Macroeconomia Aplicada, Fundação Getúlio Vargas: FGV-EESP, October 2012.

MARKOWITZ, H. Portfolio Selection. The Journal of Finance, v. 7, n. 1, p. 77$91,1952$.

MARTIN, D. M. L.; KAYO, E. K.; KIMURA, H.; NAKAMURA, W. Identifying Speculative Bubbles Rational in IBOVESPA Stock Exchange (After the Real Economic Plan), from Markovian conversion models. "Identificando Bolhas Especulativas Racionais no IBOVESPA (Pós-Plano Real), a partir de Regimes Markovianos de Conversão". João Pessoa, Brasil: Economia v. 5, n. 3, p. 219$252,2004$. 
MEIRELLES, H. Statement by the President of the Central Bank of Brazil, in the 18th anniversary of the Brazilian Commodities and Futures Exchanges (BM\&FBOVESPA). Retrieved from <http://www.bmf.com.br>. 2004.

MERTON, R. K. Social Theory and Social Structure. New York: Free Press, p. 477, 1968.

MINSKY, H. Stabilizing an Unstable Economy. Boston: McGraw Hill, 2008. Original Version: 1986.

MORALES, A.; SCHUMACHER, L. Market volatility as a soundness indicator: an application to Israel. Washington, D.C.: IMF Working Paper 03/47, 2003.

NOLAN, J. P. Numerical calculation of stable densities and distribution functions. Communications in Statistics-Stochastic Models, v. 13, Issue 4, p. 759-774, 1997.

Stable Distributions: Models for Heavy Tailed Data. Boston,

MA: Birkhauser, in progress at academic2.american.edu/ jpnolan, 2015.

NUNES, M. S.; SILVA, S. D. Rational bubbles in the Bovespa Index. "Bolhas Racionais no Índice Bovespa". Rio de Janeiro, Brasil: Revista Brasileira de Economia, v. 63, n. 2, p. 119-134. April-June, 2009.

OREIRO, J. L. Currency crises, self-fulfilling prophecies and the Tobin tax. "Crises cambiais, profecias auto-realizáveis e o imposto Tobin". Curitiba, Brasil: Revista de Economia, 2001.

PACHAMANOVA, D. A.; FABOZZI, F. J. Simulation and Optimization in Finance: Modeling with MATLAB, @ Risk, or VBA. New York: Wiley, ISBN: 978-0-470-37189-3, 2010.

RAZIN, A.; SADKA, E. A Brazilian-type debt crisis: Simple analytics. Washington, D.C.: IMF Staff Papers, 2004.

ROCHET, J-C.; TIROLE, J. Interbank Lending and Systemic Risk. Journal of Money, Credit and Banking. Part 2: Payment Systems Research and Public Policy Risk, Efficiency, and Innovation. v. 28, n. 4, p. 733-762, November, 1996.

SAMORODNITSKY, G.; TAQQU, M. S. Stable non-Gaussian random processes: stochastic models with infinite variance. CRC Press, 1994.

SCHEINKMAN, J.A. Speculation, Trading and Bubbles. Princeton University Economic Theory Center Research Paper, n. 050-2013, 2013.

SHILLER, R. J. Irrational exuberance. Crown Business, 2006.

STUMPNER, S. Trade and the Geographic Spread of the Great Recession. Berkeley Job Market Paper. Berkeley, UC Berkeley. January 10 ${ }^{\text {th }}, 2013$. 
TABAK, B. M.; GUERRA, S. M.; MIRANDA, R. C.; DE SOUZA, S. R. S. Stress Testing for Liquidity risk: the case of the Brazilian banking system "Teste de Estresse para Risco de Liquidez: o caso do sistema bancário brasileiro". Brasília, Brasil: Banco Central do Brasil Working Papers Series, n. 302, 2012.

THORTON, H. An Enquiry into the Nature and Effects of the paper Credit of Great Britain; Edited by F.A. Hayek. Fairfield: Augustus M. Kelley, 1802.

TITMAN, S. Urban land prices under uncertainty. The American Economic Review, v. 75 (3), p. 505-514, 1985.

TSAY, R. Analysis of financial time series. New York: Wiley series in probability and statistics, third edition, 2010.

VAN NORDEM, S.; SCHALLER, H. Speculative Behavior, Regime-Switching and Stock Market Crashes. Bank of Canada Working Paper, 96-13. Canada: Bank of Canada, 1996.

VEILLETE, M. Alpha Stable Algorithms. Internet: <http://math.bu.edu/people/ mveillet/research.html>. 2010.

WILLIAMS, J. T. Real estate development as an option. Journal of Real Estate Finance and Economics, v. 4 (2), p. 191-208, 1991.

WILLIAMSON, O. E. The New Institutional Economics: Taking Stock, Looking Ahead. Journal of Economic Literature, v. 38, n.3, p. 595-613, 2000.

ZANGARI, P. Catering for an event. London, England: Risk, 1997. 